NBER WORKING PAPER SERIES

\title{
INNOVATION AND TRADE POLICY IN A GLOBALIZED WORLD
}

\author{
Ufuk Akcigit \\ Sina T. Ates \\ Giammario Impullitti \\ Working Paper 24543 \\ http://www.nber.org/papers/w24543 \\ NATIONAL BUREAU OF ECONOMIC RESEARCH \\ 1050 Massachusetts Avenue \\ Cambridge, MA 02138 \\ April 2018
}

We thank seminar and conference participants at Harvard University, Princeton University, Stanford University, Duke University, the NBER Summer Institute "International Trade \& Investment" and "Macroeconomics and Productivity" groups, the University of Maryland, the University of Pennsylvania, the University of Nottingham, the University of Zurich, the University of Munich, the Federal Reserve Board, the Bank of Italy, the International Monetary Fund, the International Atlantic Economic Society, ASSA Meetings 2018, the Italian Trade Study Group, CREST Paris, SKEMA, the SED Conference, and the CompNet Conference. We also thank Daniel J. Wilson for sharing and helping with his data. Akcigit gratefully acknowledges the National Science Foundation, the Alfred P. Sloan Foundation, and the Ewing Marion Kauffman Foundation for financial support. The views in this paper are solely the responsibilities of the authors and should not be interpreted as reflecting the view of the Board of Governors of the Federal Reserve System, any other person associated with the Federal Reserve System, or the National Bureau of Economic Research.

NBER working papers are circulated for discussion and comment purposes. They have not been peer-reviewed or been subject to the review by the NBER Board of Directors that accompanies official NBER publications.

(C) 2018 by Ufuk Akcigit, Sina T. Ates, and Giammario Impullitti. All rights reserved. Short sections of text, not to exceed two paragraphs, may be quoted without explicit permission provided that full credit, including $(\subset$ notice, is given to the source. 
Innovation and Trade Policy in a Globalized World

Ufuk Akcigit, Sina T. Ates, and Giammario Impullitti

NBER Working Paper No. 24543

April 2018

JEL No. F13,O4

\begin{abstract}
$\underline{\text { ABSTRACT }}$
How do import tariffs and R\&D subsidies help domestic firms compete globally? How do these policies affect aggregate growth and economic welfare? To answer these questions, we build a dynamic general equilibrium growth model where firm innovation endogenously determines the dynamics of technology, and, therefore, market leadership and trade flows, in a world with two large open economies at different stages of development. Firms' R\&D decisions are driven by (i) the defensive innovation motive, (ii) the expansionary innovation motive, and (iii) technology spillovers. The theoretical investigation illustrates that, statically, globalization (defined as reduced trade barriers) has ambiguous effects on welfare, while, dynamically, intensified globalization boosts domestic innovation through induced international competition. Accounting for transitional dynamics, we use our model for policy evaluation and compute optimal policies over different time horizons. The model suggests that the introduction of the Research and Experimentation Tax Credit in 1981 proves to be an effective policy response to foreign competition, generating substantial welfare gains in the long run. A counterfactual exercise shows that increasing tariffs as an alternative policy response improves domestic welfare only when the policymaker cares about the very short run, and only when introduced unilaterally. Tariffs generate large welfare losses in the medium and long run, or when there is retaliation by the foreign economy. Protectionist measures generate large dynamic losses by distorting the impact of openness on innovation incentives and productivity growth. Finally, our model predicts that a more globalized world entails less government intervention, thanks to innovation-stimulating effects of intensified international competition.
\end{abstract}

Ufuk Akcigit

Department of Economics

University of Chicago

1126 East 59th Street

Saieh Hall, Office 403

Chicago, IL 60637

and NBER

uakcigit@uchicago.edu
Giammario Impullitti

School of Economics

University of Nottingham

Clive Granger Building, University Park

Nottingham, NG7 2RD

Giammario.Impullitti@nottingham.ac.uk

Sina T. Ates

Federal Reserve Board of Governors

20th \& C St.

Washington, DC 20551

sina.t.ates@frb.gov

A data appendix is available at http://www.nber.org/data-appendix/w24543 


\section{Introduction}

Since the past U.S. presidential race, a heated debate centered on the position of the United States in its trade relationships. President Donald J. Trump's speeches focused, among other issues, on the United States losing its security and competitiveness to other major economic players in the world. A favored, and widely discussed, policy suggestion was raising barriers to international trade. Finally, on March 9, 2018, the United States imposed tariffs on certain imports. Only three weeks after the implementation of U.S. tariffs, on April 2, China retaliated by imposing tariffs on various U.S. products.

Interestingly, similar concerns were raised three decades ago, during the 1970s and early 1980s, following the U.S. exposure to a remarkable convergence by advanced countries such as Japan, Germany and France, in terms of technology and productivity (see Figure 1). This generated extreme concern among U.S. policy circles, most notably the Ronald Reagan administration. As opposed to the recent focus on protectionist measures, the Reagan government, among other policies, introduced a research and development (R\&D) tax credit scheme in 1981 for the first time in U.S. history.

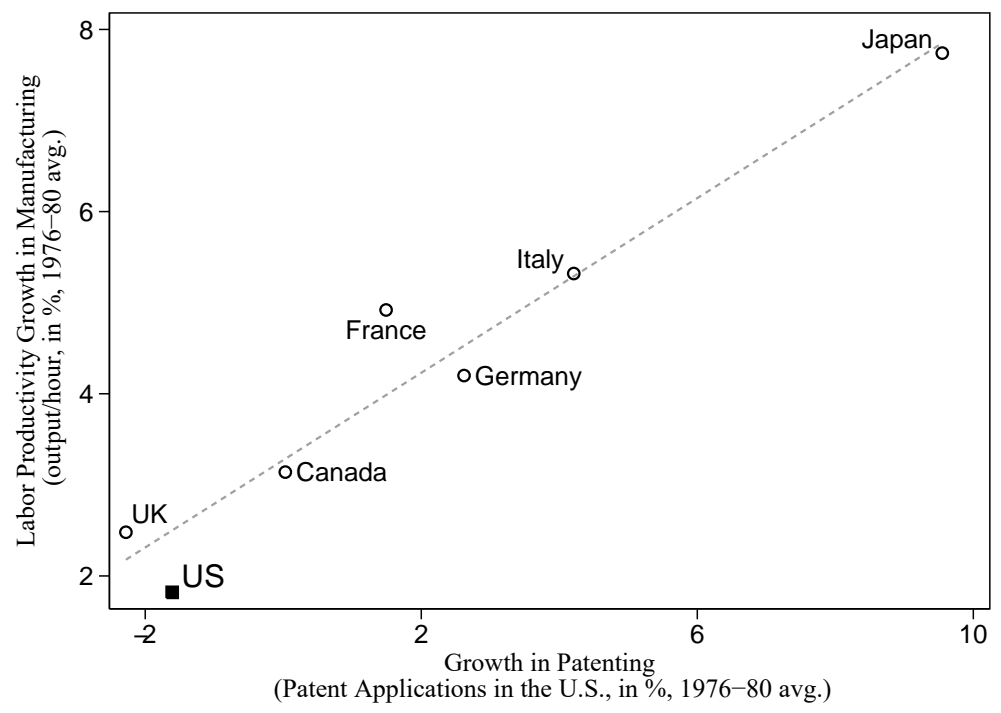

Figure 1: Convergence between the U.S. and its peers

Notes: The figure shows the relationship between growth of average labor productivity in the manufacturing sector and growth in the number of patent applications for the U.S. and its major trading partners between 1976 and 1980. We obtain data on patent applications in the U.S. from the USPTO and on international productivity comparisons from Capdevielle and Alvarez (1981).

To shed light on this recurring debate on how to tackle international technology competition, this paper evaluates alternative trade and innovation policies, focusing on strategic interactions between firms. We provide a new set of empirical facts that motivate the construction of a new dynamic general equilibrium theory of international technology competition, which we then 
employ to perform quantitative policy analysis.

As illustrated in Figure 1, the U.S. performed poorly relative to its advanced peers in terms of labor productivity and innovation in the second half of the 1970s. The average growth in outputper-hours-worked in manufacturing was the lowest in the U.S. Moreover, innovation by these foreign competitors, proxied by new patent applications registered in the U.S. by the residents of these foreign countries, expanded substantially except for the United Kingdom The figure also reveals that the largest growth rates in patent applications have been recorded by those countries whose labor productivity growth in manufacturing most outpaced the United States. Strikingly, patent applications by U.S. residents actually declined in absolute terms during the same period. United States Patent and Trademark Office (USPTO) data reveal that the ratio of foreign patents to total patents doubled between 1975 and $1985 .{ }^{1}$ While the U.S. held 70 percent of the patent applications in 1975, 10 later years this share declined to around 55 percent. $^{2}$

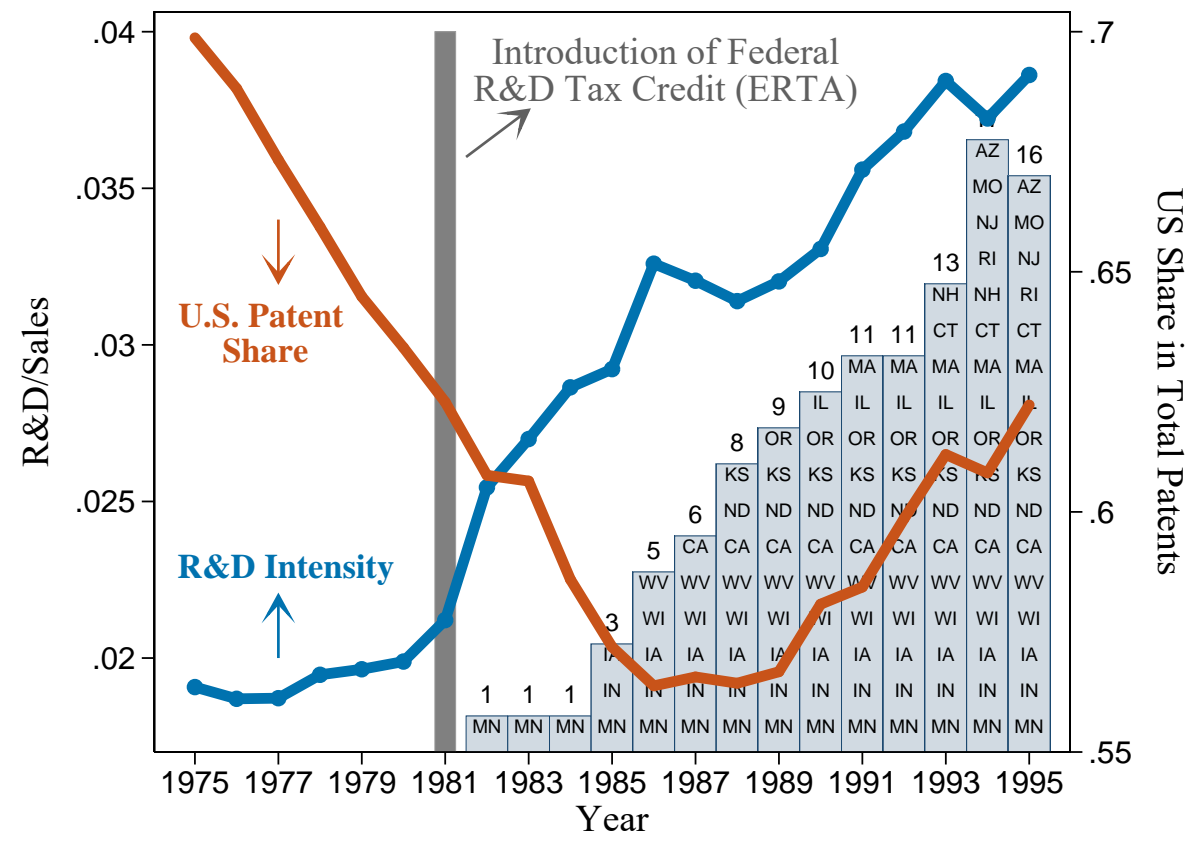

Figure 2: R\&D and innovation intensity of the U.S. firms

Notes: The figure shows the evolution of aggregate R\&D intensity (defined as the ratio of total R\&D spending over total sales) of the public U.S. firms listed in the Compustat database, and the share of patents registered by U.S. residents in total patents registered in the USPTO database from 1975 to 1995. The ratios are calculated annually. The bars show the total number of U.S. states with a provision of R\&D tax credits, along with their names, for every year since the first adoption of such a measure in 1982.

Unlike the debate today, concerns over U.S. competitiveness in those years led to the introduction of a set of demand- and supply-side policies explicitly targeting incentives for innovation. One of those was the introduction of the R\&D tax credits at the federal level for the first time in

\footnotetext{
${ }^{1}$ See Figure A.1 in Appendix A.1. This section gives a further account of the empirical findings on international technological competition and the relevant policies during the period of interest.

'Similar trends are found in countries' share of global R\&D at the sectoral level [see Impullitti (2010)].
} 
1981, immediately followed by individual states' actions. Upon these policy changes, aggregate R\&D intensity of U.S. public firms showed a dramatic increase, indicated by the blue line in Figure 2. With an expected delay, the annual share of patents registered by U.S. residents in total patent applications increased as well, as denoted by the orange line in the same figure. ${ }^{3}$ Starting in 1982 with Minnesota, several states followed suit by introducing state-level R\&D tax credits (Figure 2). In contrast, there was no significant action in R\&D policies for the other major countries (Figure 3). ${ }^{4}$ Motivated by these facts, this paper provides a new quantitative investigation of the effects of R\&D subsidies in an open economy, comparing them with the effects of raising trade barriers as a response to rising foreign technology competition. This policy comparison also provides new theoretical insights and quantitative perspectives on the gains from globalization.

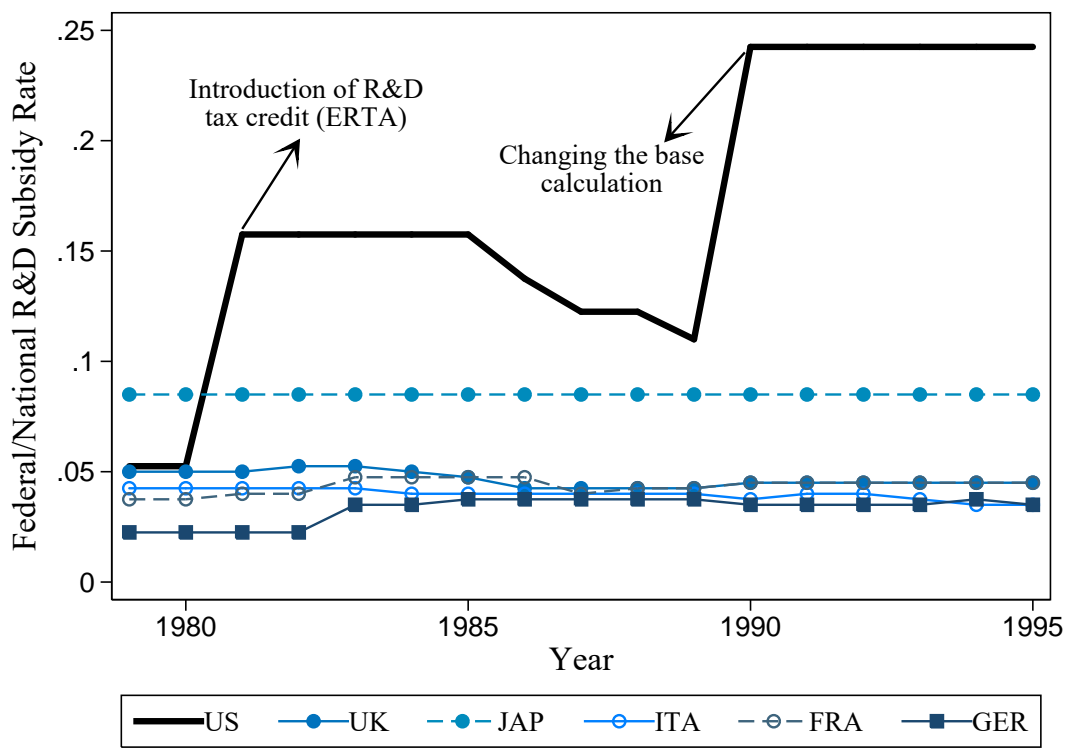

Figure 3: Effective R\&D tax credit rates across countries

Notes: The figure depicts effective R\&D subsidy rates in the U.S. and its major trading partners from 1979 to 1995 (unavailable for Canada).

A sensible quantitative analysis of the economic processes presented above necessitates an open-economy framework where economic growth is shaped by the interplay of innovation and international technological competition. The appropriate framework also needs to recognize the strategic interaction between large firms, because global $R \& D$ races and international trade are dominated by such firms, whose choices affect market aggregates and give rise to strategic market power. The aircraft industry is an example of a technology-intensive sector dominated by two

\footnotetext{
${ }^{3}$ Information on sales and R\&D expenditures of U.S. public firms are obtained from the Compustat database.

${ }^{4}$ Following Impullitti (2010), R\&D subsidies are calculated using corporate tax data from Bloom et al. (2002), who take into account different tax and credit systems. The subsidies reflect key features of the tax system aimed at reducing the cost of $R \& D$, particularly depreciation allowances and tax credits for $R \& D$ expenditures. This structure is responsible for the positive value of our subsidy measure initially. For more details, see Impullitti (2010).
} 
firms, Airbus and the Boeing Company, which compete strategically for global market leadership [Irwin and Pavcnik (2004), Baldwin and Krugman (1988)]. The top one percent of trading U.S. firms account for about 80 percent of total U.S. trade, enabling them, through their large market shares, to impact market prices [Bernard et al. (2017), Hottman et al. (2016)]. Hence, the strategic interaction between internationally competing firms is crucial when building a model to analyze our facts; and gaining new insights on trade and innovation policies. Moreover, as our facts are intrinsically dynamic, a careful policy evaluation needs to take into account the changes along the transition path.

With these key points in mind, we build a new two-country dynamic endogenous growth model where innovation determines the dynamics of technology and global market leadership. Our framework builds on the step-by-step innovation models of Schumpeterian creative destruction, which allow for strategic interaction among competitors. In both countries, final-goods firms produce output by combining a fixed factor and a set of intermediate goods, sourced from domestic and foreign producers. In each intermediate sector, a home and a foreign firm compete for global market shares and invest in $R \& D$ to improve the quality of their product. Free entry by a fringe of domestic and foreign firms creates an additional source of competitive pressure on both leaders and followers in each product line. International markets are characterized by trade costs and international diffusion of ideas in the form of knowledge spillovers. A theoretical investigation of this setting shows that, statically, openness to trade benefits the fixed factor in the final good production via higher-quality intermediate good imports. This translates into higher productivity in domestic final-good production. By contrast, the aggregate effect on business owners, which operates through a combination of larger market size for some businesses and loss of markets to foreign rivals for others, is ambiguous. More importantly, trade openness impacts the economies' dynamics by affecting firms' motives for innovation.

The open-economy dimension of our model redefines firms' incentives to innovate that are typical of the standard step-by-step models. The key driver of innovation in the generic stepby-step framework is the escape-competition effect, in which incumbent firms have an incentive to move away from the follower in order to escape competition. A novel implication of our model is that two such effects arise in a similar spirit. The main difference in an open economy is that vertical competition within each product line assumes an international dimension, as competing firms are from different countries. In each line, firms from both countries compete to serve the domestic and foreign market. Innovation generates a ranking of the product lines based on the quality/productivity difference between the home firm and the foreign firm. As in models of trade with firm heterogeneity [e.g., Melitz (2003)], trade costs generate quality cutoffs that partition the product space into exporting and non-exporting firms. But, in contrast to these models, where competition takes place horizontally between firms producing different goods and where firms are ranked based on their absolute productivity level, the ranking and, consequently, the cutoffs in our model are pinned down by firms' productivity relative to their foreign competitors. 
When the quality of domestic intermediate goods in country $c$ is too inferior relative to its foreign counterpart, final-good producers in country $c$ decide to source their intermediate goods from abroad, which determines country c's import cutoff on relative quality. Likewise, if the relative quality of the domestic producer in country $c$ is above a certain threshold, the foreign final good producers decide to import from the intermediate good producer in country $c$, which specifies the export cutoff on the relative quality for country $c$. Hence, the open-economy structure leads to two cutoffs around which strategic competition between firms becomes stiffer.

The key feature of these two cutoffs is that innovation efforts intensify around them due to increased competition. Just below the import cutoff, domestic firms exert additional effort to gain their leadership in the home market; hence, we name it the defensive RED effort. Likewise, when a domestic firm is just below the export cutoff, it exerts additional effort to improve its lead and conquer the foreign market. We call this effort the expansionary RED effort. These two new effects generate a double-peaked R\&D effort distribution over the relative quality space that, remarkably, is also supported in the USPTO patent data. From a policy point of view, the distinction between defensive and expansionary R\&D is crucial, as they generate different responses to alternative industrial policies.

Another important feature of our model is the free entry of new firms. In both the domestic and foreign economies, new entrants try to replace incumbents. The entry rate is state dependent in that there will be more domestic entry into those sectors where the domestic incumbents maintain a larger lead over their foreign rivals. This is another prediction of the model for which we find empirical support in the patent data. We observe more patents coming from new entrants in patent classes where U.S. incumbents have a larger fraction of the patents.

We parameterize the model to match key trade, innovation, and growth facts in the late 1970s and reproduce the evolution of global leadership in those years, with the U.S. initially representing the technological frontier in most sectors, while a set of European countries plus Japan leads in a few. The transitional dynamics of the model reproduces the convergence in technological leadership observed in the patent data during the 1970s and early 1980s. We validate our model's mechanism with out-of-sample tests concerning the link between innovative activity and technological leadership and the elasticity of firm-level R\&D spending to policy changes. In particular, we lay out striking similarities between the model and the data as to the innovation patterns of firms at different technological positions vis-à-vis their foreign competitors. Furthermore, simulating the calibrated model beyond the calibration period, we examine the dynamics of foreign technological convergence-a mode of globalization that has not been widely explored in the literature-in the absence of policy interventions. In particular, we demonstrate the significant deterioration in the positions of U.S. firms in international technological competition that would have arisen in the absence of any policy intervention.

In regards to policy evaluation, we first analyze welfare implications of protectionism-i.e., 
raising import tariffs unilaterally. The welfare implications of this policy change depend on the time horizon over which the policy is evaluated. A rise in tariffs generates short-run gains, as it tames international business stealing caused by foreign catching-up, keeping business profits at home. These gains more than compensate for the negative effect on aggregate productivity of replacing better-quality imported goods with inferior domestic counterparts. Over the first decade after a 20 percent increase in tariffs, there are gains of up to 0.2 percent of consumption. However, protective measures reduce incentives for domestic firms to invest in defensive innovation, because they weaken the foreign competitive pressures domestic firms are exposed to. As time goes by, this force dominates, leading to substantial drops in welfare in the long run. It operates through the key sources of gains from trade in this economy. First, declining defensive innovative effort limits the ability of the economy to make up for the foregone productivity that would otherwise be enhanced by the high-quality imports. Second, it depresses the gains from additional profits generated by protected businesses, reducing the growth in that income relative to baseline. Weaker foreign competition caused by protectionism and the ensuing reduction in defensive innovative activity also shape the optimal trade policy in our model: Lower tariffs are preferred when the welfare impact is evaluated over a longer time horizon.

As an alternative policy option to protectionism, we feed the model an increase in R\&D subsidies similar to the U.S. move in the early 1980s and assess its welfare properties over a period of intensifying foreign competition. The effective average U.S. R\&D subsidy increases from about 5 percent in the 1970s to approximately 19 percent in the post-1981 period. This subsidy increase generates non-negligible gains in the model in both the short and long run. Over the three decades following the subsidy increase, the consumption-equivalent welfare is about 0.9 percent higher, with this gain driven by both business stealing and innovation. Reducing the cost of innovation, subsidies stimulate both entrant and incumbent firms' R\&D in the U.S., thereby accelerating productivity growth and allowing U.S. firms to obtain market leadership. We also show that the optimal subsidy level for the same horizon is much higher than the observed change, as the growth-stimulating impact of subsidies, which becomes stronger over time, calls for higher subsidies over longer horizons. In fact, the observed increase in subsidies is an optimal response when only a horizon shorter than 10 years is considered.

Next, we analyze the optimal policy design when both options are available to the policymaker. A key result is that the direction of the trade policy component crucially depends on the assumption about the response of the trade partners. When the policymaker creates the policy under the assumption that unilateral changes are possible, the optimal policy favors protectionist trade measures combined with aggressive R\&D subsidies. The reason is that protectionist policies protect domestic profits, yet lower the innovation incentives. Hence, aggressive R\&D subsidies are needed to make up for the reduced innovation efforts. However, if the trade partners retaliate, the optimal trade policy reverses and calls for a regime as liberal as possible. The risk of losing the export market plays the key role in this reversal. 
Last but not least, our analysis shows that less policy intervention is needed as the world becomes more globalized through reduced trade costs. This interesting result is due to the fact that lower trade costs intensify competition in the global market place. More competitive markets induce more innovation, both defensive and expansionary. In other words, as globalization takes place, markets take care of the innovation incentives and eliminate the need for policy intervention.

We close our paper with a final exercise that sheds new light on the recent debate concerning the effect of rising import competition on firm-level and aggregate innovative activity in exposed sectors. For instance, Autor et al. (2016) find a negative relationship focusing on the U.S., whereas Bloom et al. (2016) find a positive effect for the European experience. In a simple experiment using our model, we show how this relationship may transpire in both directions depending on the sectoral composition of firms' initial technological position relative to their foreign competitors. Thus, our model provides a rationale that reconciles contradictory findings in previous empirical work.

Taking stock, foreign technological catching-up has taken its toll on the technological leadership of U.S. firms and led to significant losses in their profits through business stealing. Increasing R\&D subsidies during periods of accelerating foreign competition proves to be an effective response to foreign competition, while raising trade barriers generates only small welfare gains in the short run at the expense of substantial losses in the long run. The key message of our analysis is that when a country experiences fiercer foreign technological competition, R\&D subsidies help national firms compete without giving up gains from trade. Finally, optimal trade policy design crucially depends on the possibility of foreign retaliation, in which case the threat of losing export markets calls for a more liberal trade regime.

Literature Review. This paper is related to several lines of research in the literature. The endogenous technical change framework that we use as the backbone of our economy is a model of growth through step-by-step innovation as in Aghion et al. $(2001,2005)$ and the latest developments by Acemoglu and Akcigit (2012) and Acemoglu et al. (2016). ${ }^{5}$ These closed-economy models are solved in steady state, also abstracting from free entry, with the exception of Acemoglu et al. (2016), which features entry and transitional dynamics. We propose the first open-economy version of this class of models, introduce free entry, solve for its transition path, and provide a quantitative exploration of the gains from globalization and the role of innovation subsidies in open economies.

On modeling the trade side, our setting draws similarities to the theoretical literature that analyzes the impact of trade exposure on (industry-level) aggregate productivity in models with

\footnotetext{
${ }^{5}$ Building on another strand of growth models pioneered by Romer (1990), Grossman and Helpman (1990) use an expanding variety model to analyze the role of international trade and trade policies in determining the long-run growth. The adoption of a step-by-step framework instead enables us to study explicitly the strategic interaction between firms and its implication for innovation and trade patterns.
} 
heterogeneous firm productivities, pioneered by Melitz (2003). ${ }^{6}$ Also, our structural general equilibrium framework incorporates several forces, such as competition and market size, whose impact on firm innovation is highlighted by recent empirical work that focuses on the nexus of innovation and trade [see Muendler (2004), Bustos (2011), Iacovone et al. (2011), Autor et al. (2016), Chen and Steinwender (2016), and, in particular, Bloom et al. (2016) and Aghion et al. (2017), among others]. ${ }^{7}$ It also encompasses technology transfer alongside firm innovation as sources of productivity growth, in line with the empirical findings of Cameron et al. (2005). We contribute to this literature by formalizing and quantifying a new theory of endogenous firm decisions and openness to trade.

Building on the seminal contributions of Rivera-Batiz and Romer (1991) and Grossman and Helpman (1993), our analysis emphasizes the role of firms' innovation decisions in shaping policy-induced aggregate dynamics and, thus, makes contact with a growing literature on dynamic gains from trade. ${ }^{8}$ A set of recent papers introduced knowledge diffusion into trade models as a source that shapes dynamic gains [Perla et al. (2015), Buera and Oberfield (2016), and Sampson (2016), among others]. Impullitti and Licandro (2017), on the other hand, analyze gains from trade in a model of innovation-driven productivity growth with firm heterogeneity and variable markups. In their analysis of the balanced growth paths, they find that the growth effects of trade liberalization doubles the welfare gains obtainable in a static version of the model. Analyzing various extensions of the canonical Melitz (2003) framework, Burstein and Melitz (2013) discuss the effects of trade liberalization on firm dynamics. In parallel to our findings, they highlight how firms' innovation responses determine transitional dynamics induced by trade liberalization. Bloom et al. (2013) develop a trapped-factor model to show that trade liberalization in a low-wage country could reduce the opportunity cost of innovation. Our work contributes to this literature by emphasizing the role of strategic interaction between firms in shaping their innovation responses and, thereby, the dynamic gains from trade. We also examine these gains quantitatively along the transition path thanks to our framework, which is capable of tracking the endogenous evolution of competition and innovation patterns in a tractable fashion. Last but not least, endogenous productivity growth and transitional dynamics provide further channels through which trade liberalization and policy may affect aggregate welfare, in addition

\footnotetext{
${ }^{6}$ In the fashion of these models, firms with heterogeneous productivities select the markets to serve in our model. Conversely, openness to trade may affect the input-sourcing decisions of firms. For an analysis of this effect in a setup of heterogeneous firms, see Antràs and Helpman (2004).

7 While Bloom et al. (2016) show the positive effect of Chinese import penetration on the technical change in 12 European countries, Aghion et al. (2017) examine the differential impact of market size and competition effects on innovation decisions of exporting French firms with heterogeneous initial productivity levels. They find that the market size effect is the dominant force for firms that have higher productivity at times of increased demand. On a related note, Mayer et al. (2014) and Mayer et al. (2016) look at the product range and mix of multi-product firms as another source of within-firm productivity variations. They document the positive effect of increased export market competition on firm productivity through adjustments in these margins.

${ }^{8}$ In this regard, our attempt advances the literature in the direction pointed out by Burstein and Melitz (2013). In their recent chapter, the authors stress the need for more research on dynamic gains from trade, as opposed to extensively studied static ones, and on the implications of firm and technology dynamics as a potential source.
} 
to those considered by Atkeson and Burstein (2010) and Arkolakis et al. (2012). ${ }^{9}$

Finally, industrial policies in open economies have been studied by a large body of work. ${ }^{10}$ Spencer and Brander (1983) and Eaton and Grossman (1986) explore theoretically the strategic motive to use tariffs and subsidies (to production and innovation) to protect the rents and the market shares of domestic firms in an imperfectly competitive global economy. ${ }^{11}$ In a theoretical small open-economy framework of endogenous growth, Grossman and Helpman (1991a) study the implications of R\&D subsidies and industrial policies for optimal long-run growth and welfare. Ossa (2015) sets up a quantitative economic geography model to study production subsidy competition between U.S. states. In the spirit of our work, Impullitti (2010) uses a multi-country version of the standard Schumpeterian growth model to assess the welfare properties of $R \& D$ subsidies in an open economy, although his work is confined to the steady state. ${ }^{12}$ Considering trade policy, Demidova and Rodríguez-Clare (2009) find that an import tariff can be welfare enhancing in a static small open economy with firm heterogeneity and product differentiation. Recently, Costinot et al. (2015) and Costinot et al. (2016) provide intriguing insights on the typedependent formulation of optimal policy design in static Ricardian and monopolistic competition environments, respectively. ${ }^{13}$ In contrast to these studies, a distinct feature of our model is the link between different modes of foreign competition and innovation at the firm level. We show that in this setting, different policies affect different types of innovations: For instance, unilateral protectionism distorts incentives for defensive $R \& D$, whereas retaliation by trade partners distorts incentives for expansionary R\&D. This relationship, and the resulting dynamic gains from trade and transitional dynamics, are central to the design of optimal trade and innovation policy. Differentiating between the short and long run, we demonstrate the crucial dependence of policy implications on the horizon considered along the transition.

The rest of the paper is organized as follows. Section 2 introduces the theoretical framework, followed by Section 3 with analytical results. Section 4 outlines the calibration procedure and provides out-of-sample tests. Section 5 discusses policy implications and optimal policies. Section 6 discusses the model's implications in regards to import competition and domestic innovation. Section 7 presents sensitivity and robustness analysis. Section 8 concludes.

\footnotetext{
${ }^{9}$ Considering a simple model of sequential production in intermediate goods, Melitz and Redding (2014) also point to trade-induced changes in domestic productivity as a source of departure from the findings of Arkolakis et al. (2012), which state that welfare gains from trade in a group of standard models can be derived from a few aggregate-level sufficient statistics and, accordingly, should be fairly modest. Alessandria and Choi (2014) emphasize the significance of accounting for transition in this regard.

${ }^{10}$ Institutional challenges in applying appropriate industrial policies are beyond the scope of this paper. Interested readers can see Rodrik (2004) for an extensive discussion.

${ }^{11}$ See Leahy and Neary (1997) and Haaland and Kind (2008) for recent contributions. While the literature focuses on static models, Grossman and Lai (2004) analyze strategic intellectual property rights policy in a multi-country endogenous growth model.

${ }^{12}$ The paper also relates to the recent quantitative analysis of R\&D subsidies in a closed economy. See Acemoglu et al. (2017) and Akcigit et al. (2016a,b).

13 Analyzing trade policies over the business cycle, the recent work by Barattieri et al. (2017) explores the recessionary effects of protectionism in a DSGE framework.
} 


\section{Model}

We present a model of international technological competition in which firms from two countries, indexed by $c \in\{A, B\}$, compete over the ownership of intermediate good production. Each country has access to the same final good production technology. There is a continuum of intermediate goods indexed by $j \in[0,1]$ used in final good production. The final good is used for consumption, production of intermediate goods, and innovation. There is free trade in final good sectors and no trade in assets. Lack of trade in assets rules out international borrowing and lending and enables the two countries to grow at different rates during the transition.

In each production line of intermediate goods there are two active firms-one from each country-engaging in price competition to obtain a monopoly of production. Trade of intermediate goods is costly due to a combination of iceberg costs and tariffs. The firm that produces the variety of better quality after adjusting for the trade cost holds a price advantage. Firms innovate by investing resources to improve the quality of their product in the spirit of step-bystep models. If the quality difference between the products of two firms is large enough, then the firm with the leading technology can cover the trade cost and export to the foreign country. Because innovation success is a random process, the global economy features a distribution of firms supplying products of heterogeneous quality. In addition to trade in intermediate and final goods, there is a second channel of interdependency linking the countries: trade in ideas. The exchange of ideas consists of technology diffusion through international knowledge spillovers.

In addition to incumbent firms, there is an outside pool of entrant firms. These firms engage in research activity to obtain a successful innovation that enables them to replace the domestic incumbent in a particular product line. Introducing the entry margin allows the model to distinguish the effects of domestic and foreign competition. Understanding these distinct forces becomes particularly important once we use our model for policy evaluation.

Finally, our main goal is to investigate the quantitative policy implications of our model. For interested readers, we provide a brief theoretical discussion of a simplified version of the model in Section 3 and present analytical expressions and results of the main static and dynamic forces in Appendix C.

\subsection{Preferences}

Consider the following economy in continuous time. Both countries admit a representative household with the following CRRA utility:

$$
U_{t}=\int_{t}^{\infty} \exp (-\rho(s-t)) \frac{C_{c s}^{1-\psi}-1}{1-\psi} d s,
$$


where $C_{c t}$ represents consumption at time $t$ in country $c, \psi$ is the curvature parameter of the utility function, and $\rho>0$ is the discount rate. The budget constraint of a representative household in country $c$ at time $t$ is

$$
r_{c t} A_{c t}+L_{c} w_{c t}=P_{c t} C_{c t}+\dot{A}_{c t}+G_{c t}
$$

where $r_{c t}$ is the return to asset holdings of the household, $L_{c}$ is the fixed factor (could be labor or land) supplied inelastically in country $c, w_{c t}$ is the fixed factor income, $P_{c t}$ is the price of the consumption good in country $c$, and $G_{c t}$ is the lump-sum taxes/transfers. Households in country $c$ own all the firms in the country; therefore, the asset market clearing condition requires that the asset holdings have to be equal to the sum of firm values

$$
A_{c t}=\int_{0}^{1} \tilde{V}_{c j t}+V_{c j t} d j
$$

where tilde " " denotes values pertaining to entrant firms. We assume full home bias in asset holding, an assumption that is robustly supported by the empirical evidence in the 1980s and 1990s. ${ }^{14}$

\subsection{Technology and Market Structure}

\subsubsection{Final Good}

The final good, which is to be used for consumption, R\&D expenditure, and as an input in the intermediate good production, is produced in perfectly competitive markets in both countries according to the following technology:

$$
Y_{c t}=\frac{L_{c}^{\beta}}{1-\beta} \int_{0}^{1}\left(q_{A j t}^{\frac{\beta}{1-\beta}} k_{A j t}+q_{B j t}^{\frac{\beta}{1-\beta}} k_{B j t}\right)^{1-\beta} d j .
$$

Here, $k_{j}$ refers to the intermediate good $j \in[0,1], q_{j}$ is the quality of $k_{j}$, and $\beta$ is the share of fixed factor in total output. Intermediate goods can be obtained from any country, whereas the fixed factor $L_{c}$ is assumed to be immobile across countries. We normalize the supply of the fixed factor $L_{c}=1$ in both countries to reduce notation.

Firms in both countries may potentially produce each variety $j$, and in the absence of trade frictions they are perfect substitutes in the final good production, once adjusted for their qualities. As a result, final good producers will choose to buy their inputs from the firm that offers a higher quality of the same variety. When trade costs exist, final good producers buy the in-

\footnotetext{
${ }^{14}$ For instance, in 1989, 92 percent of the U.S. stock market was held by U.S. residents. Japan, the U.K., France, and Germany show similar patterns, at 96 percent, 92 percent 89 percent, and 79 percent, respectively. A similar picture can be observed until the early 2000s, when the home bias started to decline [see, for example, Coeurdacier and Rey (2013)].
} 
termediate good of higher quality, once the prices are adjusted to reflect the trade costs. Final good producers in both countries have access to the same technology, which will allow us to focus on the heterogeneity of the intermediate goods sector. Both countries produce the same identical final good, which, under the assumption of frictionless trade in final goods, implies that the price of the final output in both countries will be the same. ${ }^{15}$ We normalize that price to be the numeraire without any loss of generality.

\subsubsection{Intermediate Goods and Innovation}

Incumbents. In each product line $j$, two incumbent firms-one from each country-compete for the market leadership à la Bertrand. Each of these firms has the same marginal cost of production, $\eta$, yet they differ in terms of their output quality, $q_{c j}$. We say that country $A$ is the leader in industry $j$ if $q_{A j t}>q_{B j t}$ and the follower if $q_{A j t}<q_{B j t}$. Firms are in a neck-and-neck position when $q_{A j t}=q_{B j t}$. The quality $q_{A j t}$ improves through successive innovations in $A$ or spillovers from $B$ (detailed later). When there is an improvement in country $c$ specific to product line $j$ during an interval of time $\Delta t$, the quality increases proportionally such that $q_{c j(t+\Delta t)}=\lambda^{n_{t}} q_{c j t}$, where $\lambda>1$ and $n_{t} \in \mathbb{N}$ is a random variable, which will be specified below. We assume that initially $q_{c j 0}=1, \forall j \in[0,1]$.

Let us denote by $N_{t}=\int_{0}^{t} n_{s} d s$ the number of quality jumps up to time $t$. Hence, the quality of a firm at time $t$ is $q_{c j t}=\lambda^{N_{c j t}}$. The relative state of a firm with respect to its foreign competitor is called the technology gap between two countries (in the particular product line) and can be summarized by a single integer $m_{A j t} \in \mathbb{N}$ such that

$$
\frac{q_{A j t}}{q_{B j t}}=\frac{\lambda^{N_{A j t}}}{\lambda^{N_{B j t}}}=\lambda^{N_{A j t}-N_{B j t}} \equiv \lambda^{m_{A j t}} .
$$

As we shall see, $m_{c j t}$ is a sufficient statistic for describing line-specific values, and we will therefore drop the subscript $j$ when a line-specific value is denoted by $m$. We assume that there is a relatively large but exogenously given limit in the technology gap, $\bar{m}$, such that the gap between two firms is $m_{c t} \in\{-\bar{m}, \ldots, 0, \ldots, \bar{m}\}$.

Firms invest in R\&D in order to obtain market leadership through improving the quality of their products. Let $R_{c j}^{x}$ and $x_{c j}$ denote the amount of R\&D investment and the resulting Poisson arrival rate of innovation by country $c$ in $j$, respectively. The production function of innovations takes the following form: $x_{c j t}=\left(\gamma_{c} \frac{R_{c j t}^{x}}{\alpha_{c} q_{c j t}}\right)^{\frac{1}{\gamma_{c}}}$.

Note that $q_{c j t}$ in the denominator captures the fact that a quality is more costly to improve if it is more advanced. This production function implies the following convex cost for generating

\footnotetext{
${ }^{15}$ Freeing intermediate good demand and profits from relative final good price movements, frictionless trade in final goods provides significant computational tractability to our already intricate structure, with endogenous forwardlooking innovation decisions solved over transition while also keeping track of the endogenous gap distribution.
} 
an arrival rate $x_{c j t}$ :

$$
R^{x}\left(x_{c j t}, q_{c j t}\right)=q_{c j t} \frac{\alpha_{c}}{\gamma_{c}} x_{c j t}^{\gamma_{c}}
$$

Entrants. Every period, a new entrepreneur in each product line and from each country invests in innovation to enter the market. If an entrepreneur succeeds in her attempt, the entrant firm replaces the domestic incumbent; otherwise, the firm disappears. The innovation technology for entrants is, $\tilde{x}_{c j t}=\left(\tilde{\gamma}_{c}{\tilde{\tilde{x}_{c j t}}}_{\tilde{x}_{c j t}}\right)^{\frac{1}{\tilde{\gamma}_{c}}}$, which implies the following convex cost function:

$$
\tilde{R}^{x}\left(\tilde{x}_{c j t}, q_{c j t}\right)=q_{c j t} \frac{\tilde{\alpha}_{c}}{\tilde{\gamma}_{c}} x_{c j t}^{\tilde{\gamma}_{c}}
$$

Figure 4 demonstrates the evolution of leadership in intermediate product lines as a result of incumbent innovation, entry, and exit.

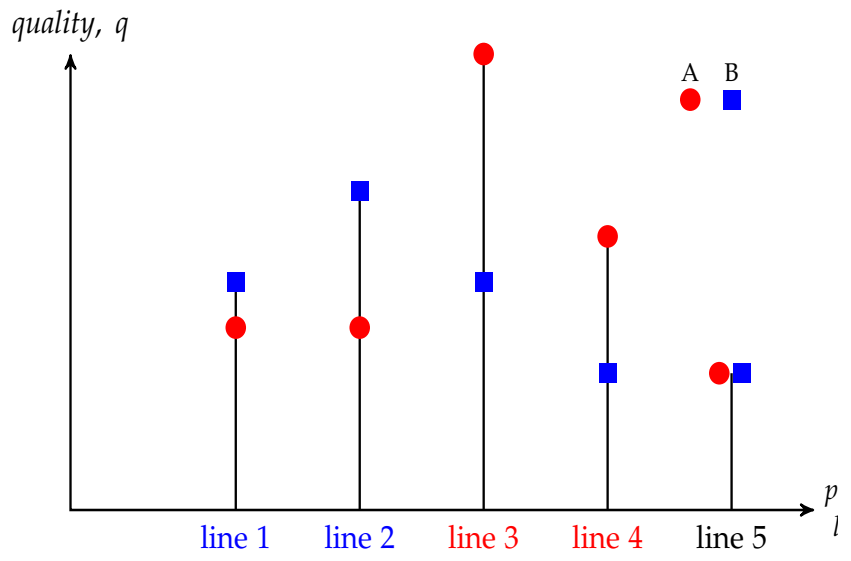

A) Product lines

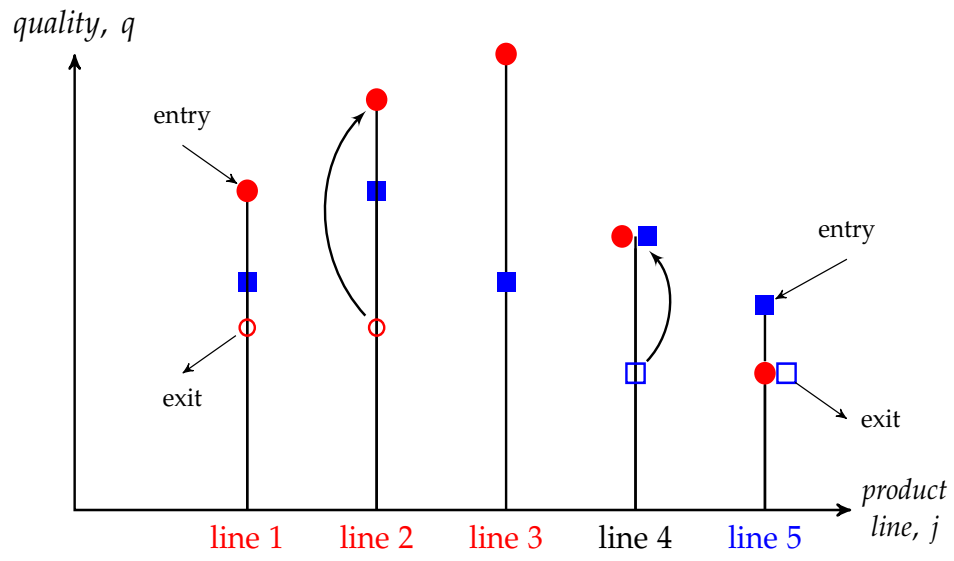

в) Entry, exit, and leadership

Figure 4: Evolution of product lines

Notes: Panel A exhibits the positions of competing incumbent firms with heterogeneous quality gaps in a set of product lines. Firms from country $B$ (designated by blue squares) are technological leaders in the first two lines, firms from country $A$ (red circle) are leaders in the next two lines, and firms are in neck-and-neck position in the last line. Panel B illustrates the effects of innovation by incumbents and entrants and the resulting dynamic of entry, exit, and technological leadership. Empty squares or circles denote the previous position of firms that innovate or exit.

In the left panel, five product lines with heterogeneous technology gaps are shown. In the first two lines, firms from country $B$ (designated by a square) lead, and in the next two lines, firms from country $A$ (designated by a circle) lead. In the last line, firms are in neck-and-neck position. The right panel exhibits how these positions evolve. Country $A$ seizes technological leadership in the first two lines in two different ways. In line 1, an entrant from $A$ enters with a large enough quality improvement, moving ahead of the previous leader, who is from $B$, and also driving the previous domestic incumbent out of business. In line 2, the incumbent from $A$ generates an innovation with a step size that is larger than the existing gap, which enables it 
to surpass the previous leader. While there is no change in line 3, firms become neck-and-neck in line 4 as a result of a successful innovation by the incumbent from $B$. In line 5 , an entrant innovation from $B$ breaks the neck-and-neck competition and brings the technological leadership to $B$, while also forcing the country's previous incumbent to exit.

Lastly, notice that changes in technological leadership may not result in business stealing when trade costs exist. Consider line 2, where country B's final good producers initially buy domestic inputs from the technologically superior domestic intermediate producer. Even if technological leadership changes hands in this line, country $B$ 's final good producers may still prefer buying domestic intermediate inputs instead of importing the better-quality foreign input if trade costs make it unprofitable despite the quality advantage of country $A^{\prime}$ s firm.

Innovations and Step Size. Each innovation improves the relative position of the firm in the technological competition. Conditional on innovation, the new position at which the firm will end up is determined randomly by a certain probability mass distribution $\mathbb{F}_{m}(\cdot) \cdot{ }^{16}$ Because the maximum number of gaps is capped by $\bar{m}$, there is a different number of potential gaps that each firm may reach depending on its current position in the technological competition. For instance, if a firm is leading by 10 gaps, with a single innovation it can potentially open up the advantage to $\{11, \ldots, \bar{m}\}$, whereas for a neck-and-neck firm, an innovation can help it reach $\{1, \ldots, \bar{m}\}$. Hence, the probability mass function that determines the new position, $\mathbb{F}_{m}(\cdot)$, is a function of $m$.

In order to keep the model parsimonious, we assume that there exists a fixed given distribution $\mathbb{F}(\cdot)$, and we derive $\mathbb{F}_{m}(\cdot)$ from this distribution in the following way. First, we define the benchmark distribution over positions larger than $-\bar{m}$, the most laggard position, as depicted in Figure 5a. We assume that it has the following functional form:

$$
\mathbb{F}(n) \equiv c_{0}(n+\bar{m})^{-\phi} \quad \forall n \in\{-\bar{m}+1, \ldots, \bar{m}\}
$$

This parametric structure is defined by only two parameters: a curvature parameter $\phi>0$ and a shifter $c_{0}$ that ensures $\sum_{n} \mathbb{F}(n)=1$. It implies a decaying probability in the new position $n$. This decay translates into a decay in the probability of an innovation generating larger technological jumps.

The highest gap size a firm can reach is $\bar{m}$. Therefore, the step size distribution specific to the firm's position, $\mathbb{F}_{m}(\cdot)$, is defined over positions $n \in\{m+1, \ldots, \bar{m}\}$ and is derived as follows:

$$
\mathbb{F}_{m}(n)=\left\{\begin{array}{cc}
\mathbb{F}(m+1)+\mathcal{A}(m) & \text { for } n=m+1 \\
\mathbb{F}(s) & \text { for } n \in\{m+2, \ldots, \bar{m}\}
\end{array} .\right.
$$

As demonstrated in Figure $5 b, \mathcal{A}(m) \equiv \sum_{s=-\bar{m}+1}^{m} \mathbb{F}(s)$ is an additional probability of improving

\footnotetext{
${ }^{16}$ Conversely, each innovation comes with an associated step size that is randomly generated by some probability mass function.
} 


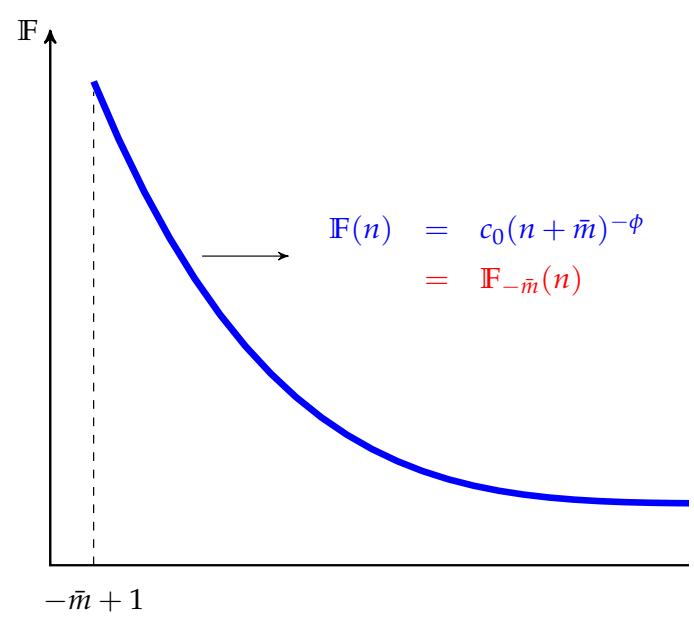

A) Benchmark

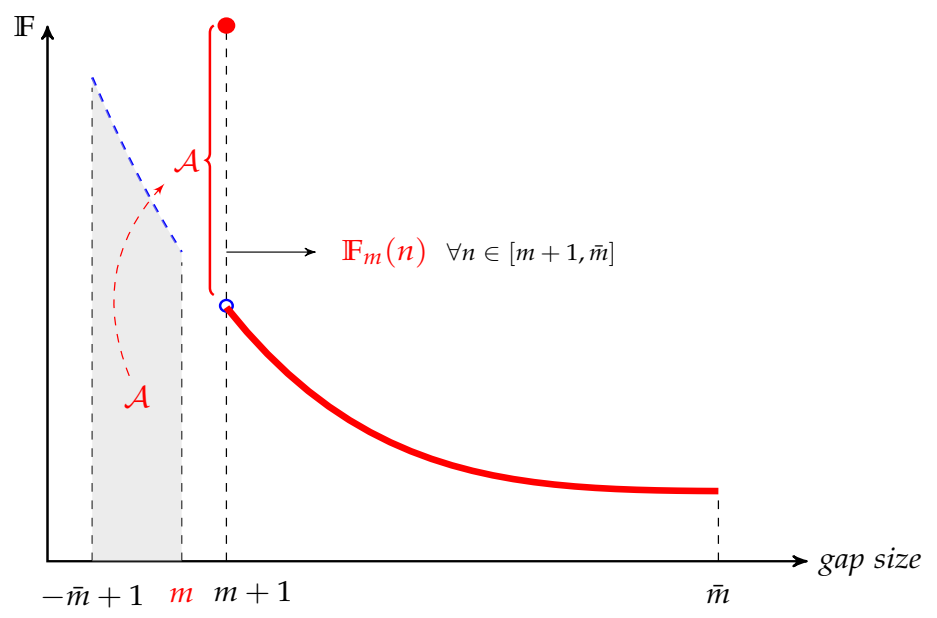

в) At position $m$

Figure 5: Probability mass function for new position

Notes: Panel A illustrates the function $\mathbb{F}(\cdot)$, defined in equation (6), which we use to generate the position-dependent distributions of innovation size. Thus, it describes also the probability distribution over potential positions, where an innovation can take the most laggard incumbent, denoted by $\mathbb{F}_{\bar{m}}(\cdot)$. Similarly, Panel B illustrates $\mathbb{F}_{m}(\cdot)$ for a generic position $m$.

the current quality only one more step, on top of what $\mathbb{F}(\cdot)$ would imply for that event, which is given by $\mathbb{F}(m+1)$. This specification for position-specific distributions implies that as firms become technologically more advanced relative to their competitors, it is relatively harder to open up the gap more than one step at a time. Moreover, their derivation comes at no additional cost in terms of parameters thanks to the additive nature of $\mathcal{A}$. Finally, notice that $\mathbb{F}_{-\bar{m}}(n)=\mathbb{F}(n)$.

An explanation for this particular way of modeling innovation step sizes is in order. In the basic step-by-step model, each innovation improves the existing quality of the follower either by a single step or by making the follower catch up with the leader no matter how big the initial gap is. The former is dubbed "slow catch-up regime," while the latter is dubbed "quick catch-up regime" in Acemoglu and Akcigit (2012). A slow catch-up regime would imply a slow process of convergence in leadership shares in contrast to what is observed in the data, and yet the quick catch-up regime would have the opposite effect. Therefore, by incorporating $\mathbb{F}(n)$, we generalize the modeling of firms' catching up and equip the model with enough flexibility to replicate the convergence process observed in the data. ${ }^{17}$

The treatment of $\mathcal{A}(m)$ in the derivation of position-specific distributions serves the same purpose. An alternative could assume equal distribution of the truncated probability mass $\mathcal{A}(m)$ across potential positions $\{m+1, \ldots, \bar{m}\}$. This alternative would imply a relatively fatter right tail in $\mathbb{F}_{m}(n)$ and, thus, a higher chance of climbing up the position ladder. However, this structure would favor the U.S., most of whose firms are technological leaders in their products, as opposed to the foreign countries, whose firms are lagging in most product lines. Even though a laggard

\footnotetext{
${ }^{17}$ Note that this specification converges to the standard step-by-step model as $\phi \rightarrow \infty$.
} 
firm can close the gap by multiple steps, a leading firm in this alternative setup could easily open up the gap again. It happens because for a leading firm, equal allocation of $\mathcal{A}(m)$ across the few better positions the firm may reach entails a higher chance of reaching better positions quickly again (as compared to the current specification where the probability of one-step improvements is disproportionately higher at larger leads). Because of this advantage of the leading firms, the model, once initiated at the empirical distribution, would have a strong force working against the shift in the leadership distribution toward smaller gaps. This feature would contrast with the convergence process in the data, as the empirical distribution strongly favors the U.S. in the early years of the sample period. By contrast, our current structure with innovations of heterogeneous step sizes helps the model generate the correct speed of convergence as in the data, while the distributional assumptions capture the idea of "advantage of backwardness" as in Gerschenkron (1962), as relatively more laggard firms are in a more advantageous position to receive multiplestep innovations.

During a small time interval $\Delta t \rightarrow 0$, the resulting law of motion for the quality level of an incumbent from $A$ that operates in product line $j$ can be summarized as follows. For $m>-\bar{m}$ the law of motion becomes

$$
q_{A j(t+\Delta t)}=\left\{\begin{array}{l}
\lambda^{n} q_{A j t} \text { with probability }\left(x_{A j t}+\tilde{x}_{A j t}\right) \mathbb{F}_{m}(n) \Delta t \quad \text { for } n \in\{m+1, \ldots, \bar{m}\} \\
q_{A j t} \quad \text { with probability } 1-\left(x_{A j t}+\tilde{x}_{A j t}\right) \mathbb{F}_{m}(n) \Delta t
\end{array}\right.
$$

and for $m=-\bar{m}$ the law of motion follows

$$
q_{A j(t+\Delta t)}= \begin{cases}\lambda^{n} q_{A j t} & \text { with probability }\left(x_{A j t}+\tilde{x}_{A j t}\right) \mathbb{F}_{-\bar{m}}(n) \Delta t \quad \text { for } n \in\{-\bar{m}+1, \ldots, 2 \bar{m}\} \\ q_{A j t} \quad \text { with probability } 1-\left(x_{A j t}+\tilde{x}_{A j t}\right) \mathbb{F}_{-\bar{m}}(n) \Delta t \\ \lambda q_{A j t} & \text { with probability }\left(x_{B j t}+\tilde{x}_{B j t}\right) \mathbb{F}_{m}(n) \Delta t\end{cases}
$$

Consider the quality levels associated with the incumbent firms from country $A$. In a product line where the firm from $A$ is in position $m$, the quality improves when either the domestic incumbent or entrant innovates. Moreover, the quality in a product line where the firm from $A$ is in the highest possible lag $-\bar{m}$ improves not only with innovations by the domestic incumbent and entrant, but also with innovations by the foreign incumbent or entrant, reflecting knowledge spillovers. The assumption of a maximum number of gaps and the resulting spillovers imply that in industries where this maximum is reached, an additional innovation by the leader, despite improving its quality, cannot widen the gap further. The underlying economic intuition is that when the leader at gap $\bar{m}$ innovates, the technology at gap $-\bar{m}+1$ becomes freely available to the follower in this product line. Because in this economy the leader and the follower belong to different countries by construction, this knowledge spillover implies a technology flow across country borders. This spillover helps our model economy generate cross-country convergence in innovation, technology, and income. 


\subsection{Equilibrium}

In this section, we solve for the Markov Perfect Equilibrium of the model where the strategies are functions of the payoff relevant state variable $m$. We start with the static equilibrium. Then we build up the value functions for the intermediate producers and entrants and derive their closed form solutions along with the R\&D decisions. These variables help us characterize the evolution of the world economy over time. Henceforth, we will drop the time index $t$ unless it causes confusion and denote export-related variables by an asterisk.

\subsubsection{Households}

We start with the maximization problem of the household. The Euler equation of the household problem determines the interest rate in the economy as: $r_{c t}=g_{c t} \psi+\rho$.

\subsubsection{Final and Intermediate Good Production}

Next, we turn to the maximization problem of the final good producer in country $c \in\{A, B\}$. Using the production function (3), the final good producers generate the following demand for the fixed factor $L_{c}$ and intermediate $\operatorname{good} j \in[0,1]$ :

$$
\begin{aligned}
& w_{c t}=\frac{\beta}{1-\beta} L_{c}^{\beta-1} \int_{0}^{1} q_{j t}^{\beta} k_{j t}^{1-\beta} d j \\
& p_{c j t}=L_{c}^{\beta} q_{c j t}^{\beta}\left(q_{A j t}^{\frac{\beta}{1-\beta}} k_{A j t}+q_{B j t}^{\frac{\beta}{1-\beta}} k_{B j t}\right)^{-\beta} .
\end{aligned}
$$

Now we consider the intermediate good producers' problem. In our open-economy setting, producers can sell their goods both domestically and internationally. However, as trade is subject to iceberg costs, the producer faces different demand schedules on domestically sold and exported goods. Therefore, the producer earns different levels of profits on these goods depending on the destination country. Let us start with the case of domestic business. Intermediate firms produce using the final good as input with a constant marginal cost $\eta .{ }^{18}$ Then, the profit

\footnotetext{
${ }^{18}$ The structure with the final good being the only input to intermediate good production helps the computation of the model substantially, as the intermediate production and export decisions become independent of fixed factor prices. Appendix E presents a version of the model where the fixed factor is an input to intermediate good production in a particular way, providing a benchmark to study the detrimental effect of foreign catch-up and the resulting loss of intermediate production on the compensation of the fixed factor.
} 
maximization problem of the monopolist in product line $j$ becomes ${ }^{19}$

$$
\pi\left(q_{j t}\right)=\max _{k_{j t} \geq 0}\left\{L_{c}^{\beta} q_{j t}^{\beta} k_{j t}^{1-\beta}-\eta k_{j t}\right\} \forall j \in[0,1] .
$$

The optimal quantity and price for intermediate variety $j$ follow from the first order conditions:

$$
k_{j t}=\left[\frac{1-\beta}{\eta}\right]^{\frac{1}{\beta}} q_{j t} \quad \text { and } \quad p_{j}=\frac{\eta}{1-\beta},
$$

with $L_{c}$ set to 1 . The realized price is a constant markup over the marginal cost and is independent of the individual product quality. Thus, the profit earned by selling an intermediate good domestically is

$$
\pi\left(q_{j t}\right)=\pi q_{j t}
$$

where $\pi \equiv \eta^{\frac{\beta-1}{\beta}}(1-\beta)^{\frac{1-\beta}{\beta}} \beta$. Notice that in deriving profits, we assumed that the monopolist is able to charge the unconstrained monopoly price. Assumption 1 introduced below ensures that the leaders are able to act as unconstrained monopolists.

The problem when selling abroad is different due to trade costs. In line with the trade literature, we assume that in order to export one unit of an intermediate good, the exporting firm needs to ship $1+\kappa$ units of that good $(\kappa \geq 0)$. Moreover, a firm in country $A$ exporting to country $B$ pays $\tau^{B}$ units of flat-rate excise import tariffs. ${ }^{20}$ This means that when the firm considers meeting the foreign demand, it will take into account that its marginal cost will be $\left(1+\kappa+\tau^{B}\right) \eta$. Given the trade costs, only the firm with the higher cost-adjusted quality will find it profitable to sell in the other country. Hence, the firm from country $A$ exports intermediate good $j$ to country $B$ if and only if

$$
\frac{q_{A j t}}{\left(1+\kappa+\tau^{B}\right)^{\frac{1-\beta}{\beta}}} \geq q_{B j t} .
$$

In this Bertrand competition setting, the existence of a competitor with inferior quality-by definition, located in the foreign country-could potentially push the leader to limit pricing. To simplify the analysis we make the following assumption:

Assumption 1 In every product line, incumbents enter a two-stage game where each incumbent pays an arbitrarily small fee $\varepsilon>0$ in the first stage in order to bid prices in the second stage.

Assumption 1 ensures that only the incumbent with the highest cost-adjusted quality pays the fee and is therefore able to set the monopoly price in the second stage. Under this assumption,

\footnotetext{
${ }^{19}$ The monopolist's maximization problem assumes the equilibrium property that a final good producer buys an intermediate input from one firm only. Therefore, the monopolist producer's demand $k_{j}$ is given by equation (9) with the amount supplied by the other firm $k_{-j}$ set to zero (see Assumption 1).

${ }^{20}$ In the baseline model, we assume that the governments burns out the tariff revenue, thus making tariffs to operate similar to iceberg costs. In Section 7.5, we relax this assumption as a robustness experiment.
} 
similar derivations as in the case of domestic sales lead to the following optimal quantity of exports and associated profits:

$$
k_{c j t}^{*}=\left[\frac{1-\beta}{\left(1+\kappa+\tau^{c^{\prime}}\right) \eta}\right]^{\frac{1}{\beta}} L_{c^{\prime}} q_{c j t} \quad \text { and } \quad p_{c j}^{*}=\frac{\left(1+\kappa+\tau^{c^{\prime}}\right) \eta}{1-\beta} \Rightarrow \quad \pi_{c}^{*}\left(q_{j t}\right)=\pi_{c}^{*} L_{c^{\prime}} q_{c j t},
$$

with $c \in\{A, B\}, c \neq c^{\prime}$, and $\pi_{c}^{*}=\left(\left(1+\kappa+\tau^{c^{\prime}}\right) \eta\right)^{\frac{\beta-1}{\beta}}(1-\beta)^{\frac{1-\beta}{\beta}} \beta$. Figure 6 summarizes the effect of positive trade costs on the technology frontier of two competing countries.

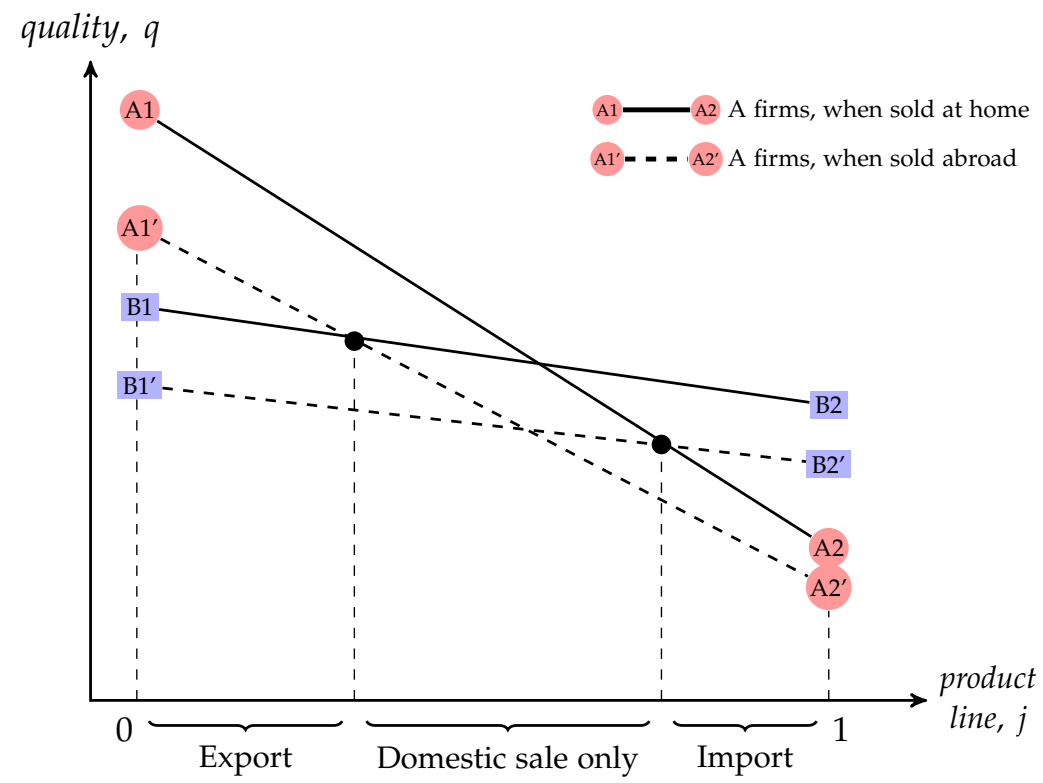

Figure 6: Effect of iceberg cost on quality and trade flows

Notes: The figure exhibits the technology frontiers, defined as the product qualities of incumbent firms over all product lines, of two countries in an example economy (shown by the solid lines). When exporting, the effective technology frontiers (given by the dashed lines) are lower than the actual ones because the exporters need to incur iceberg costs.

Without loss of generality, Figure 6 illustrates a special case where the quality frontiers of the two economies align perfectly in a descending order of qualities across sectors. The solid lines define the quality frontier of the domestic intermediate producers, where $A$ and $B$ denote the home and the foreign country, respectively. The dashed lines show the level of these qualities when adjusted by trade costs. Firms of the home country can export a product as long as the cost-adjusted quality, denoted by the dashed line $A^{\prime}$, is higher than the domestic quality of that product available in the foreign country, denoted by the solid $B$ line. When the reverse occurs, the home country imports the higher-quality product. Otherwise, firms serve only their domestic markets. Two intersections of dashed and solid lines determine two cutoffs that define three regions of product lines according to their position in trade. Next, we define these cutoffs analytically. 
We denote by $m_{c}^{*}$ the smallest gap by which a leader from country $c \in\{A, B\}$ needs to lead its follower in order to be able to export its good. Due to trade costs, it is possible that an intermediate good producer has a higher-quality product compared to its foreign competitor (e.g., $\left.q_{c}>q_{c^{\prime}}\right)$, but in cost-adjusted terms the quality of its good is lower than the foreign counterpart such that the firm cannot export $\left(q_{c} /\left(1+\kappa+\tau^{c^{\prime}}\right)^{\frac{1-\beta}{\beta}}<q_{c^{\prime}}\right)$. To secure a quality advantage even after trade costs are accounted for, the technology gap between a leader and its follower has to reach the threshold

$$
m_{c}^{*} \equiv \arg \min _{m}\left\{m \in[0, \bar{m}]: \lambda^{m} \geq\left(1+\kappa+\tau^{c^{\prime}}\right)^{\frac{1-\beta}{\beta}}\right\}
$$

Now we define the quality index of sectors where firms from country $c$ are in state $m$. Denote the measure of product lines where firms from $c$ are $m$-steps ahead by $\mu_{c m}$. Then the aggregate quality across these product lines is given by

$$
Q_{c m t} \equiv \int q_{c j t} \mathbb{I}_{\left\{j \in \mu_{c m}\right\}} d j
$$

Using the equilibrium conditions derived previously, total output is given as

$$
Y_{c t}=\sum_{m=-m_{c^{\prime}}^{*}+1}^{\bar{m}}\left[\frac{1-\beta}{\eta}\right]^{\frac{1-\beta}{\beta}} \frac{Q_{c m t}}{1-\beta}+\sum_{m=-\bar{m}}^{-m_{c^{\prime}}^{*}}\left[\frac{1-\beta}{\left(1+\kappa+\tau^{c}\right) \eta}\right]^{\frac{1-\beta}{\beta}} \frac{Q_{c^{\prime} m t}}{1-\beta} .
$$

The first sum denotes the contribution of domestic intermediate goods. The second sum, which is across product lines where foreign exporters lead domestic firms by at least $m_{c^{\prime}}^{*}$ gaps, denotes the contribution of imported goods. Finally, the fixed factor price is $w_{c t}=\beta Y_{c t}$, which follows from the first order condition of the final good producer given by equation (8).

We complete the description of equilibrium properties of goods' production with their implications for trade flows. The final good is freely traded and it absorbs possible imbalances in intermediate goods trade. Hence, trade in this economy is balanced, and the relative price driving the adjustment is the relative price of the fixed factor $w_{A} / w_{B}$.

\subsubsection{Firm Values and Innovation}

This subsection presents equilibrium firm values and innovation decisions. ${ }^{21}$

\footnotetext{
${ }^{21}$ In equilibrium, $m$ is a sufficient statistic for firm value. Lemma 1 at the end of this subsection verifies this result. Accordingly, we replace subscript $j$ with $m$ unless otherwise necessary.
} 
Incumbent Firms. We can write the value function for country $A$ 's incumbents: ${ }^{22}$

$$
\begin{aligned}
r_{A t} V_{A m t}\left(q_{t}\right)-\dot{V}_{A m t}\left(q_{t}\right) & =\max _{x_{A m t}}\left\{\Pi\left(m ; \tau^{A}, \tau^{B}\right) q_{t}-\left(1-s^{A}\right) \alpha_{A} \frac{\left(x_{A m t}\right)^{\gamma_{A}}}{\gamma_{A}} q_{t}\right. \\
& +x_{A m t} \sum_{n_{t}=m+1}^{\bar{m}} \mathbb{F}_{m}\left(n_{t}\right)\left[V_{A n t}\left(\lambda^{\left(n_{t}-m\right)} q_{t}\right)-V_{A m t}\left(q_{t}\right)\right] \\
& +\tilde{x}_{A m t}\left[0-V_{A m t}\left(q_{t}\right)\right] \\
& \left.+\left(x_{B(-m) t}+\tilde{x}_{B(-m) t}\right) \sum_{n_{t}=-m+1}^{\bar{m}} \mathbb{F}_{-m}\left(n_{t}\right)\left[V_{A(-n t)}\left(q_{t}\right)-V_{A m t}\left(q_{t}\right)\right]\right\},
\end{aligned}
$$

where $\Pi\left(m ; \tau^{A}, \tau^{B}\right)$ is defined as

$$
\Pi\left(m ; \tau^{A}, \tau^{B}\right)=\left\{\begin{array}{cll}
\pi L_{A}+\pi^{*} L_{B} & \text { if } m \geq m_{A}^{*} \\
\pi L_{A} & \text { if } m_{A}^{*}>m>-m_{B}^{*} . \\
0 & \text { if } m \leq-m_{B}^{*}
\end{array}\right.
$$

Note that profit level depends on foreign tariffs because profits from exports, derived in equation (11), are affected by it.

The first line on the right-hand side denotes the operating profits net of $R \& D$ costs, where $s^{A}$ is the R\&D subsidy. Profits are linear in product quality, creating an incentive for innovation even for firms at the largest lead. As is evident from the definition of $\Pi\left(m ; \tau^{A}, \tau^{B}\right)$, capturing the domestic market or expanding into foreign markets adds to profits, thereby intensifying the incentives to innovate. Expansion of markets through exports reflects the market-size effect. The second line denotes the expected gains from innovation. This expectation is over potential new positions. The exact position is determined probabilistically by the step size of innovation. For firms that are close to their rivals and, thus, feel the competition at its most intense, the innovation effort reflects a dominant incentive for taking over the competitor in order to gain market power. This is an escape-competition effect typical of step-by-step innovation models. A distinguishing feature of our model, however, is that this force emerges at two distinct positions instead of a single one as is typical of closed-economy versions. The first case is when a laggard firm is one-step behind short of beating the foreign exporter and gaining access to domestic production. This leads to an intense innovation activity by the laggard firm, which we label as defensive RED. Second, a similar intensification happens when a domestic producer is one step short of gaining access to export markets, in which case expansionary RED is observed. We further discuss this extension of the escape-competition effect across multiple stages of competition-in particular, over domestic and foreign markets-in Section 4.2 by confronting the model with the data.

The last two lines on the right hand side capture the creative destruction by domestic and

\footnotetext{
${ }^{22}$ The problem for incumbent firms from country $B$ is defined reciprocally.
} 
foreign competitors. The third line reveals that entry by domestic firms forces the incumbent to exit with probability one, as by construction every product line is forced to have one firm from each country. This domestic business-stealing effect reduces the value of an incumbent firm and therefore its incentive to innovate. Moreover, in an open economy, there is an additional channel through business stealing. The last line explains the changes as a result of innovation in the foreign country. Any innovation there, regardless of the source being an entrant or an incumbent, deteriorates the position and the value of the domestic incumbent, and the size of the deterioration is again determined probabilistically by $\mathbb{F}_{-m}(\cdot) \cdot{ }^{23}$ We label this additional channel as the international business-stealing effect. ${ }^{24}$

The firms' problems are characterized by an infinite-dimensional space of intermediate good qualities. The following lemma renders the firm environment independent of the current quality of their products, reducing the state space to finite dimensions and allowing for numerical tractability.

Lemma 1 The value functions are linear in quality such that $V_{c m}(q)=q v_{c m}$ for $m \in\{-\bar{m}, \ldots, \bar{m}\}$ where

$$
r_{A t} v_{A m t}-\dot{v}_{A m t}=\max _{x_{A m t}}\left\{\begin{array}{c}
\Pi\left(m ; \tau^{A}, \tau^{B}\right)-\left(1-s^{A}\right) \alpha_{A} \frac{\left(x_{A m t}\right)^{\gamma_{A}}}{\gamma_{A}} \\
+x_{A m t} \sum_{n_{t}=m+1}^{\bar{m}} \mathbb{F}_{m}\left(n_{t}\right)\left[\lambda^{\left(n_{t}-m\right)} v_{A n t}-v_{A m t}\right] \\
+\tilde{x}_{A m t}\left[0-v_{A m t}\right] \\
+\left(x_{B(-m) t}+\tilde{x}_{B(-m) t}\right) \sum_{n_{t}=-m+1}^{\bar{m}} \mathbb{F}_{-m}\left(n_{t}\right)\left[v_{A(-n t)}-v_{A m t}\right]
\end{array}\right\},
$$

This ensures that the innovation decision of the firm does not depend on $j$ once controlled for $m$.

Proof. See Appendix B.1.

The first order conditions of the problems defined above yield the following equilibrium $\mathrm{R} \& \mathrm{D}$ decisions for an incumbent in state $m$ :

$$
x_{c m t}=\left\{\begin{array}{cl}
{\left[\frac{1}{\alpha_{c}\left(1-s^{c}\right)} \sum_{n=m+1}^{\bar{m}} \mathbb{F}_{m}(n)\left\{\lambda^{\left(n_{t}-m\right)} v_{c n t}-v_{c m t}\right\}\right]^{\frac{1}{\gamma_{c}-1}}} & \text { if } m<\bar{m} \\
{\left[\frac{1}{\alpha_{c}\left(1-s^{c}\right)}(\lambda-1) v_{c \bar{m} t}\right]^{\frac{1}{\gamma_{c}-1}}} & \text { if } m=\bar{m}
\end{array} .\right.
$$

Entrants. Recall that entry is directed at individual product lines and a successful entrant improves on the active domestic incumbent's technology. The problem of an entrant that aims at a product line where the current domestic incumbent is $m>0(m<0)$ steps ahead (behind) is as

\footnotetext{
${ }^{23}$ The distribution function is labeled with the subscript $-m$ because it is associated with the competitor's position. Note that there is no threat of exit posed by the foreign entrant, as that entrant replaces the incumbent of its own country.

${ }^{24}$ We define the value functions for the two boundary cases where the incumbent is $\bar{m}$-steps ahead (behind) in Appendix B.2. As discussed there, the international knowledge spillover manifest itself in the value function of $\bar{m}$-stepbehind incumbent.
} 
follows:

$$
\tilde{V}_{c m t}\left(q_{t}\right)=\max _{\tilde{x}_{c m t}}\left\{-\frac{\tilde{\alpha}_{c}}{\tilde{\gamma}_{c}}\left(\tilde{x}_{c m t}\right)^{\tilde{\gamma}_{c}} q_{t}+\tilde{x}_{c m t} \sum_{n_{t}=m+1}^{\bar{m}} \mathbb{F}_{m}\left(n_{t}\right) V_{c n t}\left(\lambda^{\left(n_{t}-m\right)} q_{t}\right)\right\} .
$$

Again, $\mathbb{F}_{m}(\cdot)$ denotes the probability distribution of potential step sizes, from which a random step will realize conditional on having an innovation. An entrant who fails to innovate exits the economy. Solving this problem leads to the following equilibrium value of the entrant firm:

$$
\tilde{V}_{c m t}\left(q_{t}\right)=\left(1-\frac{1}{\tilde{\gamma}_{c}}\right) \tilde{\alpha}_{c}\left(\tilde{x}_{c m t}\right)^{\tilde{\gamma}_{c}} q_{t}>0
$$

which is independent of the production line's index $j$ and is determined by the current gap size. The equilibrium innovation rates for entrants become

$$
\tilde{x}_{c m t}=\left\{\begin{array}{cc}
{\left[\lambda v_{c \bar{m} t} \cdot \tilde{\alpha}_{c}^{-1}\right]^{\frac{1}{\gamma_{c}-1}}} & \text { if } m=\bar{m} \\
{\left[\tilde{\alpha}_{c}^{-1} \sum_{n=m+1}^{\bar{m}} \mathbb{F}_{m}(n) \lambda^{\left(n_{t}-m\right)} v_{c n t}\right]^{\frac{1}{\bar{\gamma}_{c}-1}}} & \text { if } m<\bar{m}
\end{array} .\right.
$$

Closing the model, aggregate consumption is derived from the budget constraint in equation (2). Aggregate R\&D spending $R_{c t}$ is derived combining equations (4), (5), (15), and (17):

$$
R_{c t}=\sum_{s=-\bar{m}}^{\bar{m}}\left(\alpha_{c} x_{c s t}^{\gamma_{c}}+\tilde{\alpha}_{c} \tilde{x}_{c s t} \tilde{\gamma}_{c}\right) Q_{c s t}
$$

and total intermediate production input $K_{c t}$ is determined by equations (10)-(11):

$$
K_{c t}=\sum_{s=m_{c}^{*}}^{\bar{m}}\left(1+\kappa+\tau^{c^{\prime}}\right) \eta\left[\frac{1-\beta}{\left(1+\kappa+\tau^{c^{\prime}}\right) \eta}\right]^{\frac{1}{\beta}} Q_{c s t}+\sum_{s=-m_{c^{\prime}}^{*}+1}^{\bar{m}-1} \eta\left[\frac{1-\beta}{\eta}\right]^{\frac{1}{\beta}} Q_{c s t} .
$$

The government spending reads as

$$
G_{c t}=s^{c} \sum_{s=-\bar{m}}^{\bar{m}} \alpha_{c} x_{c s t}^{\gamma_{c}} Q_{c s t}
$$

implying that the total expenditure on subsidies is funded by the total lump-sum taxes collected. Notice that tariffs do not generate revenue in the baseline model (Section 7.5 relaxes this assumption). We leave the analytical discussion of the evolution of the aggregate quantities such as $\mu_{c m t}$ and $Q_{c m t}$, which summarize the dynamics of the model, to Appendix B.3. Now we define the equilibrium.

Definition 1 (Equilibrium) Let the world economy consist of two countries $c \in\{A, B\}$. A Markov 
Perfect Equilibrium is an allocation

$$
\left\{r_{c t}, w_{c t}, p_{j}, k_{j t}, k_{j t}^{*}, x_{c j t}, \tilde{x}_{c j t}, Y_{c t}, C_{c t}, R_{c t}, K_{c t}, G_{c t}, L_{c},\left\{\mu_{c m t}, Q_{c m t}\right\}_{m \in\{-\bar{m}, \ldots, \bar{m}\}}\right\}_{c \in\{A, B\}, j \in[0,1]}^{t \in[0, \infty)}
$$

such that (i) the sequence of prices and quantities $p_{j}, k_{j t}, k_{j t}^{*}$ satisfy equations (10)-(11) and maximize the operating profits of the incumbent firm in the intermediate good product line $j$; (ii) the RED decisions $\left\{x_{c j t}, \tilde{x}_{c j t}\right\}$ are defined in equations (15) and (17), and $R_{c t}$ is given in equation (18); (iii) labor supply $L_{c}$ is equal to the profit-maximizing labor choice of the final good producers defined by equation (8); (iv) $Y_{c t}$ is as given in equation (13); (v) $C_{c t}$ is as derived from equation (2); (vi) $K_{c t}$ is given in equation (19); (vii) wages $w_{c t}$ clear the labor markets at every $t$; (viii) interest rates $r_{c t}$ satisfies the households' Euler equation; (ix) government has a balanced budget at all times in line with equation (20); $(x)$ and $\left\{\mu_{c m t}, Q_{c m t}\right\}_{m \in\{-\bar{m}, \ldots, \bar{m}\}}$ are consistent with optimal RED decisions.

\subsection{Welfare}

Aggregate welfare in economy $c$ over horizon $T$ calculated at time $t_{0}$ is given by

$$
\mathbb{W}_{t_{0}}^{c}=\int_{t_{0}}^{t_{0}+T} \exp (-\rho(s-t)) \frac{C_{c s}^{1-\psi}-1}{1-\psi} d s
$$

In the quantitative section, we will report the welfare differences between a counterfactual and the baseline economy in consumption equivalent terms using the following relationship:

$$
\int_{t_{0}}^{t_{0}+T} \exp \left(-\rho\left(s-t_{0}\right)\right) \frac{\left(C_{c s}^{n e w}\right)^{1-\psi}-1}{1-\psi} d s=\int_{t_{0}}^{t_{0}+T} \exp \left(-\rho\left(s-t_{0}\right)\right) \frac{\left((1+s) C_{c s}^{\text {base }}\right)^{1-\psi}-1}{1-\psi} d s .
$$

If a policy change at time $t_{0}$ yields a new income sequence $C_{c t}^{n e w}$ between $t_{0}$ and $t_{0}+T$ satisfying the above relationship, we say that the policy change results in $\varsigma \%$ variation in consumptionequivalent welfare over horizon $T$. This means that the representative consumer in the baseline economy would need to receive $\varsigma \%$ additional income at each point in time between $t_{0}$ and $t_{0}+T$ in order to obtain the level of welfare it would have in the counterfactual scenario.

\section{Analytical Results in a Simplified Model and Taking Stock}

Before proceeding to the quantitative investigation of the model, we find it worthwhile to discuss some of the key economic forces of our model in more detail. ${ }^{25}$ We split the discussion into two parts: static and dynamic. Even though it is not possible to express the equilibrium objects in a

\footnotetext{
${ }^{25}$ We refer the reader who is interested in quantitative analysis to Section 4 .
} 
fully analytical form in transition, we make significant progress in that direction by focusing on a slightly simplified version here. ${ }^{26}$ We start with the discussion of static forces.

\subsection{Static Effects of Openness}

In this subsection, we will abstract from iceberg costs and we will consider two extreme economies: open economy (i.e., no tariffs) versus autarky (i.e, tariff rates are infinite). We can solve for the static equilibrium for these two alternative economies and show that income of the fixed factor is always bigger in an open economy-i.e., $w^{\text {autarky }}<w^{\text {open }}$. This result is intuitive. In a world with open economies, more productive intermediate good producers sell to the final good producers in both countries. This selection channel facilitates the transfer of better-quality intermediate goods across countries, increasing the productivity of the fixed factor utilized in the production of domestic final output. Therefore, this channel, labeled as direct transfer of technology in Keller (2004), leads to a higher fixed factor income in both countries.

However, the impact of openness on profits is not obvious. In contrast to the state of autarky, the open economy allows relatively more productive firms to sell to a larger market by providing the opportunity to export. Yet, at the firm level the selection channel implies that less productive domestic firms lose their profits to foreign competitors, which they would earn otherwise in autarky, causing a decline in aggregate profit income. As a result, the net effect of openness on total profits remains ambiguous. Proposition 1 summarizes these findings.

Proposition 1 In the environment without iceberg trade costs described above:

A) Opening the economy to international trade increases the income of the fixed factor, i.e., $w^{\text {autarky }}<$ $w^{o p e n}$. However, the total change in profits of the domestic business owners is ambiguous and depends on the initial composition of the technology gaps between two countries, i.e., $\int_{0}^{1} \Pi_{j}^{\text {autarky }} d j \lessgtr$ $\sum_{m=-\bar{m}}^{\bar{m}} \mu_{m} \Pi_{m}^{o p e n}$.

B) The static effect of unilateral trade policy liberalization (reduction in tariffs) on aggregate income is shaped by the loss of profits to foreign exporters and the gain in fixed factor income and has an ambiguous direction.

\section{Proof. See Appendix C.}

For instance, in an extreme case where a country is lagging in all sectors by a very small margin, opening to trade from autarky may decrease national income initially, as the small productivity gain from transferring slightly better technology may not compensate for the loss of profits in all sectors.

\footnotetext{
${ }^{26}$ For a thorough discussion of similar channels in the context of a basic Schumpeterian creative destruction model, see Chapter 15 in Aghion and Howitt (2009).
} 


\subsection{Dynamic Effects of Openness and Escape Competition}

In order to emphasize the dynamic strategic interaction between intermediate producers introduced by foreign competition, we focus on a special case of our model. In particular, we consider a standard step-by-step open-economy setting with two symmetric countries that abstracts from firm entry, features quick catch-up by followers, and minimizes the incentives for quality improvements. First, we take $\tilde{\alpha}_{c} \rightarrow \infty$ implying zero entry in both countries. Second, innovations improve a leader's position by a single step-i.e. $\mathbb{F}_{m}(n=m+1)=1, \forall m \geq 0$. Third, we set $\mathbb{F}_{m}(n=0)=1, \forall m<0$, to allow any innovating follower to reach neck-and-neck position. Fourth, we assume that $\lambda=1+\varepsilon$ where $\varepsilon$ is arbitrarily close to zero, implying that quality improvements from innovations are minuscule. ${ }^{27}$ The following proposition argues that, in this environment, firms in neck-and-neck position have the highest innovation intensity.

Proposition 2 The above assumptions imply that

1. the innovation intensity becomes the highest at neck-and-neck position;

2. the followers innovate at the same intensity and strictly less than the neck-and-neck firms;

3. the leaders do not innovate.

Formally, $x_{0}>x_{-m}=x_{-\bar{m}}>x_{\bar{m}}=x_{m}=0$ for $m>0$.

Proof. See Appendix C.

Proposition 2 formalizes the fact that the positive effect of foreign competitive pressures on innovation incentives becomes the strongest when firms compete against rivals producing goods of similar quality. This effect is analogous to the one in closed-economy step-by-step modelsnamely, the "escape-competition" effect-but it gains an international aspect in the context of a small open economy. Moreover, notice that in our general model, the international structure modifies the escape-competition effect in more subtle ways than merely shifting the origin of the competitive pressure from domestic to foreign. In fact, the intensification of innovation as a result of international competition arises at two points in our generalized model instead of one because of trade costs. Firms have an incentive to escape competition for two similar yet distinct reasons: to capture domestic profits (defensive R\&D) and to capture export markets (expansionary R\&D).

In Section 4, we proceed with the full-fledged model, removing simplifying features introduced in this subsection for the sake of analytical investigation.

\footnotetext{
${ }^{27}$ Therefore, innovation incentives are driven by business-stealing and escape-competition effects.
} 


\section{Quantitative Analysis}

In this section, we study the quantitative implications of our theoretical framework. After calibrating the model, we first discuss its performance in terms of out-of-sample predictions. Then, we focus on the implications of R\&D subsidies and tariff policies for technological competition. We evaluate alternative scenarios including the simultaneous use of measures and retaliation by trade partners in terms of their welfare consequences. We start our exploration with the calibration of our model.

\subsection{Calibration}

When mapping our two-country model to the data, we envision a world that consists of the U.S. and a foreign country, which is a weighted combination of the six countries employed in the empirical section: Canada, France, Germany, Italy, Japan, and the U.K. ${ }^{28}$ The weights associated with each country, listed in Table 1, reflect the count of patents registered in the U.S. by the residents of a specific country in the initial year of the sample (1975) as a fraction of all foreign patents registered in the U.S. in that year. ${ }^{29}$ In the remainder of this section, country $A$ will represent the U.S. and country $B$ the foreign country.

Table 1: Patent weights of countries

\begin{tabular}{cccccc}
\hline \hline Canada & France & Germany & Italy & Japan & U.K. \\
\hline $6.2 \%$ & $11.7 \%$ & $30.0 \%$ & $3.8 \%$ & $33.1 \%$ & $14.6 \%$ \\
\hline \hline
\end{tabular}

As Figure 3 shows, there is a significant break in the R\&D policy before and after 1981. Moreover, as shown in Figures A.1 in Appendix A.1, there is a strong convergence in the relative shares of domestic and foreign patents registered in the U.S. prior to 1981, which also holds true for the share of sectors led by domestic and foreign firms. A key objective of our calibration strategy is to reproduce this convergence in order to conduct our policy evaluation exercises in an environment that mimics the intensification of the foreign technological competition faced by U.S. firms in those years. Therefore, we match the model to a set of moments that we obtain from the data that span 1975 to 1981. Then, we impose to the calibrated model the changes in R\&D policy observed in the data and analyze their implications for the post-1981 period (1981 to 1995)..$^{30}$

\footnotetext{
${ }^{28}$ These are the most innovation-intensive countries competing with the U.S., measured by their share of patent applications in the USPTO patent data.

${ }^{29}$ Weights may not sum to 1 because of rounding.

${ }^{30}$ We focus our analysis on the period before 1995 for several reasons. First, we want to avoid the run-up to the U.S. dot-com bubble and the crisis that followed in the early 2000s. Second, we isolate our period from heightened
} 
In the calibrated model, we try to keep the least amount of heterogeneity across countries other than subsidy levels in order to focus solely on the effect of policy differences. The two large open economies share symmetric technologies except the scale parameters of R\&D cost functions and the imposed R\&D subsidies. These assumptions leave us with the following 16 structural parameters to be determined:

$$
\theta \equiv\left\{\alpha_{A}, \alpha_{B}, \tilde{\alpha}_{A}, \tilde{\alpha}_{B}, \gamma, \tilde{\gamma}, \rho, \psi, \beta, \kappa, \eta, \lambda, \phi, \tau_{75-81}, s_{75-81}^{A}, s_{75-81}^{B}\right\}
$$

Some of these parameters are calibrated externally and the remaining are calibrated internally. We start with the external calibration.

\subsubsection{External Calibration}

We take the CRRA parameter of the utility function $\psi=2$, a standard value in the macroeconomics literature. We set the time discount parameter $\rho=1 \%$. These preference parameters imply a 2.8 percent interest rate in the balanced growth path and an average rate of 1.8 percent between 1975 and 1981 for the U.S. We set $\beta=0.5$, which leads to a roughly 65 percent share of fixed factor income in U.S. GDP in the balanced growth path, with $\eta$ set equal to $1-\beta .{ }^{31}$ We assume $R \& D$ cost functions to have a quadratic shape such that $\gamma=\tilde{\gamma}=2$, which is the common estimate in the empirical R\&D literature (see Acemoglu et al. (2017) for a thorough discussion). The left panel of Table 2 lists these values.

Table 2: List of parameter values

\begin{tabular}{lll||lll}
\hline \hline \multicolumn{3}{c||}{ Panel A: Externally calibrated } & \multicolumn{3}{c}{ Panel B: Internally calibrated } \\
Parameter & Value & Description & Parameter & Value & Description \\
\hline$\psi$ & 2 & Elasticity of substitution & $\alpha_{A}$ & 0.64 & R\&D scale, incumbents US \\
$\gamma, \tilde{\gamma}$ & 2 & R\&D cost curvature & $\alpha_{B}$ & 1.14 & R\&D scale, incumbents FN \\
$\rho$ & $1 \%$ & Rate of time preference & $\tilde{\alpha}_{A}$ & 44.6 & R\&D scale, entrants US \\
$\beta$ & 0.6 & Factor income share & $\tilde{\alpha}_{B}$ & 8.77 & R\&D scale, entrants FN \\
$s_{75-81}^{A}$ & $5.3 \%$ & R\&D subsidy US, 75-81 & $\phi$ & 1.35 & Curvature of $\mathrm{F}(n)$ \\
$s_{75-81}^{B}$ & $3.8 \%$ & R\&D subsidy FN, 75-81 & $\lambda$ & $1.49 \%$ & Innovation step size \\
& & & $\kappa$ & $11.4 \%$ & Iceberg trade cost \\
& & & $\tau_{75-81}$ & $8 \%$ & Tariff rate \\
\hline \hline
\end{tabular}

A crucial set of parameters is the $R \& D$ subsidy rates. The numbers we use are those cal-

competition exerted by China. Although valuable in itself, this would introduce a second period of exogenous variation to our analysis, making it more complicated for no apparent benefit. Finally, our theoretical assumption of home bias is better suited for this relatively earlier period of financial globalization.

${ }^{31}$ By income approach, GDP is equal to the sum of profits and wages earned. 
culated in Impullitti (2010), which lack only Canada. ${ }^{32}$ These data go back to 1979. Given that the rates in the sample countries do not markedly fluctuate before the mid-1980s, we assume the values before 1979 to be the same as in 1979. For the calibration part, the subsidy rates for both countries are 1975-1981 averages, which are again weighted for the foreign countries. When we simulate the model for the post-1981 period, we will recalculate the subsidy rates to match the averages across 1982 to 1995 . We also recalculate the weights of foreign countries the same way but use 1981 patent counts.

\subsubsection{Internal Calibration and Identification}

We have eight remaining parameters: $\left\{\alpha_{A}, \alpha_{B}, \tilde{\alpha}_{A}, \tilde{\alpha}_{B}, \lambda, \phi, \kappa, \tau_{75-81}\right\}$. One of these, $\phi$, determines the shape of the generic step-size distribution. In order to calibrate them, we use seven data points and the distribution of firms across technology gaps that we derive using USPTO patent data. We start with the discussion of the seven moments, summarized in Table 3, that are not directly related to the gap distribution. Again, moments pertaining to the foreign country are weighted averages of the values for individual countries.

The first two moments are the average growth rates of total factor productivity (TFP) in both countries, calculated using TFP series in Coe et al. (2009). The next two moments are aggregate non-defense $R \& D$ expenditure as a percentage of GDP, which we obtain from the Main Science and Technology Indicators (MSTI) database of the OECD. ${ }^{33}$ As a fifth target, we include the birth rate of new establishments for the U.S. computed using the BDS database. ${ }^{34}$ The sixth moment is the ratio of U.S. manufacturing exports to GDP, which we derive using World Bank data. These moments allow us to determine six parameters as follows. Aggregate R\&D shares discipline the scale parameters of the incumbent $R \& D$ cost functions $\left\{\alpha_{A}, \alpha_{B}\right\}$. The scale parameter of the entrant R\&D cost function for country $A\left(\tilde{\alpha}_{A}\right)$ is determined by the U.S. establishment birth rate. Then, TFP growth rates pin down the basic step size $\lambda$ and the entrant R\&D cost for country $B$ $\left(\tilde{\alpha}_{B}\right)$. The U.S. export-to-GDP ratio determines the iceberg cost $\kappa$, as $\kappa$ sets $m^{*}$, the minimum gap a firm needs to open up in order to export, given $\lambda$. Finally, average U.S. tariff revenue during the calibration period, which we obtain from U.S. International Trade Commission, determines the tariff rate, which we take to be common for both countries.

The last parameter to be internally calibrated is $\phi$, which controls the curvature of the generic probability function over technology gaps, $\mathbb{F}(n)$. As manifested by equations (A.1), this function,

\footnotetext{
${ }^{32}$ We address this issue by recalculating the patent weights after dropping Canada.

33 Non-defense R\&D spending data do not include Japan. However, Science and Engineering Indicators reports of the National Science Foundation, based on MSTI data, provide estimates of this variable for Japan, which we use to amend our calculations with the OECD data. Also, MSTI data start in 1981, which is why we use the initial values of this variable.

${ }^{34}$ We prefer entry by establishments instead of firms because while in the data firms enter at different sizes, in our model every firm operates in one product line.
} 
by forming the basis of position-specific $\mathbb{F}_{m}(n)$, becomes an integral determinant of the model dynamics that govern the evolution of firms' measure across technology gaps $\left(\mu_{\mathrm{cm}}\right.$ 's). We make use of this relationship to discipline the shape of $\mathbb{F}(n)$. To this end, we first derive the empirical distribution of sectors across technology gaps using the information on patents provided by the USPTO data. This procedure, illustrated in Figure 7, provides us with the data counterpart of firms' measure across technology gaps (gap distribution) in the model.

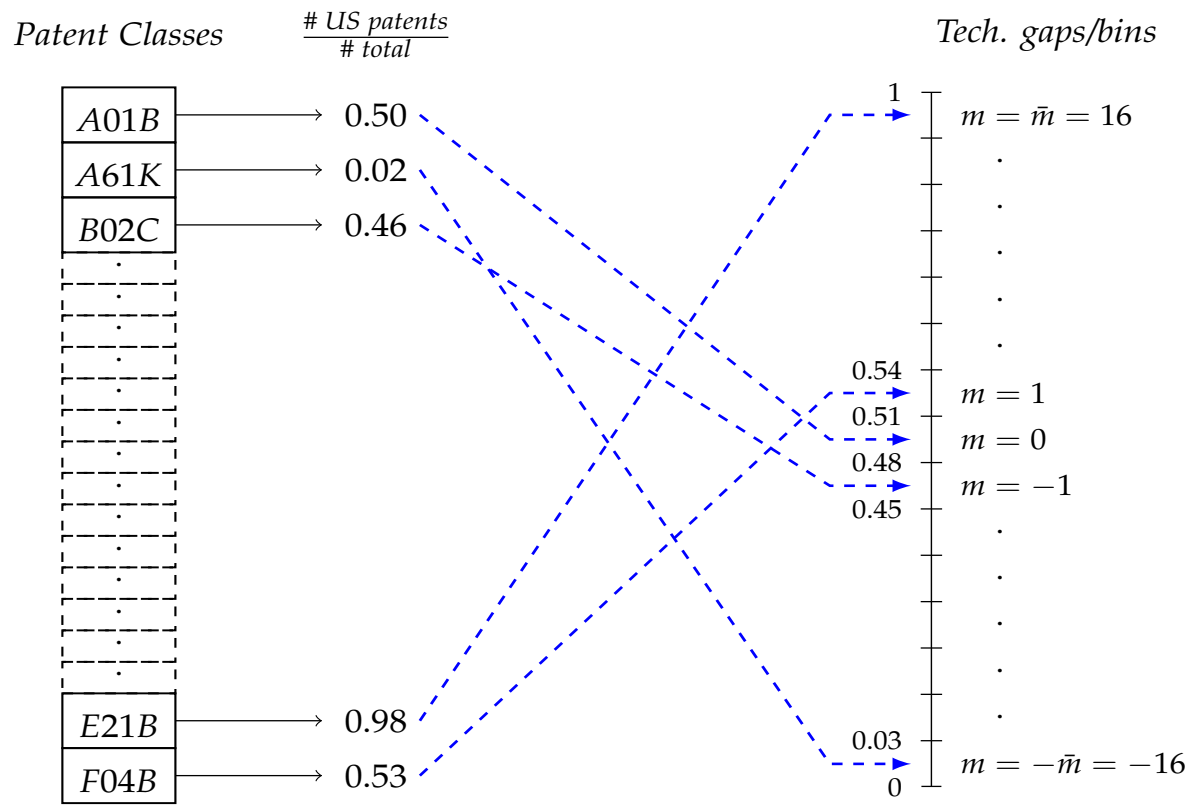

Figure 7: Mapping USPTO patent data to the model

Notes: The figure illustrates how patent classes in the USPTO data are assigned to equally sized bins on a unit measure according to the share of patents owned by U.S. residents, obtaining an empirical distribution of technology gaps.

We start with sorting sectors in a given year according to the fraction of patents in each sector that are registered by U.S.-based entities in that year. ${ }^{35}$ Then, we divide this unit interval into 33 equally spaced bins, each of which corresponding to a range of approximately 3 percent. For instance, sectors with a fraction of U.S. patents between 0 and 3 percent would fall into $m=-16$, sectors with a fraction between 4 percent and 6 percent would fall into $m=-15$, and so on. Sectors in the data correspond to product lines in our model and, thus, the measure of sectors across bins (normalized to sum to 1 ) corresponds in our model to $\mu_{m}$ 's for country $A$ across 33 gap levels from $-\bar{m}=-16$ to $\bar{m}=16 .{ }^{36}$ Figure 8a shows the distribution in the data for

\footnotetext{
${ }^{35}$ The total mass of patents in a given year consists of patents by registrants from the U.S. and the other six foreign countries that we used throughout the paper. For the robustness of our results to a method where sectoral country shares are calculated based on cumulative patent counts over a number of years, see Section 7.4.

36 We chose the maximum gap to allow for a realistic catch-up process for laggard firms while having enough observations in each bin of the empirical distribution.
} 
years 1975 (circled black line) and 1981 (solid blue line). ${ }^{37}$ It reveals that, initially, a substantial mass of U.S. firms are technological leaders, with the mean gap being close to seven; however, subsequently, their distribution has shifted leftward, with the mean gap falling to around four in 1981. This shift translates into a larger mass of U.S. firms in relatively smaller gap sizes and, therefore, signifies a strong foreign technological catch-up. The calibration of $\phi$ aims to match the dynamics of this catch-up process that occurred between 1975 and 1981, as described in the discussion of the model fit below.

In order to obtain the model counterparts of our data targets, we simulate the two economies between 1975 and 1981, initializing the model at the empirical gap distribution in 1975. Initially, we normalize the quality of U.S. intermediate goods to one-i.e., $q_{A j 1975}=1 \forall j{ }^{38}$ We solve the transition path of the model over 1975 to 1981 as described below. We derive the model counterparts of the seven moments presented in Table 3 by taking averages of the simulated series over the relevant period. We also compute the evolution of the gap distribution in the model using equations (A.1) defined in Appendix B.3 and try to hit the empirical gap distribution in 1981 as the terminal point of the economy in transition.

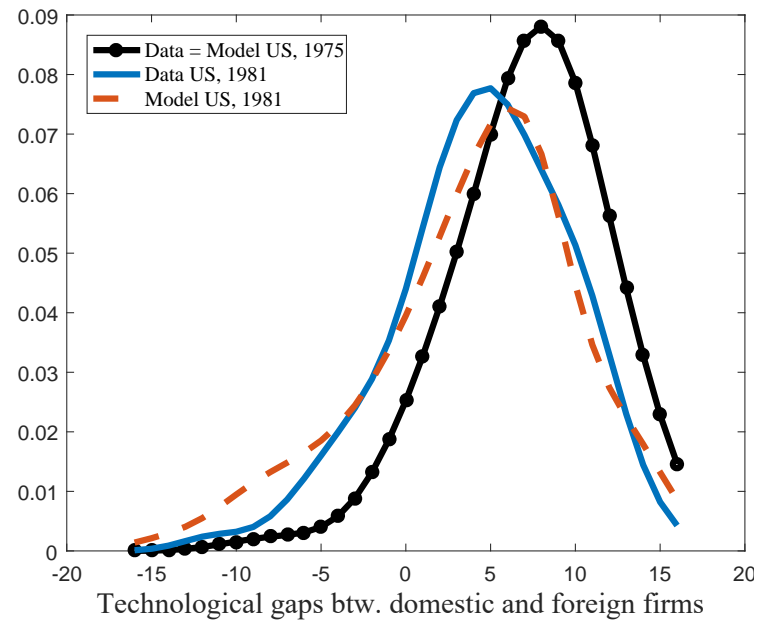

A) Technological gap distribution: data and calibration

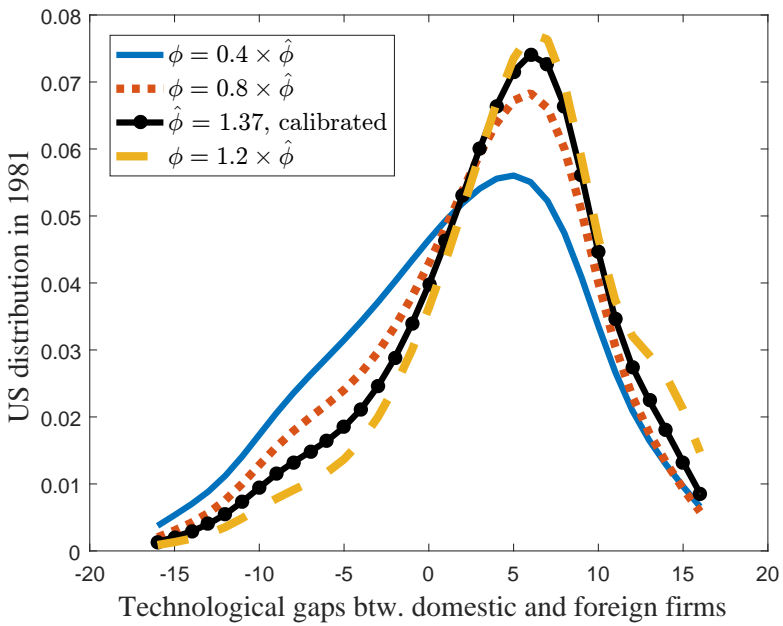

B) Identification of $\phi$

Figure 8: Gap distribution after policy changes

Notes: Panel A depicts three technology gap distributions and demonstrates the model's performance (positive values on the horizontal axis denote U.S. technological leadership). The dotted solid line is the empirical distribution in 1975, which also defines the initial distribution for the model simulation in the calibration. The solid blue line is the empirical distribution in 1981 and defines the target distribution of the simulation. The dashed red line is the model-generated distribution in 1981, simulated at the calibrated parameters. Panel B illustrates the effect of $\phi$ (the curvature parameter of the step-size distribution function) on the simulated gap distribution, the variation in which enables the identification of $\phi$. It exhibits various model-generated distributions in 1981 that result from simulations with varying levels of $\phi$ as other parameters being held at their calibrated values.

\footnotetext{
${ }^{37}$ Distributions are smoothed using a kernel density function with a bandwidth of 1.8 .

${ }^{38}$ The quality levels of firms from $B$ are initialized accordingly with respect to their position in technological competition. Mathematically, this normalization implies that if in product line $j$ the firm from $A$ is at position $m$, then $q_{B j 1975}=\lambda^{-m}, m \in\{-\bar{m}, \ldots, \bar{m}\}$.
} 
Solution Algorithm and Model Fit. In order to solve the model, we first discretize it. The solution algorithm assumes that the economy starts in 1975 and transitions to the balanced growth path in $T$ periods, where each period is divided into $(\Delta t)^{-1}=2^{5}$ sub-periods. The algorithm is an iterative backward solution method. The main procedure of the algorithm consists of solving for the balanced growth path and then deriving the values over the transition period going backward from the balanced growth path. A brief description is as follows: ${ }^{39}$

1. Let $\mathbb{M}$ be the set of data moments and $\mathbb{M}^{m}$ be the model counterpart. Define $\mathbf{R}\left(\mathbb{M}-\mathbb{M}^{m}\right)$ as the objective function that calculates a weighted sum of the difference between data and model moments.

2. Guess a set of values for the internally calibrated parameters $\theta_{\text {guess }}$.

3. Calculate the balanced growth path, where time derivatives are zero by definition. Compute the innovation rates, the implied growth rates, and finally the interest rates compatible with balanced growth.

4. Next calculate the equilibrium over the transition. Guess a time path for interest rates with the terminal values being set to balanced-growth levels at every iteration. Solve for firm values and innovation rates backward in time starting from the balanced growth path. Using the resulting sequences, simulate forward the income path and its growth rate. Use the Euler equation to derive the implied interest rates and compare them to the series fed initially.

5. Once step 4 converges, use the final interest rate series to compute the aggregate variables and the model counterparts of the data moments.

6. Minimize $\mathbf{R}\left(\mathbb{M}-\mathbb{M}^{m}\left(\theta_{\text {guess }}\right)\right)$ using a minimization routine. We use the sum of squared errors as the objective function. ${ }^{40}$

The targeted moments and the model performance in matching these moments are summarized in Table 3 and Figure 8a.

Along the transition, the catching-up country exhibits higher R\&D-to-GDP ratios and grows faster than the leading country. The model captures these differences between the two economies observed in the data quite successfully. The entry rate and the export shares are also well fitted. Finally, the position of the dashed red line relative to the solid blue one in Figure 8a indicates the strong performance of the model in matching the 1981 distribution of technology gaps.

In the model, the forces of cross-country convergence that enable the reproduction of the catch-up observed in the data are chiefly governed by the curvature of the step-size distribution $\phi$. Figure $8 \mathrm{~b}$ illustrates how different values of $\phi$ lead to various shapes of technology gap

\footnotetext{
${ }^{39}$ A detailed explanation of the steps is presented in Appendix D.1.

${ }^{40}$ The moments that pertain to the gap distribution are weighted by the targeted number of bins in order to make the total weight of the distribution-related moments the same as the other targets.
} 
Table 3: Model fit

\begin{tabular}{cccc}
\hline \hline Moment & Estimate & Target & Source \\
\hline TFP Growth U.S. & $0.47 \%$ & $0.55 \%$ & Coe et al. (2009) 1975-81 \\
TFP Growth FN & $1.98 \%$ & $1.73 \%$ & Coe et al. (2009) 1975-81 \\
R\&D/GDP U.S. & $1.65 \%$ & $1.75 \%$ & OECD 1981 \\
R\&D/GDP FN & $1.90 \%$ & $1.96 \%$ & OECD 1981 \\
Entry Rate U.S. & $9.98 \%$ & $10.0 \%$ & BDS 1977-81 \\
Export Share U.S. & $7.06 \%$ & $7.00 \%$ & WB 1975-81 \\
Tariff revenue U.S. & $5.70 \%$ & $7.70 \%$ & U.S. ITC 1975-81 \\
\hline \hline
\end{tabular}

distribution. Each line in the figure represents a distribution that emerges in 1981 once the model is simulated between 1975 and 1981 at the calibrated parameter values except $\phi$, which takes a different value in each iteration. Lower values of $\phi$ mean a flatter probability distribution $\mathbb{F}(n)$ over step sizes (or, equivalently, positions ahead), allowing technologically laggard firms to catch up more quickly. Therefore, a low value of $\phi$ would imply a larger leftward shift in the initial gap distribution of U.S. firms. The position of the solid blue line in Figure $8 \mathrm{~b}$ relative to the circled black line, which represents the calibration result, illustrates this case. The converse happens for larger values of $\phi$, as demonstrated by the relative position of the yellow dashed line, which is generated by a value that is 20 percent higher than the calibrated one.

The distribution across new positions, $\mathbb{F}(n)$, is the engine of convergence. More precisely, the international knowledge spillover allows laggard firms from the foreign country to stay in the global innovation race. Importantly, an innovation can generate an improvement of multiple steps for laggard firms, whereas the number of potential steps to improve becomes smaller as a firm opens up the technological gap with its follower. In Gerschenkron (1962)'s terms, this structure creates an "advantage of backwardness" for followers-i.e., laggard firms have an advantage in the number of steps they can improve with each innovation, while far-ahead leaders cannot open their lead further quickly. Thus, foreign firms catch up with domestic firms along the transition, generating a cross-country technological convergence. This convergence in our economy echoes that in the Solow model with the key difference that while in Solow convergence is driven by decreasing returns in capital accumulation, in our economy knowledge spillovers and an "advantage of backwardness" drive the convergence.

The internally calibrated parameters resulting from this procedure are listed in the right panel of Table 2. The combination of the trade costs and the step size implies $m^{*}=11$-i.e., a firm needs to lead by at least 11 technological gaps to export. The level of $\phi$ generates a considerable chance of improving multiple steps with a single innovation for laggard firms. For example, the probability that an innovation by the most laggard firm brings a multi-step improvement is 60 
percent. $^{41}$

\subsection{Validation of the Model}

Before discussing the properties and the policy implications of the calibrated model, we present four out-of-sample tests to assess the quantitative plausibility of the integral mechanism of our model in light of empirical relationships not used in the calibration process.

\section{Validation Exercise I: Incumbent Innovation vs. Leadership}

Figure 9 compares the relationship between innovation efforts of incumbent firms and their technological position relative to their competitors in the model and in the data. Figure 9a displays incumbents' innovation intensity as a function of the technology gap. Figure 9b shows average patenting intensity of U.S. firms in the USPTO data, measured by patent applications per firm, across sectors ranked according to their share of patents registered by U.S. residents, as described in Section 4.1.2. ${ }^{42}$ In Figure 9a, we observe two spikes at $-m^{*}=-12$ and $m^{*}-1=11$ that are related to cutoffs defined in equation (12). The left one emerges because of the defensive $R \mathcal{E} D$ effort, as the firm increases its innovation to improve its position and capture domestic production. Similarly, the right peak emerges because of the expansionary RED effort of firms that sell domestically. They increase their innovation efforts massively when closer to the export cutoff, as a new innovation right before that threshold enables the domestic firm to expand into the export market. Interestingly, we observe a similar shape with two peaks also in the data, as illustrated in Figure 9b. Again, the peaks emerge in sectors where U.S. firms hold a strong technological advantage or disadvantage as measured by the sectoral share of total patents registered by U.S. residents. The remarkable performance of the model in capturing the innovation intensity observed in the data provides further evidence for our model's ability in mimicking firms' innovation behavior.

The jump in innovation in the proximity of the export cutoff is consistent with a large body of evidence showing that firms innovate in order to enter the export market. Using Chilean plantlevel data, López (2009) finds that productivity and investment increase before plants begin to export. Aw et al. (2011), using Taiwanese plant-level data, estimate a dynamic structural model

\footnotetext{
${ }^{41}$ Conversely, the probability that the most laggard firm receives a single-step innovation is 40 percent.

${ }^{42}$ We create the empirical measure of average innovation intensity across technology gaps as follows. First, we calculate the total number of domestic patent applications and unique domestic owners of those patents for each pair of technology class and year. Next, we rank these class-year pairs according to the share of domestic applications in total applications and assign them to technology bins as in Figure 7. Then, in each bin, we sum the total domestic patents and unique domestic assignees across class-year pairs. The ratio of those is the average patenting intensity per assignee in a given bin, which proxies for innovation intensity in our model. The exercise considers applications between 1975 and 1995, a long span of time, as the comparison is to the balance growth path in the model. To generate the figure, we also drop patents assigned to the assignee id " 0 ", as most of the other assignee values have more than six digits. Figure A.6 in Appendix D.2 shows that including those patents leads to sharper spikes in the data.
} 


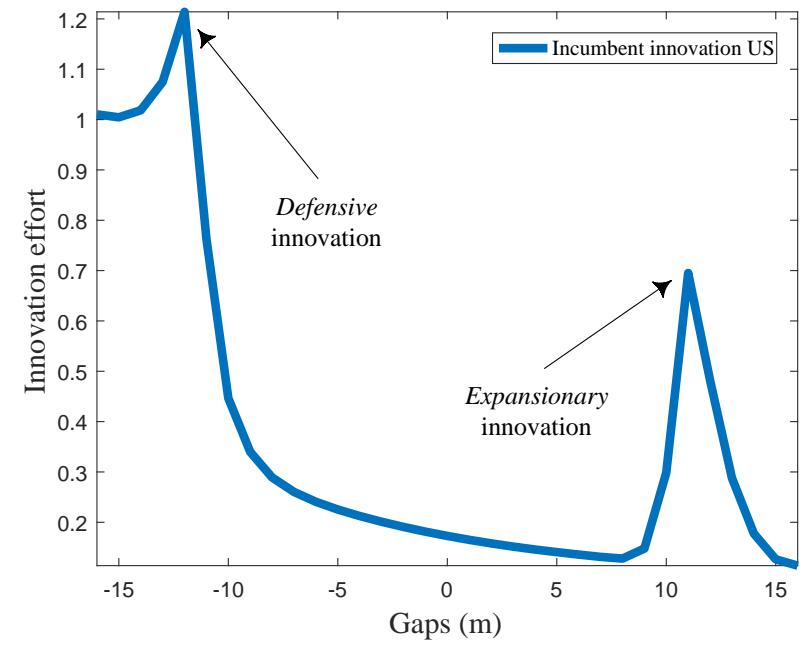

A) Model: Incumbent innovation intensity

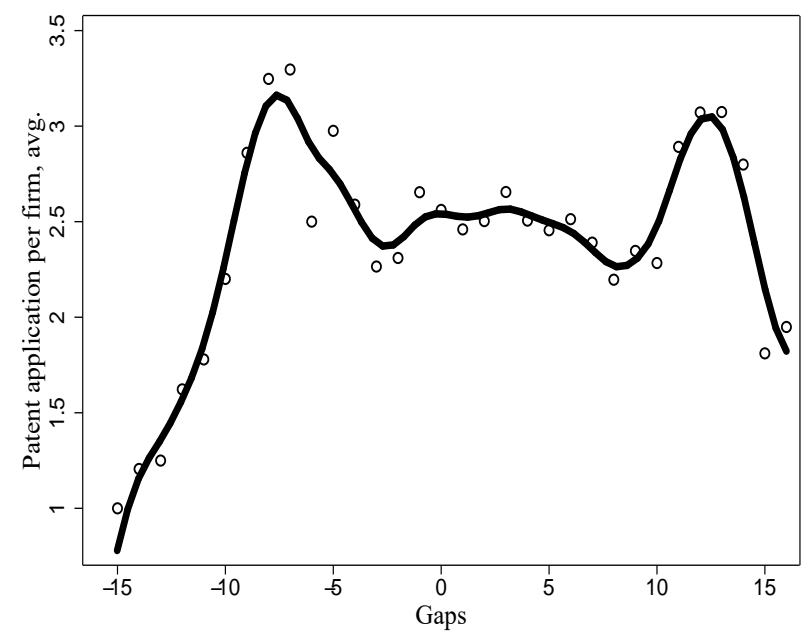

в) Data: Patenting intensity of U.S. incumbents

Figure 9: Innovation effort and leadership

Notes: Panel A shows the innovation intensity of U.S. incumbent firms in the balance growth path of calibrated economy. Panel B shows the average number of patents applied for by the U.S. firms in the USPTO data across technology gaps (the creation of the technology gaps is illustrated in Figure 7). The hollow markers designate actual data points (circles for the earlier period and triangles for the later), and the lines are fit using smoothing splines.

of the decisions of firms to innovate and to enter the export market. They find that these two decisions are highly correlated-i.e., firms entering the export market are more likely to also speed up their investment in R\&D. Lileeva and Trefler (2010) find that Canadian plants that were induced by the U.S. tariff cuts to start exporting (i) increased their labor productivity, (ii) engaged in more product innovation, and (ii) had higher adoption rates for advanced manufacturing technologies.

\section{Validation Exercise II: Innovation Intensity in Manufacturing}

As another validation test, we present a case study on the link between trade barriers and firms' innovation efforts. Our model implies that because of intensified competition around trade thresholds, which are determined by trade costs, firms increase their innovation efforts in these regions. One way to detect this relationship in the data is to focus on firms' innovation behavior in a specific sector and its evolution over time with respect to changes in trade barriers in that sector. To perform such an analysis, we map USPTO patent data to Standard International Trade Classification (SITC) industries (revision 2) and concentrate on the manufacturing sector, which makes up about half of patenting activity, over a period with substantial reductions in tariff rates. ${ }^{43}$ Data on tariffs are available from the World Integrated Trade Solution (WITS) database of the World Bank. Studying tariff reductions in a specific sector instead of a cross-industry comparison allows us to proceed without resorting to using a reliable estimate

\footnotetext{
${ }^{43}$ We obtain crosswalks for mapping USPTO data to SITC industry level from Lybbert and Zolas (2014).
} 
of industry-specific trade costs-known to be notoriously difficult to obtain [Anderson and van Wincoop (2004), Hummels and Lugovskyy (2006)]—as long as non-tariff barriers are not rising over time.

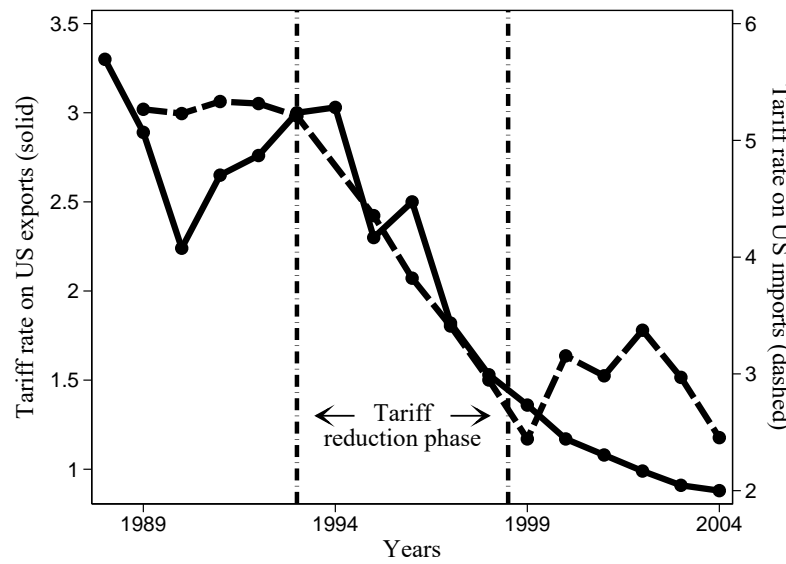

A) Tariff rates over time

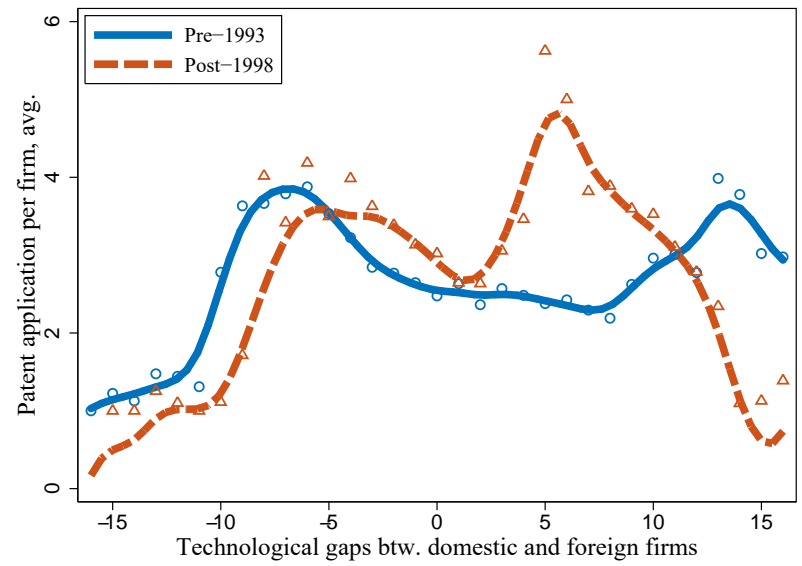

в) Incumbent innovation before 1993 and after 1997

Figure 10: Tariffs and incumbents' innovation intensity across technology gaps in manufacturing

Notes: Panel A shows the reduction in the average effective tariff rates applied to U.S. imports and exports of manufactured goods following the Uruguay round of the GATT. Tariff rates applied by or to goods of individual countries are obtained from WITS and are weighted by the patenting intensity of the trade partners in the USPTO data. Panel B shows the change in the innovation intensity of incumbent U.S. patentees in the manufacturing sector across technology gaps. The hollow markers designate actual data points (circles for the earlier period and triangles for the later), and the lines are fit using smoothing splines.

Figure 10a shows the decline in the tariff rates to which manufacturing imports and exports of the U.S. were subject over 1990s. ${ }^{44}$ On average, both barriers were 2 percent lower between 1997 and 2004 than between 1989 and 1993, in part as a result of the Uruguay round of the General Agreement on Tariffs and Trade completed in 1994 and other bilateral trade agreements. In parallel, Figure 10b depicts the innovation intensity of incumbent patentees in the U.S. manufacturing sector with respect to their technological position relative to foreign competitors, again before and after the mid-1990s. ${ }^{45}$ Noticeably, incumbent-innovation intensity in the manufacturing sector exhibits a double-peaked profile in line with our findings for the complete set of patents in the USPTO data. Moreover, we observe that the period of tariff reductions coincides

\footnotetext{
${ }^{44}$ The tariff data on WITS go back to 1989. The U.S. is one of the few countries that reports tariffs on imports reliably across time and trade partners. We use the same sample of trade partners as in the original analysis (Canada, Germany, France, Italy, Japan, and the U.K.) and weight the average effective tariff to manufacturing imports from each of them by their patent share in the USPTO data in 1988. Similar reductions in tariffs are observed when accounting for larger groups of countries as well. Tariffs on U.S. manufacturing exports are more limited, reported only by Canada and Japan. We use the Japanese series, as Japan constitutes about half of foreign patents registered in the U.S. by the late 1980s. Finally, we use the broad sector grouping for manufacturing in WITS data, which comprises chapters 6 (manufactured products) and 8 (miscellaneous manufactured articles) of the SITC classification (excluding non-ferrous metals with the code 68).

${ }^{45}$ We constructed the innovation intensity of incumbents in the manufacturing sector over technology gaps following similar steps to those described in Section 4.1.2, except that we used SITC subindustries instead of patent classes as the unit of analysis. To be in line with the WITS data, we used the same specification of the manufacturing sector, which consists of SITC chapters 6 and 8.
} 
with an inward shift of peaks in incumbents' innovation intensity profile across technology gaps. This observation mirrors the predictions of our model: Lower bilateral trade barriers imply that firms with a lesser technology advantage over their competitors start exporting, making the competition for markets stiffer at smaller technology gaps and thereby resulting in peaks closer to (purely technological) neck-and-neck position (which occurs at zero). ${ }^{46}$

\section{Validation Exercise III: Entrant Innovation vs. Leadership}

Entry is another source of business stealing in the model. However, in contrast to incumbents, entrants are not subject to immediate competitive pressures from the other country's firms. Therefore, the shape of entrants' R\&D effort profile, demonstrated in Figure 11a, reflects mainly the market size effect around the two cutoffs and not a direct effect of foreign competition.

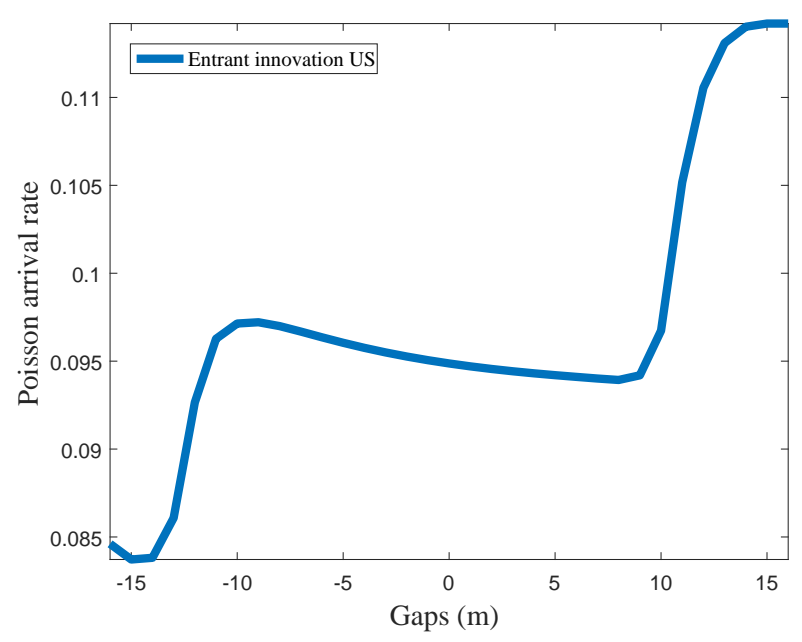

A) Entrant innovation intensity in model

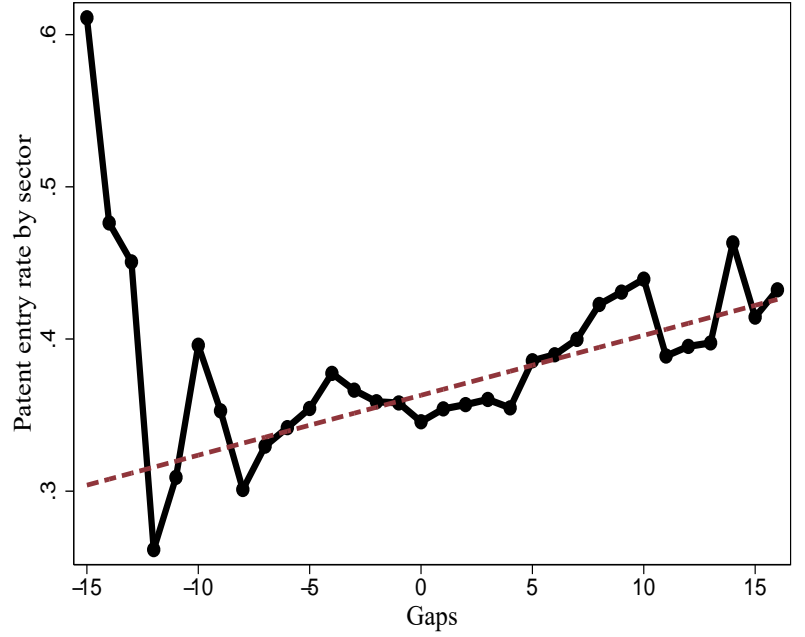

в) Patenting intensity of U.S. entrants in data

Figure 11: Innovation effort and leadership

Notes: Panel A shows the innovation intensity of U.S. entrant firms in the balance growth path of calibrated economy. Panel B shows the average entry rate of patents applied for by the U.S. firms that appear in a sector in the USPTO data for the first time across technology gaps (for the creation of the technology gaps, see Figure 7). Number of patents by new patentees is weighted by the number of all patents registered by U.S. residents. The fitted line shows predicted values from a weighted linear regression of average entry rate on bins weighted by the number of sector-year observations in each bin.

Moreover, because entry to the highest gaps implies access to export markets, it is more profitable, and this leads to a higher entry effort aimed at these positions. Figure 11b shows that this is indeed the case in the USPTO patent data, where we again classified sectors into bins according to the technological lead, as in Figure 9b. The solid black line in the figure depicts the flow of new patents (normalized by the number all U.S. patents in that sector-year observation to eliminate sectoral differences in patenting intensity) registered by U.S. residents that appear

\footnotetext{
${ }^{46}$ Figure 20 in Section 5.7 illustrates the effect of bilateral changes in trade costs on incumbents' innovation intensity profile in our model.
} 
for the first time in a sector, averaged out across sector-year observations between 1975 and 1995 in each bin. ${ }^{47}$ We observe that the entry intensity is higher for sectors where existing U.S. firms have larger technological leads over their foreign competitors.

\section{Validation Exercise IV: Credit Elasticity of R\&D}

The ultimate source of growth in our model is innovation. Therefore, when analyzing the effect of policies on aggregate outcomes, a correct measurement of the responsiveness of innovative activity to policy changes is of utmost importance. In order to evaluate our estimated model's implications in that regard, we now investigate the empirical elasticity of innovative activity to $\mathrm{R} \& \mathrm{D}$ credits and compare it with its model counterpart.

In order to measure the credit-elasticity of innovation, we exploit the state-level variation in the dates when credit policies came into action and conduct a simple firm level regression analysis using the Compustat database. The regression specification is as follows:

$$
\ln Y_{j s t}=\beta_{0}+\beta_{1} \ln S C_{s t}+\beta_{2} \ln Y_{j s t-1}+\psi_{j}+\psi_{t}+u_{t}
$$

where $\psi_{j}$ and $\psi_{t}$ represent firm and year dummies, respectively, and $u_{t}$ is the error term. $S C_{s t}$ is the tax credit level in state $s$ where firm $j$ operates. For the dependent variable $Y$ we use both $R \& D$ and patent counts. We utilize two different specifications for this regression that differ in the inclusion of the lagged value of the dependent variable. The results are summarized in Table 4. All versions (represented by columns of the table) reveal the positive effect of state level $R \& D$ tax credits on the firms' innovative activities. This effect is also robust to the existence of lagged values of the dependent variable in the regression.

The first column of Table 4 shows that, on average, the elasticity of R\&D spending with respect to changes in $R \& D$ credit is 3.15 . To ensure the quantitative validity of firms' response to policy changes in our model, we derive the model counterpart of the same statistic. We first compute the log-difference in $R \& D$ expenditure for incumbent firms of country $A$ in each position $m$ right before and after the subsidy change from $s_{75-81}^{A}$ to $s_{81-95}^{A}$. Following the same steps used to create empirical variables, the average elasticity of R\&D spending to subsidy is given by

$$
\int_{0}^{1} \frac{d \log \left(\alpha_{A} x_{A j 1981}^{\gamma_{c}} q_{j 1981}\right)}{d \log \left(1+s_{1981}^{A}\right)} d j=\sum_{m} \frac{d \log \left(\alpha_{A} x_{A m 1981}^{\gamma_{c}} Q_{A m 1981}\right)}{\log \left(1+s_{81-95}^{A}\right)-\log \left(1+s_{75-81}^{A}\right)} .
$$

This model statistic has a value of 2.27 in contrast to 3.15 in the data. It implies that in the model, an increase in $R \& D$ subsidy induces a solid response of $R \& D$ expenditure, in line with its empirical counterpart, although its strength is somewhat weaker than in the data. Note

\footnotetext{
${ }^{47}$ Observations of the same sector over different years are treated as separate entries in Figure 11b.
} 
Table 4: The effect of R\&D tax credit on innovation (excl. federal credits)

\begin{tabular}{ccccc}
\hline \hline Dep. Var.: & $\begin{array}{c}\ln \left(R \& D_{t}\right) \\
(1)\end{array}$ & $\begin{array}{c}\ln \left(R \& D_{t}\right) \\
(2)\end{array}$ & $\begin{array}{c}\ln \left(\text { Patents }_{t}\right) \\
(3)\end{array}$ & $\begin{array}{c}\ln \left(\text { Patents }_{t}\right) \\
(4)\end{array}$ \\
\hline $\ln \left(\right.$ State credit $\left._{t}\right)$ & 3.153 & 0.524 & 2.948 & 1.203 \\
& $(10.92)^{* * *}$ & $(2.12)^{* *}$ & $(10.93)^{* * *}$ & $(4.28)^{* * *}$ \\
$\ln \left(R \& D_{t-1}\right)$ & - & 0.631 & - & - \\
$\ln \left(\right.$ Patent $\left._{t-1}\right)$ & - & $(106.67)^{* * *}$ & - & - \\
Year Dummy & - & - & - & 0.499 \\
Firm Dummy & Yes & - & - & $(72.83)^{* * *}$ \\
\hline \hline
\end{tabular}

Notes: The table lists the results obtained from different OLS specifications that illustrate the effect of (U.S. state-level) tax credits on U.S. firms' innovation. t-statistics are provided in parentheses. ${ }^{* * *},{ }^{* *}$, and ${ }^{*}$ denote significance at 1 percent, 5 percent, and 10 percent, respectively.

that the empirical economy-wide elasticity is likely to be lower than state-level elasticity due to reallocation of resources across states; therefore, it is also reassuring to see that our simulated macro elasticity is below the state-level empirical estimate.

\section{Policy Evaluation}

In this section, we first demonstrate the foreign catch-up process that the U.S. would experience in absence of policies. Then we perform a quantitative investigation of various policy alternatives and assess their welfare implications. We discuss the design of optimal policies considering different horizons for policy and accounting for the transition period. We start the discussion with protectionist measures. Then, we continue with R\&D policies, analyzing both the observed post-1981 R\&D subsidy changes and the optimal subsidy levels. We also consider the design of optimal joint policy and conclude with a discussion of how retaliation for domestic trade policies by trade partners can alter the structure of optimal policies.

\subsection{Technological Convergence and Foreign Catching-Up}

Foreign technological catch-up is a key implication of the model. Improvements in a country's trade partners' technology is a mode of globalization that has received less attention in the literature than the reduction of trade and offshoring barriers. To explore this relationship in our model, we focus on how foreign technological catch-up manifests itself in the technological advantage of the leading country, which again represents the U.S. In particular, Figure 12 shows the evolution of the average technological lead that U.S. firms would have over their foreign 
competitors in the absence of any policy intervention.

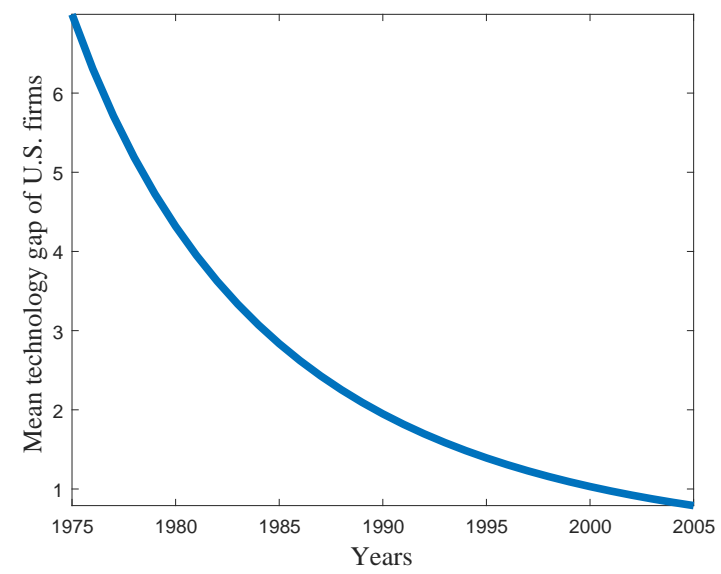

Figure 12: Average technology lead of the U.S. firms, no policy intervention

Notes: The figure exhibits the evolution of the average technology lead that the U.S. firms have over their foreign competitors across years along the transition of the calibrated economy.

The dramatic decline is the symptom of a strong international business-stealing effect, whereby foreign firms progressively capture leadership in more and more markets, and profits that were previously collected by the U.S. firms are now going into the pockets of foreign firms. This negative welfare consequence of the international business-stealing effect suggests that the foreign technological convergence indeed hurt the U.S. economy. Now we turn to the analysis of industrial policies that could potentially help the economy tackle foreign technological catch-up.

\subsection{A Unilateral Increase in Import Tariffs}

In this subsection, we explore the implications of a unilateral increase in tariffs as an alternative to R\&D subsidies and discuss optimal tariff policy. Figure 13a shows the consumption-equivalent welfare gains/losses for the representative household generated by a 50 percent rise in tariffs $\tau^{U S}$ in 1981 (equivalent to a 4 percentage point change). Compared to the path in a counterfactual economy that does not experience any policy intervention, protectionism seems to pay off in the short run, where small gains are generated from the increase in home profits. However, over time, the gains decline and turn negative after two decades.

Digging deeper, unilaterally higher trade barriers initially generate a small increase in profit income by protecting some sectors from import penetration and shifting market ownership toward home firms. Recall, though, that the measure of relatively most laggard firms that can benefit from trade protection is relatively small for the U.S., as indicated by the left tail of the dashed line in Figure 8a. Therefore, the initial gain from laggard firms recapturing production in the domestic market is limited. Moreover, the replacement of foreign exporters by the laggard 


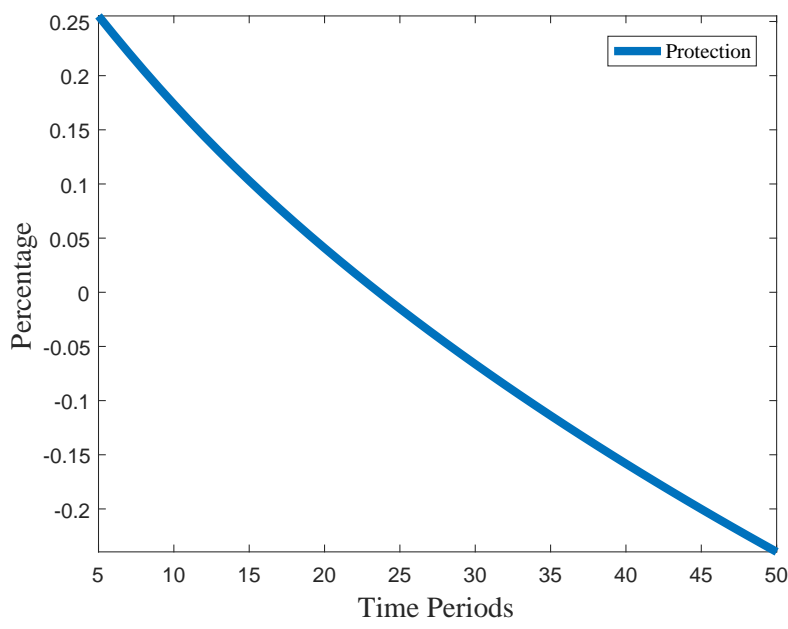

A) Consumption equivalent welfare

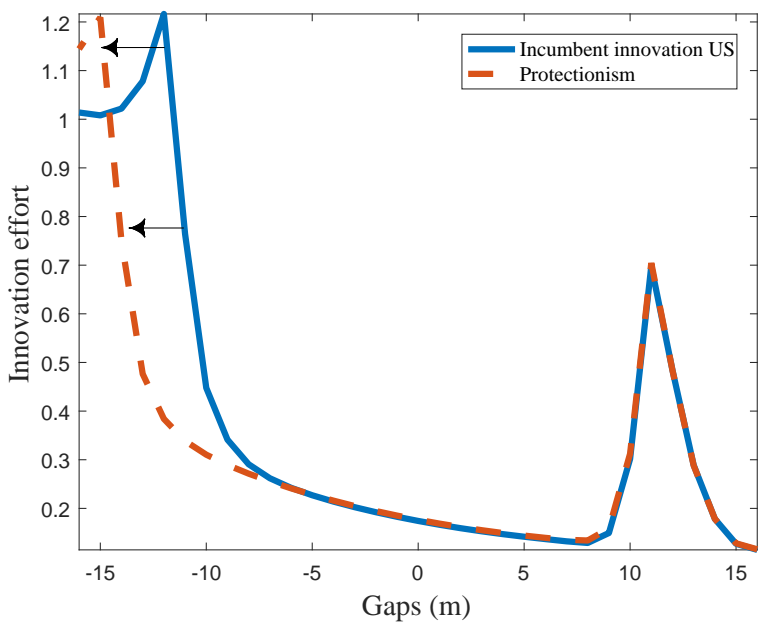

в) Innovation response to protectionism

Figure 13: Welfare effects of protectionism: unilateral 50 percent (4 ppts) increase in tariffs

Notes: The figure illustrates the effects of a unilateral 20 percent increase in U.S. trade barriers (protectionist U.S. policy without retaliatory response). Panel A shows the welfare change in consumption equivalent terms over different time horizons. Panel B shows the shift in the innovation-effort profile of U.S. incumbent firms over technology gaps.

home firms means that the high-quality foreign products are foregone and replaced by inferior domestic alternatives. This foregone intermediate good quality leads to substantial welfare losses. Even though the combined welfare effect is slightly positive over the short run, it turns significantly negative over time.

As time passes, the factor that governs variations in welfare is the decline in competitive pressures on domestic firms, which leads to a drop in their innovative activity. Figure 13b shows that innovation efforts by most of the laggard U.S. firms decrease substantially. Because the protectionist policy shifts the threshold for losing the domestic market to a foreign competitor further to the left, more firms move further from such an immediate threat. This weaker defensive innovation motive leads to a compression of innovation efforts by these firms, making it harder to compensate for the loss of imported frontier technology. Moreover, most U.S. firms, being either exporters or solid domestic producers that are technologically close to or ahead of their competitors, do not benefit from higher domestic tariffs. As shown in Figure 13b, innovation decisions of this large group of firms barely change, implying that they do not contribute any additional boost to profit income or factor productivity in response to the policy move. ${ }^{48}$ All in all, the short-run gains from profits are subdued over time by the loss of foreign technology, while weaker defensive innovation incentive leads to less domestic innovation and, thus, to a slower growth of productivity and profit income.

\footnotetext{
${ }^{48}$ Evidently, the time path of the average technology lead of the U.S. firms is lower than the one in the "nointervention" case depicted in Figure 12 (see Figure A.5a in Appendix D.2).
} 


\subsection{Optimal Unilateral Tariffs}

The negative relationship between the aggregate innovation effort and protection plays also an important role for the design of optimal tariff policy. As shown in Figure 14a, the optimal tariff policy, where the U.S. unilaterally sets the tariffs on goods imported to the U.S., effectively closes the borders to imports, when the relevant horizon over which the policymaker calculates the welfare is very short, such as a decade. However, the preferred level of tariffs decreases as the relevant horizon becomes longer and suggests a more liberal tariff regime with respect to the calibrated economy when the horizon considered extends beyond two decades. As Figure $14 \mathrm{~b}$ demonstrates, the reason is the damping effect of higher tariff rates on domestic aggregate innovation. This dynamic negative effect dominates static gains over time and, therefore, implies lower tariffs for optimal policy when longer time horizons are considered.

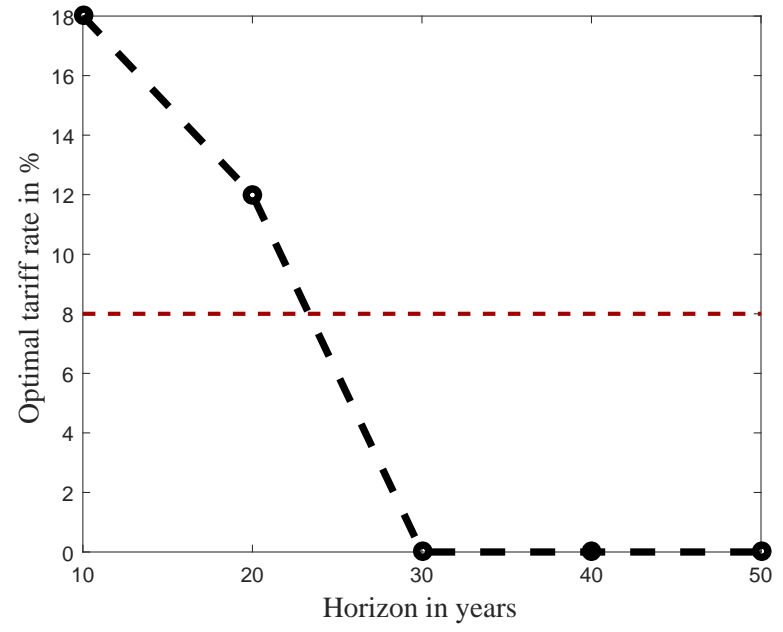

A) Optimal tariff policy over time horizons

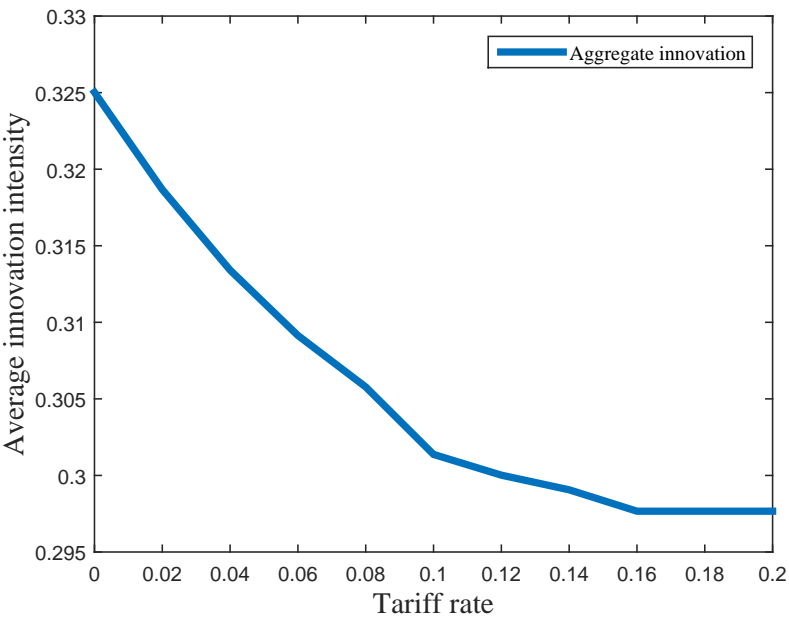

в) Average innovation over openness

Figure 14: Optimal tariff policy and innovation over openness

Notes: Panel A shows the optimal unilateral tariff policy for the U.S. over various policy horizons. Horizontal dashed line denotes the calibrated tariff level. Panel B shows the negative effect of unilaterally higher U.S. tariff rates on average innovation intensity of both entrant and incumbent U.S. firms, with 1 denoting the calibrated tariff rate.

\subsection{Introduction of R\&D Subsidies}

Policy intervention in the early 1980s to improve the competitiveness of U.S. companies pushed up the level of R\&D subsidies significantly from an average of 5.1 percent in the pre- 1981 period to an average of 19.2 percent in the subsequent period. The subsidy level in the foreign country remained fairly constant, with 3.8 percent and 4.1 percent in the respective periods. Figure 15 shows the effect of the subsidy to incumbents' R\&D spending on the post-1981 distribution of technology gaps. 

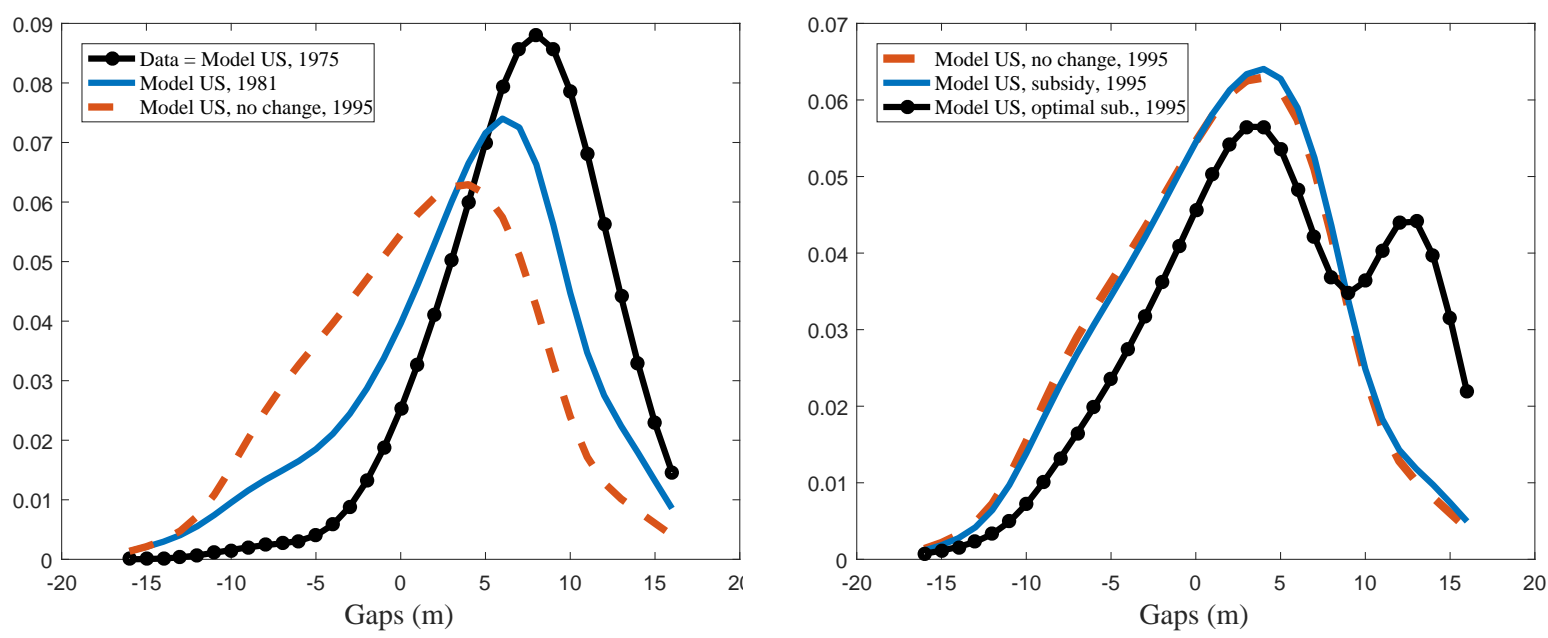

Figure 15: Gap distribution after policy changes

Notes: Panel A exhibits the technology gap distributions in the calibrated model at three points in time: initially in 1975 (dotted solid line, the same as in the data), in 1981 (solid blue line), and in 1995 (dashed red line) assuming there was no policy change. Positive values on the horizontal axis denote U.S. technological leadership. Panel B exhibits the resulting gap distributions in 1995 under three different scenarios: under no policy change (dashed red line, the same as in Panel A), under the actual R\&D policies after 1981 (solid blue line), and under the model-implied optimal R\&D policy rate for the horizon between 1981 and 1995 (dotted solid line).

In the left panel, the model gap distribution in 1981 is the solid blue line, which is closely calibrated to data in 1981 (not shown). In the benchmark economy with no policy intervention, the transition after 1981 results in a large leftward shift, leading to the red dashed line distribution by 1995 on both panels. By contrast, in the alternative economy where subsidies were introduced in 1981, the resulting distribution in 1995 becomes the solid blue line in the right panel. The effect of higher subsidies is a small shift to the right relative to the no-intervention benchmark case represented by dashed lines. This positive shift would have been drastic had the optimal level of R\&D subsidy been introduced in 1981 (circled solid line). We will discuss optimal subsidies in the next subsection.

Table 5: Observed R\&D Subsidy: 1981-2016

\begin{tabular}{lcc}
\hline \hline & Subsidy rate & $\begin{array}{c}\text { Welfare gains } \\
1981-2016\end{array}$ \\
\hline Observed R\&D Subsidy in the 1980s & $19.2 \%$ & $0.87 \%$ \\
\hline \hline
\end{tabular}

Now we examine the welfare properties of the R\&D subsidy intervention. We compute the welfare difference for a 35-year horizon from 1981 until the present (2016). The result is reported in Table 5. We find that the U.S. subsidy increase generates a 0.9 percent consumption gain every year over a span of 35 years. Decomposing the overall welfare change into variations in individual sources of income (not shown), we find that these gains are driven by an increase in innovation by U.S. firms, which in turn leads to faster growth in both the U.S. factor productivity and profit 
income. As illustrated in Figure 16a, the underlying economic mechanism is straightforward: By reducing the cost of R\&D, subsidies stimulate innovation in U.S. incumbent firms, thereby accelerating productivity growth and allowing U.S. firms to obtain market leadership, and the related profits, in most sectors of the economy. The gains from these channels more than offset the resources devoted to the higher aggregate R\&D spending. ${ }^{49}$

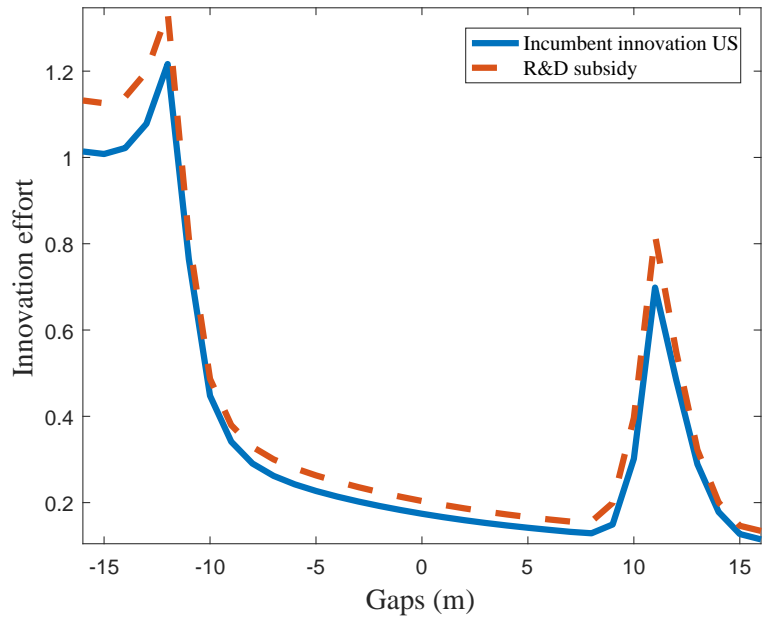

A) Change in innovation by incumbents

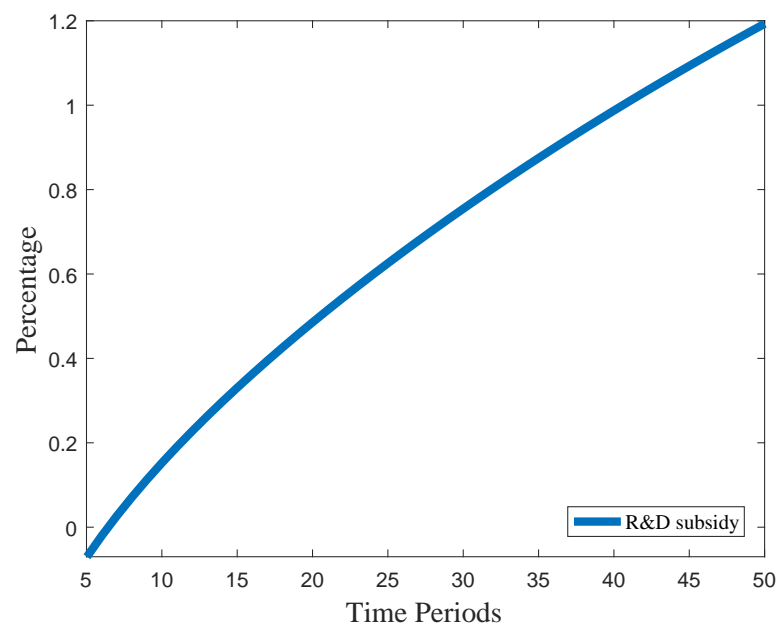

в) Consumption equivalent welfare

Figure 16: Consumption equivalent welfare

Notes: The figure illustrates the effects of a unilateral R\&D-subsidy increase in the U.S. (replicating actual policy changes). Panel A shows the shift in the innovation-effort profile of U.S. incumbent firms over technology gaps. Panel B shows the welfare change in consumption equivalent terms over different time horizons.

In Figure 16b, we show the evolution of welfare gains over time generated by the increase in U.S. subsidies. The figure shows that in the short run of less than 10 years, the subsidy change leads to a welfare loss, which rapidly turns to gains as years go by. This early loss is due to a subsidy-induced shift of resources from consumption to innovation. Over time, the profit shifting and, even more importantly, the increase in labor productivity generated by higher domestic innovation offset the losses, leading to sizable gains.

\subsection{Optimal R\&D Subsidies}

Next we compute the optimal R\&D subsidies for the home country and compare them with the U.S. subsidy observed in the data in the post-1981 period (reported in Table 5). Precisely, we compute the subsidy rate that maximizes the present discounted value of welfare in a 35-year horizon from 1981 to 2016 and calculate the welfare gains from the optimal subsidy with respect to the benchmark scenario, where the U.S. subsidy does not change in 1981. We also compare

\footnotetext{
${ }^{49}$ Figure A.5b demonstrates the positive effect of higher subsidies on the time path of average technology lead of the U.S. firms, resulting in a significantly higher path than the one in the "no-intervention" case in Figure 12.
} 
these welfare gains under optimal subsidy with those obtained under the observed post-1981 subsidy. Table 6 reports the results for the optimal policy.

Table 6: Optimal U.S. R\&D Subsidy: 1981-2016

\begin{tabular}{lcc}
\hline \hline & Subsidy rate & $\begin{array}{c}\text { Welfare gains } \\
1981-2016\end{array}$ \\
\hline Optimal R\&D Subsidy & $66 \%$ & $5.49 \%$ \\
\hline \hline
\end{tabular}

The comparison of Table 5 to Table 6 indicates that although U.S. policymakers went in the right direction by increasing the subsidy rate in response to accelerating foreign catching-up in the 1980s, they did not go far enough. According to our model, the subsidy rate should have been about 66 percent, more than three times higher than the observed one. This high subsidy would have increased welfare by a striking 5.8 percent every year in the 35 -year period considered. In fact, the observed post-1981 subsidy is only optimal for a time horizon of about 8 years.

In our model, the optimal subsidy is determined by a rich set of externalities typical of Schumpeterian growth models, albeit with some novel twists. ${ }^{50}$ First, future innovations build on the stock of current innovations, but current innovators do not take into account that their activity will benefit future innovators. This effect, known as the intertemporal spillover effect, leads to underinvestment in $R \& D$ and provides a reason to subsidize $R \& D$. Second, entrant innovation destroys domestic incumbents' business, exerting a negative externality on domestic incumbent innovation. This effect, known as the business-stealing effect, leads to overinvestment in R\&D and rationalizes a tax on $R \& D$. In addition, the international aspect of our model generates a third externality that misses in standard closed-economy models of Schumpeterian creative destruction. Through catching up or leapfrogging, a laggard domestic firm can steal the foreign leader's business (or part of it). This effect, which we label as the international business-stealing effect, can encourage or discourage innovation, depending on the technology gap between the competing firms. Finally, our model also features international technology spillovers, which is another source of inefficiency in R\&D. Hence, the open-economy dimension of our model introduces additional interesting channels on top of the classic strategic trade and industrial policy literature [e.g., Eaton and Grossman (1986)]. By increasing innovation, R\&D subsidies help domestic firms compete in the global market, thereby shifting profits from foreign firms to national ones and increasing national income.

Figure 17a shows optimal subsidy levels for several horizons. Evidently, optimal subsidy level increases with the length of the policy horizon, because a longer horizon allows larger gains from policy-induced growth to materialize. Intuitively, optimal R\&D subsidies are trading

\footnotetext{
${ }^{50}$ Closed-form expressions defining these externalities in standard versions of the quality-ladder model can be found in Grossman and Helpman (1991b) and Segerstrom (1998).
} 


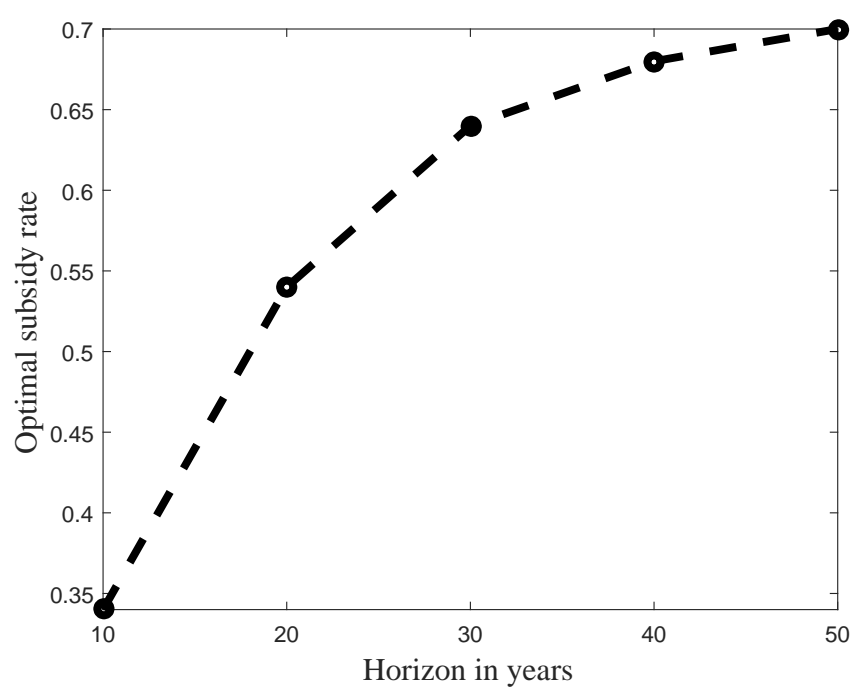

A) Over different horizons

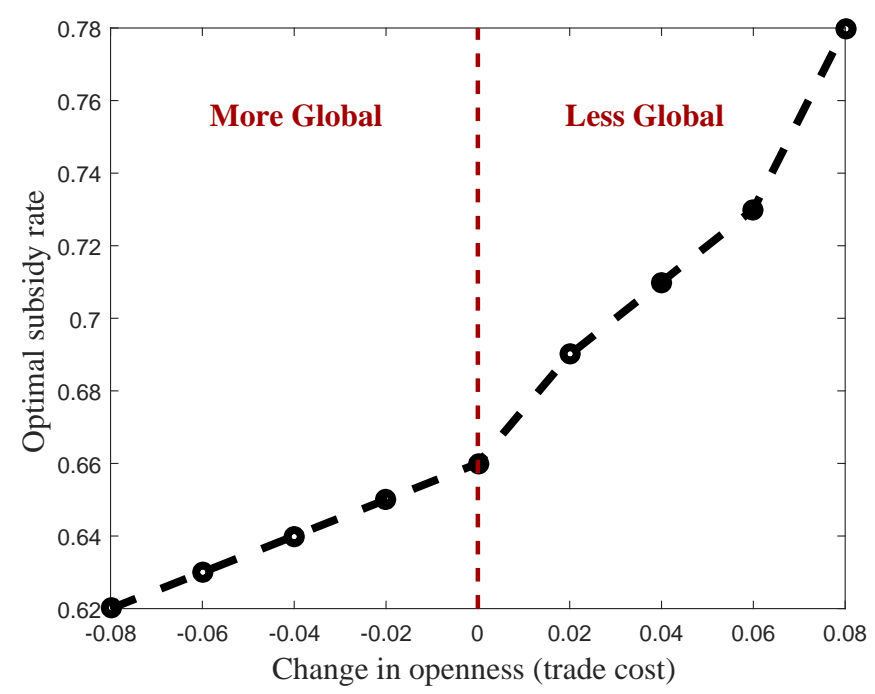

в) Over openness (over the fixed horizon of 35 years)

Figure 17: Optimal U.S. R\&D subsidy, over different horizons and levels of openness

Notes: Panel A exhibits the profile of the optimal R\&D policy for the U.S. over various policy horizons. Panel B exhibits optimal R\&D policy rate for the U.S. over a fixed horizon of 35 years subject to varying degrees of globalization. Zero means the calibrated level of tariffs for both countries, and negative numbers mean a more global world.

off the current reduction in consumption with future gains in growth rates. The longer the horizon, the larger the realized gain from the increased growth rate of aggregate consumption.

Another interesting result is shown in Figure 17b, where we plot the level of optimal subsidy for a fixed 35-year horizon in economies with varying degrees of openness. It is evident that in a more open economy with smaller trade costs, the level of optimal R\&D subsidy is lower, implying that a less aggressive policy is appropriate. This result is again driven by the innovation-boosting effect of foreign competition, which intensifies defensive and expansionary R\&D motives.

\subsection{Joint Policy Analysis: Optimal Innovation and Trade Policy}

Having analyzed the implications of individual policy options, we now focus on the optimal joint policy in which the U.S. could use both R\&D subsidy and one-sided tariff policy in tandem. Figure 18 plots the optimal R\&D subsidy under this scenario over different horizons with a solid blue line, and the optimal tariff rate with a dashed blue line. The figure reveals that the optimal subsidy levels are close to the ones found when R\&D subsidies were considered in isolation (Figure 17a), being only slightly higher in some horizons. ${ }^{51}$ However, we find that

\footnotetext{
${ }^{51}$ Although the close levels of R\&D subsidies in single and joint policy exercises may appear to be indicative of a weak interaction between trade and R\&D policies, Figure A.7 in Appendix D.2 demonstrates that this is not the case. The figure shows optimal R\&D subsidy levels over policy horizons for three different values of unilateral import tariffs. The figure reveals that while the optimal R\&D-policy profile barely differs between cases of no-tariff-change and 40 percent higher tariffs, it is substantially lower when the tariff levels are reduced 70 percent. The reason for this difference is that unilateral protectionist policies affect incentives of a small portion of U.S. firms (as suggested by the
} 
the policymaker optimally chooses a strongly protectionist measure over any horizon with a constant 16 percent tariff rate, effectively closing the borders to any import penetration. This is in stark contrast with Figure 14a, which shows that optimal tariffs decline with longer horizons, when considered in isolation. The reason is that, being allowed to set subsidy levels freely, the home country can incentivize its firms to innovate at higher rates, compensating for the loss of innovative efforts as a result of lower competitive pressure that protectionism causes. Therefore, allowing the economy to adjust both margins freely, the joint policy alternative leads to a highly protectionist regime. However, it is crucial to note that when considering optimal policies, we assumed away any reaction from the foreign country and focused only on one-sided tariff policies. Next, we delve into the implications of such foreign response.

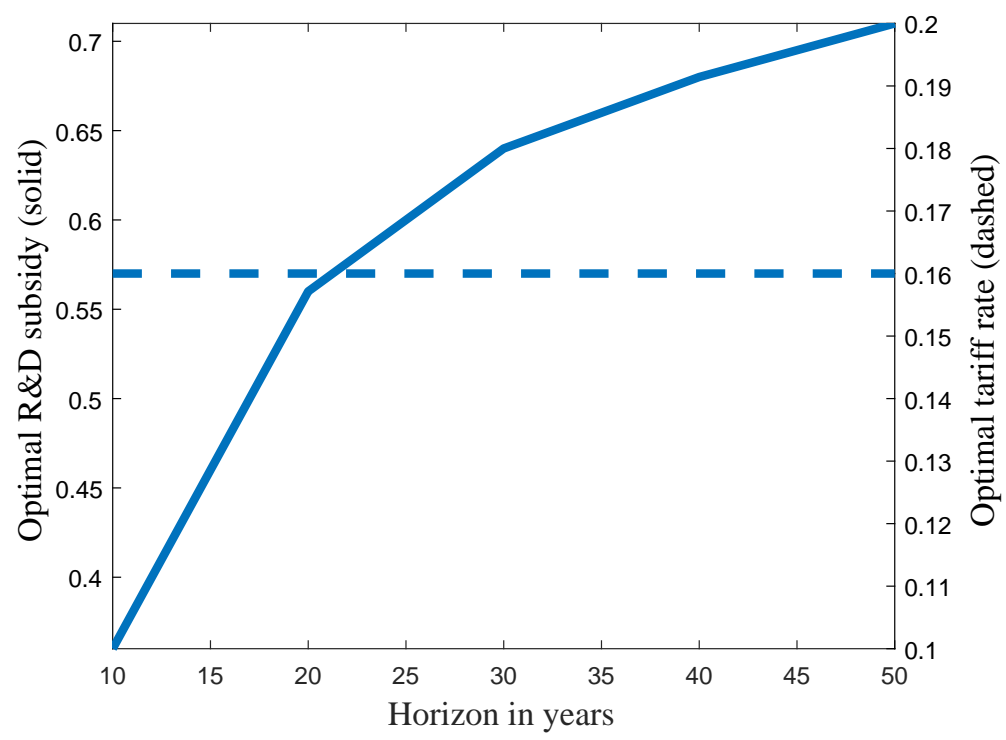

Figure 18: Optimal joint policy with unilateral tariff changes

Notes: The figure compares horizon-dependent optimal joint policy in case of (trade-policy) retaliation to that in the baseline.

\subsection{Effect of Foreign Retaliation on Optimal Joint Policy}

Until now, we analyzed the trade policy in a unilateral fashion: The home country could set its tariff rates freely, without facing a response from the foreign country. Although this analysis serves as a helpful benchmark, such unilateral moves would be unlikely in reality. The natural question is, what would be the effect of foreign retaliation on the design of trade policy? ${ }^{52}$ To

share of very laggard U.S. firms in the data), whereas a large enough reduction changes the incentives of a significant share of U.S. firms. In fact, increased competition induces a bigger share of U.S. firms to increase their innovation effort, reducing the need for aggressive R\&D subsidies.

${ }^{52}$ The introduction of the Smoot-Hawley Tariff Act in the U.S. during the early stages of the Great Depression provides an example of how the unilateral introduction of trade policies could trigger retaliatory responses from trade partners, potentially harming the domestic economy. 
answer this question, we analyze our policy alternatives under the assumption that any change in tariffs imposed by the home country is perfectly matched by the foreign one. Figure 19 shows the optimal joint policy in this modified setting with bilateral tariff changes (circled black lines), in juxtaposition with the results obtained in the benchmark setting (blue lines).

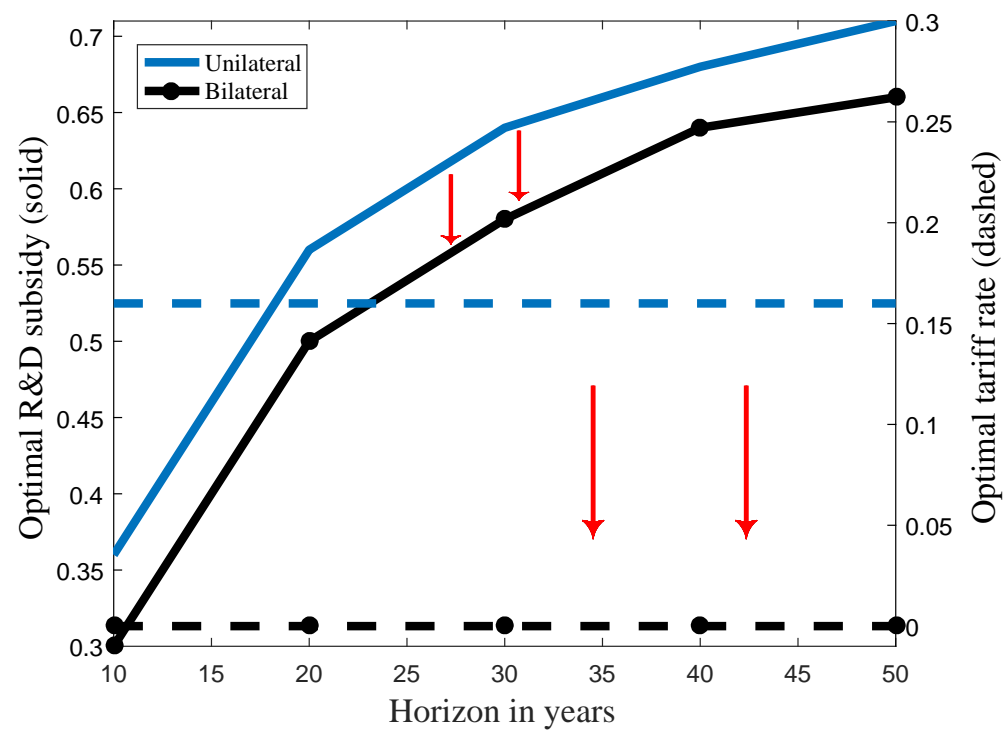

Figure 19: Optimal joint policy in unilateral and bilateral tariff changes

Notes: The figure compares horizon-dependent optimal joint policy in case of (trade-policy) retaliation to that in the baseline.

While there are no significant qualitative differences in the optimal R\&D subsidy levels, there is a complete reversal in the trade policy. Now, the optimal policy liberalizes the economy's trade regime as much as possible, removing tariffs irrespective of the length of the policy horizon under consideration. This result arises because in this setting, protectionist policies limit not only the market for imports to the home country, but also exports from the home country, because the tariff changes are replicated by the foreign trade partner. The effects of retaliatory tariff increases on the U.S. incumbents are demonstrated in Figure 20. As opposed to Figure 13b, the cutoff for exports increases, making them accessible to only a small group of firms. Moreover, a reduction in innovative activity_driven by similar reasons explained in the analysis of unilateral policies-happens now for a wider range of firms. Conversely, liberal policies expand the export market of the home country and stimulate innovation for a large set of firms via a more intense expansionary R\&D motive. Given that most U.S. incumbents are in technologically leading positions, the optimal trade policy under the assumption of retaliation favors these firms by opening up their markets to export at the expense of a few more laggard firms losing their markets to foreign importers. ${ }^{53}$

\footnotetext{
${ }^{53} \mathrm{~A}$ similar reversal happens when individual trade policy is applied in the case of foreign retaliation, with full liberalization being preferred even when the shortest horizons are concerned.
} 


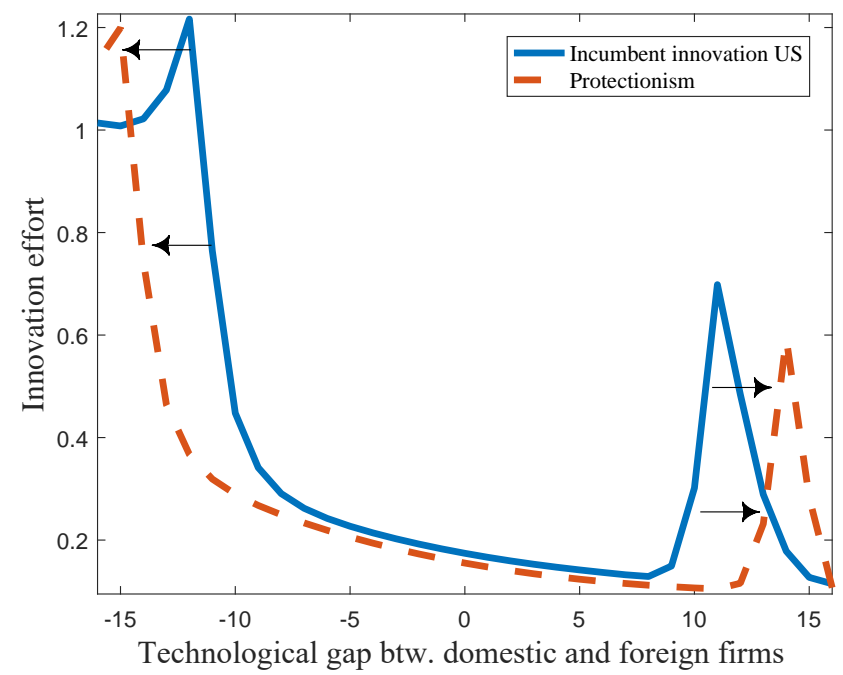

Figure 20: Innovation effort in case of retaliation, 4 percentage point bilateral increase in trade costs

Notes: The figure shows the shift in the innovation-effort profile of U.S. incumbent firms over technology gaps as a result of bilateral protectionist policies.

\section{Foreign Competition and Domestic Innovation}

A recent strand of papers in the empirical trade and firm dynamics literature has drawn notable attention thanks to their important and seemingly contradictory contributions to a heated topic: the effect of foreign competition on domestic firms and industries and, in particular, their innovative activity. Bloom et al. (2016) argue that Chinese import competition induced innovative activity in exposed domestic sectors in Europe [see also Coelli et al. (2016), Gorodnichenko et al. (2010), and Iacovone (2012)], whereas Autor et al. (2016) argue the opposite, using data on U.S. firms and sectors [see also Hashmi (2013) and Hombert and Matray (2015)], and yet a third set of papers including Aghion et al. (2017) find ambiguous results.

In this section, we show that our framework can help reconcile these seemingly contradictory observations in the literature. In particular, we present an exercise on rising import competition and illustrate that its effect on aggregate innovation crucially depends on the sectoral composition of domestic firms in terms of their technological competence relative to the foreign competitors. As a result, import competition has a non-monotonic impact on aggregate innovation, given the innovation profile in Figure 9a.

Our exercise considers six different economies: Three of them in a relatively laggard initial condition-i.e., in most sectors, their firms are distant followers-and three relatively frontier ones. To generate intensifying import competition in our model, we consider the removal of tariffs. As is evident from the earlier discussion of unilateral protectionist policies, this change shifts the defensive-R\&D cutoff inwards, creating heterogeneous effects on firm innovation: Firms that 
fall further behind the defensive-R\&D cutoff decrease their innovation effort, while firms that become closer to the cutoff intensify theirs. The overall effect at the aggregate level depends on the distribution of sectors across relative technological positions in foreign competition. Figure 21a illustrates this point, displaying three economies that are distinguished by their technological gap distribution across domestic firms' positions. The values in the figure show the percentage change in the industry-level innovation rate in response to lower tariffs. In the economy with the largest mass of the relatively most laggard sectors, the effect is negative, while it becomes positive as the technological gap distribution shifts to the right. The reason is that the economy with the least negatively skewed distribution includes relatively more firms that happen to be around the new defensive-R\&D cutoff, feeling the more intense threat of losing markets and therefore exerting more innovative effort. However, it is not correct to draw the conclusion that relatively more advanced economies benefit from intensifying foreign competition, as we discuss next.

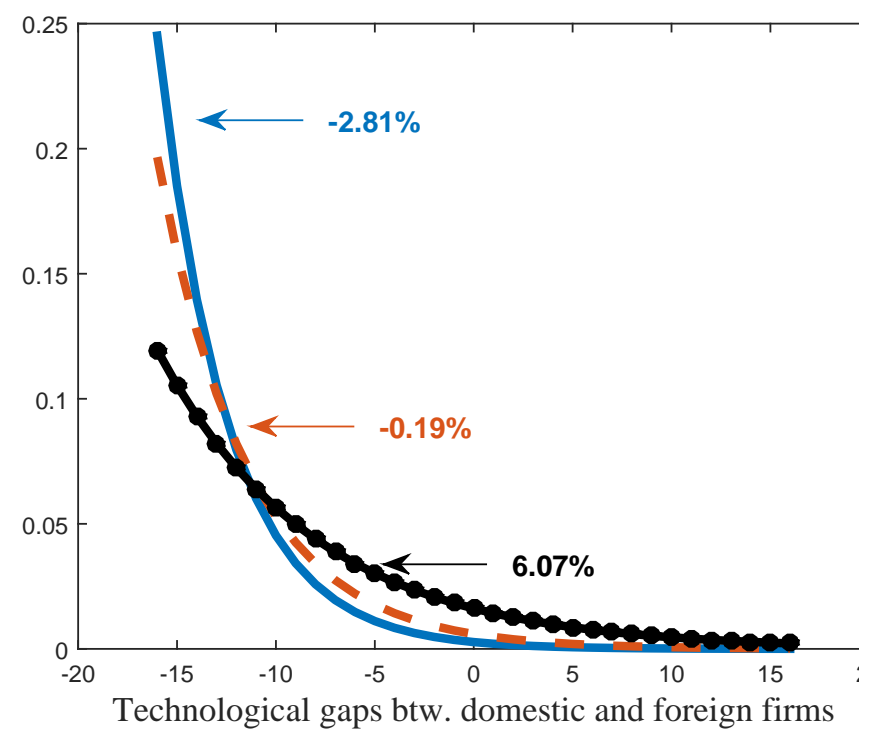

A) Three relatively laggard sectors

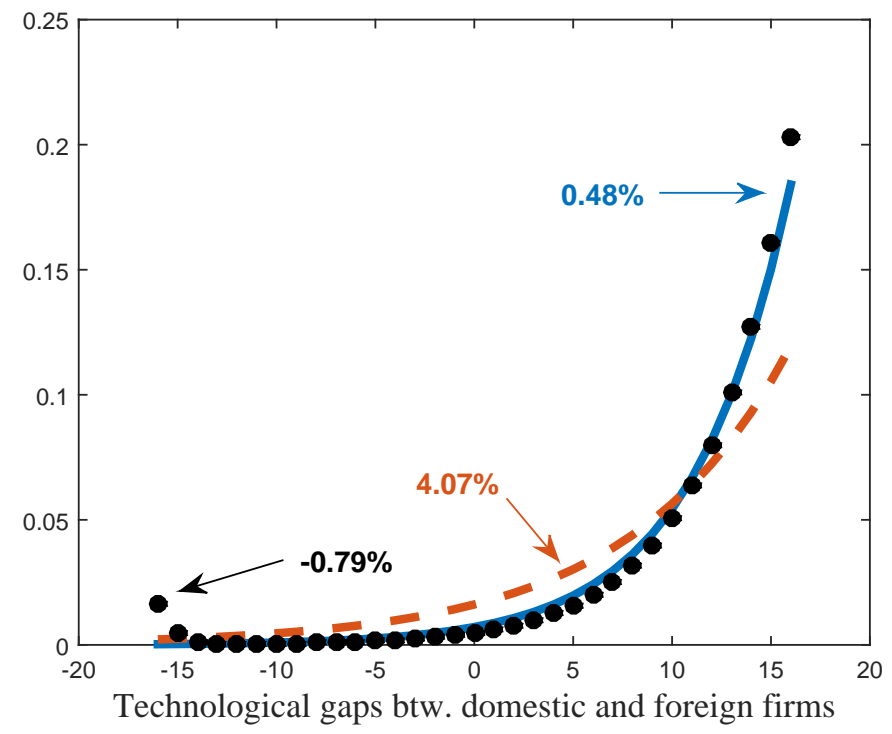

в) Three relatively advanced sectors

Figure 21: Effect of trade liberalization on aggregate innovation

Notes: The figure contrasts the change in aggregate innovation caused by trade liberalization in various sectors defined by different initial technological gap distributions. Specified values show percentage change in aggregate innovation in each sector.

Figure $21 \mathrm{~b}$ compares three economies where most firms are leaders in global technological competition. We observe that while the economy denoted by the solid blue line experiences a small rise in overall innovative activity in response to stiffer foreign competition, the relatively less advanced economy (red dashed line) experiences a considerably larger increase. The result hinges again on the share of firms in each economy that increase their innovative activity the most with intensifying competition. Finally, the economy denoted by black dots experiences a decline in overall innovation, proving that even an advanced economy-like the countries of interest in most studies referenced above-may get hurt by more intense foreign competition. 
Although minuscule in absolute terms, the relatively larger mass of relatively most laggard firms drive this implication, because these firms, now with their chances of capturing a market being diminished, decrease their innovation efforts in response to the more foreign competition.

In sum, our analysis indicates that the impact of trade liberalization might have a positive or negative impact on the liberalizing economy's aggregate innovation level depending on the initial relative technology gap between the competing countries. Moreover, even a relatively very advanced economy might experience a reduction in aggregate innovation, if it has an enough number of sectors that are getting discouraged by foreign competition.

\section{Sensitivity and Robustness}

In this section, we provide various robustness checks for our main results.

\subsection{Lower Maximum Technology Gap $\bar{m}$}

Our first exercise considers the robustness of the baseline results to the value of the maximum technology gap that can separate two incumbent firms. In our baseline, this value is set to $\bar{m}=16$. As a robustness check, we calculate the empirical gap distribution by setting $\bar{m}=10$ and recalibrate our model accordingly. When a unilateral increase in U.S. tariffs considered, we observe a similar shift in incumbent innovation as in Figure 13b. Panel A of Table 7 compares the resulting consumption-equivalent changes to the baseline experiment for various horizons. The results resonate with the baseline values, except with a slightly larger welfare cost over the long run. Furthermore, profiles of optimal unilateral R\&D and tariff policies over different horizons, summarized in Panel B and Panel C, respectively, are very similar to those found in the baseline calibration. Hence, we conclude that our original findings are robust to the values of $\bar{m}$.

\subsection{Dropping the U.K.}

As illustrated in Figure 1, the U.K. has a similar productivity and innovation performance to the U.S. in the late 1970s, in stark contrast with the other advanced competitors of the U.S. Conjecturing that idiosyncratic factors may have negatively separated the performance of the U.K. from its peers, we recalibrate our model using data that exclude the U.K. For this exercise, we re-weight our targets using data on the remaining five foreign countries and re-compute the empirical gap distribution. Figure A.8a in Appendix D.2 shows that the shift in the initial distribution caused by dropping the U.K. is minuscule, which is also the case with the other 
Table 7: Policy experiment results and comparison to the baseline results

\begin{tabular}{cccccc}
\hline \hline Panel A & \multicolumn{5}{c}{ Welfare for 50\% tariff increase } \\
Horizon in years & 10 & 20 & 30 & 40 & 50 \\
\cline { 2 - 6 } Baseline & $0.17 \%$ & $0.04 \%$ & $-0.07 \%$ & $-0.16 \%$ & $-0.24 \%$ \\
$\bar{m}=10$ & $0.20 \%$ & $0.04 \%$ & $-0.11 \%$ & $-0.26 \%$ & $-0.39 \%$ \\
\hline \hline Panel B & \multicolumn{5}{c}{ Optimal subsidy levels } \\
Horizon in years & 10 & 20 & 30 & 40 & 50 \\
\cline { 2 - 6 } Baseline & $34 \%$ & $54 \%$ & $64 \%$ & $68 \%$ & $70 \%$ \\
$\bar{m}=10$ & $34 \%$ & $56 \%$ & $68 \%$ & $70 \%$ & $72 \%$ \\
\hline \hline Panel C & \multicolumn{5}{c}{ Optimal unilateral tariff levels } \\
Horizon in years & 10 & 20 & 30 & 40 & 50 \\
\cline { 2 - 6 } Baseline & $18 \%$ & $12 \%$ & $0 \%$ & $0 \%$ & $0 \%$ \\
$\bar{m}=10$ & $16 \%$ & $12 \%$ & $0 \%$ & $0 \%$ & $0 \%$ \\
\hline \hline
\end{tabular}

targets. Consequently, the parameter values obtained by this alternative calibration, as well as the quantitative results, barely differ from the baseline; hence, we do not repeat them here.

\subsection{Quality-adjusted Patents}

In this exercise, we test the robustness of our analysis to the use of citation-weighted patent counts when forming moments from the data as well as the empirical technology gap distribution. Using citation-weighted patents implies about a 4 percent higher share for Japan among all countries in 1975 at the expense of Germany, the share of which declines by the same amount. As illustrated in Figure A.8b in Appendix D.2, this reshuffling leads to only minimal changes in the empirical technology gap distribution, which also holds true for other moments. As a result, the calibration output is very similar to baseline, as one would expect, when using the alternative measure. Therefore, we skip the rest of the results generated by this alternative calibration.

\subsection{Gap Distribution Based on Cumulative Patent Count}

In our baseline calibration, we match the shift in the empirical gap distribution from 1975 to 1981, where we generate the distributions using patent counts in individual years. ${ }^{54}$ In this exercise, we test the robustness of our results to computing the empirical gap distributions based on the cumulative patent counts starting from 1965. Doing so, we measure the evolution of technological leadership based on the cumulative patent stock. In particular, when we compute the U.S. patent share in a sector in a certain year as in Figure 7, we use the patents registered in that sector

\footnotetext{
${ }^{54}$ One reason for starting in 1975 is that in the raw USPTO data, the number of patents that are assigned to a technology class is much smaller before the mid-1970s compared to subsequent years.
} 
between 1965 and the particular year of interest. For example, to generate the empirical gap distribution in 1975, we rank sectors using information from patents registered between 1965 and 1975 instead of 1975 alone. As can be expected, the shift in the empirical gap distribution is less pronounced in this method, because the country shares of patent stocks vary more slowly. Therefore, in Figure A.9a in Appendix D.2, the distribution in 1981 is to the right of the baseline one. However, this limited change does not lead to substantial differences in our calibration. Indeed, as shown in Table 8, the optimal unilateral tariff policy looks quite similar to the one in the baseline economy. Hence, we conclude that our results are immune to the alternative empirical computation method of distributional targets. ${ }^{55}$

Table 8: Cumulative Patents and the Optimal Unilateral Tariffs

\begin{tabular}{cccccc}
\hline \hline Horizon in years & 10 & 20 & 30 & 40 & 50 \\
\cline { 2 - 6 } Baseline & $18 \%$ & $12 \%$ & $0 \%$ & $0 \%$ & $0 \%$ \\
Cumulative patents & $28 \%$ & $20 \%$ & $2 \%$ & $0 \%$ & $0 \%$ \\
\hline \hline
\end{tabular}

\subsection{Tariff Revenue as a Lump-sum Transfer}

In the baseline exercises, tariffs operate similar to iceberg costs without generating any revenue for the government. In this exercise, we explore the implications of a tariff policy, whose revenue is shared by the households via lump-sum subsidies. Then, net government spending becomes $G_{c t}=s^{c} \sum_{s=-\bar{m}}^{\bar{m}} \alpha_{c} x_{c s t}^{\gamma_{c}} Q_{c s t}-\tau^{c} \sum_{m=-\bar{m}}^{-m_{c^{\prime}}^{*}}\left[\frac{1-\beta}{\left(1+\kappa+\tau^{c}\right) \eta}\right]^{\frac{1-\beta}{\beta}} \frac{Q_{c^{\prime} m t}}{1-\beta}$ in a modified version of equation (20), accounting for tariff revenue. The profile of the optimal unilateral tariff policy, summarized in Table 9, mirrors what we found in our baseline setting in that liberalization is optimal for a far-sighted policymaker. However, complete removal of tariffs becomes optimal at a longer horizon than in the baseline. This result should be expected because in this case, tariff reduction comes at a cost to households, decreasing the amount of lump-sum subsidies generated by the tariff revenue. Nevertheless, the main message that protectionist policies are only optimal for policymakers that have relatively shorter horizons remains intact in this alternative setting.

Table 9: Optimal unilateral tariffs and comparison to the baseline results

\begin{tabular}{cccccc}
\hline \hline Horizon in years & 10 & 20 & 30 & 40 & 50 \\
\cline { 2 - 6 } Baseline & $18 \%$ & $12 \%$ & $0 \%$ & $0 \%$ & $0 \%$ \\
Tariff with revenue & $14 \%$ & $10 \%$ & $4 \%$ & $0 \%$ & $0 \%$ \\
\hline \hline
\end{tabular}

\footnotetext{
${ }^{55}$ As shown in Figure A.9b in Appendix D.2, the calibration to the alternative distributions also performs well in matching the limited shift, resulting in a model-generated gap distribution in 1981 that lies to the right of the one in the baseline calibration. This comparison reveals that the similarity of policy implications in both calibrations is not driven by a spuriously stronger force of foreign convergence emerging in the alternative calibration than implied by the relatively limited shift in the empirical distributions.
} 


\subsection{Lower Discount Rate $\rho$}

In the baseline calibration, we fixed the discount rate of the households to 1 percent. In order to test the sensitivity of our results to this parameter, we also ran an alternative calibration, setting the discount rate to 0.5 percent. Our calibration outcome barely changes in this exercise suggesting that our analysis is robust to varying degrees of the discount rate. Because the effects are negligible, we do not present the results here.

\subsection{Modeling Labor in the Intermediate Goods Sector}

A central concern in the debate on gains from trade is the potential harm that import penetration can cause to domestic workers by stealing the market of the domestic firms [Autor et al. (2013)]. In our baseline model, labor, which is used in the final good sector, benefits from trade liberalization thanks to the higher labor productivity, which is brought about by better-quality imports replacing inferior domestic counterparts. As a robustness exercise, we modify the baseline model in order to allow trade to have an adverse impact on labor. In this version, labor is utilized in the production of intermediate goods; therefore, foreign catch-up leads to a wage loss as a byproduct of business stealing. We re-estimate this new version of the model and compare its key policy implications with the ones of the baseline model. For the sake of brevity, we present the details of the exercise and the results in Appendix E. Our key baseline results go through in this version as well, except that unilateral tariff policies appear to increase economic welfare for longer horizons. However, the threat of retaliation works just as in our baseline framework, inducing the policymaker optimally choose to remove tariffs across all horizons.

\section{Conclusion}

In this paper, we shed light on a recurring debate about the competitiveness of U.S. firms relative to their foreign competitors and how to improve their position. Motivated by a set of novel facts on advanced foreign countries catching up to the U.S. during the 1970s and 1980s, we build an open-economy general equilibrium framework of endogenous growth and trade to evaluate the effectiveness of innovation and trade policies in improving the competitiveness of U.S. firms. Firm innovation decisions in our model are motivated by defensive and expansionary innovation motives as well as domestic and international business-stealing effects. While knowledge spillovers and decreasing returns to knowledge accumulation lead to cross-country convergence, productivity differences drive trade flows. While realistically mimicking an extensive set of empirical relationships, our machinery is still tractable enough to allow for the analysis of transitional dynamics, which proves to be crucial for policy evaluation. 
Our theoretical and quantitative analysis obtains several key results. Theoretically we show that in the static sense, increased openness benefits the fixed factor in final production by raising its compensation via higher-quality intermediate imports, while the impact on business owners is ambiguous, because larger export demand and loss of markets to better foreign rivals exert opposing forces. In the dynamic sense, increased openness, and thus foreign competition, encourages more domestic innovation through stronger incentives for defensive and expansionary R\&D. Quantitatively, we first show that foreign technological catching-up hurts U.S. welfare by stealing away business and profits of U.S. firms. Second, we assess that the introduction of R\&D subsidies in the U.S. was a viable response to restore the technological competitiveness of U.S. firms, with a notable welfare contribution in the medium term. Moreover, our model implies that the optimal subsidy is increasing over time horizons and decreasing in openness. The latter is an intriguing result, which owes again to the dynamic innovation-stimulating effect of foreign competition on domestic firms. Finally, we consider a counterfactual protectionist response to foreign catching-up. We find that, in the context of our model, increasing trade barriers for imports unilaterally increases U.S. economic welfare only in the short run, chiefly through the substitution of imports, with domestic production leading to higher domestic profits. However, failing to incentivize U.S. firms to accelerate technological improvement, the protectionist policy cannot compensate for the loss of high-quality imports and leads to substantial welfare losses in the medium to long run. Therefore, protectionist policies in our model, despite helping businesses to retain profits in the short run, make consumers worse off over the longer term.

\section{References}

Acemoglu, Daron and Ufuk Akcigit, "Intellectual Property Rights Policy, Competition and Innovation," Journal of the European Economic Association, 2012, 10 (1), 1-42.

_, , , Douglas Hanley, and William R. Kerr, "Transition to Clean Technology," Journal of Political Economy, 2016, 124 (1), 52-104.

_, , Harun Alp, Nicholas Bloom, and William R. Kerr, "Innovation, Reallocation and Growth," 2017. National Bureau of Economic Research Working Paper 18993.

Aghion, Philippe and Peter Howitt, The Economics of Growth, MIT Press, 2009.

_, Antonin Bergeaud, Mathieu Lequien, and Marc Melitz, "The Impact of Exports on Innovation: Theory and Evidence," 2017. Manuscript.

_ , Christopher Harris, Peter Howitt, and John Vickers, "Competition, Imitation and Growth with Step-by-step Innovation," Review of Economic Studies, 2001, 68 (3), 467-492.

_, Nicholas Bloom, Richard Blundell, Rachel Griffith, and Peter Howitt, "Competition and Innovation: An Inverted-U Relationship," Quarterly Journal of Economics, 2005, 120 (2), 701-728.

Akcigit, Ufuk and William R. Kerr, "Growth through Heterogeneous Innovations," Journal of Political Economy, 2017. 
_ , Douglas Hanley, and Nicolas Serrano-Velarde, "Back to Basics: Basic Research Spillovers, Innovation Policy and Growth," 2016. Centre for Economic Policy Research Discussion Paper 11707.

_ , , , and Stefanie Stantcheva, "Optimal Taxation and R\&D Policies," 2016. National Bureau of Economic Research Working Paper 22908.

Alessandria, George and Horag Choi, "Establishment Heterogeneity, Exporter Dynamics, and the Effects of Trade Liberalization," Journal of International Economics, 2014, 94 (2), 207-223.

Anderson, James E. and Eric van Wincoop, "Trade Costs," Journal of Economic Literature, 2004, 42 (3), 691-751.

Antràs, Pol and Elhanan Helpman, "Global Sourcing," Journal of Political Economy, 2004, 112 (3), 552-580.

Arkolakis, Costas, Arnaud Costinot, and Andrés Rodríguez-Clare, "New Trade Models, Same Old Gains?," American Economic Review, February 2012, 102 (1), 94-130.

Atkeson, Andrew and Ariel T. Burstein, "Innovation, Firm Dynamics, and International Trade," Journal of Political Economy, 2010, 118 (3), 433-484.

Autor, David, David Dorn, Gordon H. Hanson, Gary Pisano, and Pian Shu, "Foreign Competition and Domestic Innovation: Evidence from U.S. Patents," 2016. National Bureau of Economic Research 22879.

Autor, David H., David Dorn, and Gordon H. Hanson, "The China Syndrome: Local Labor Market Effects of Import Competition in the United States," American Economic Review, October 2013, 103 (6), 2121-2168.

Aw, Bee Yan, Mark J. Roberts, and Daniel Yi Xu, "R\&D Investment, Exporting, and Productivity Dynamics," American Economic Review, 2011, 101 (4), 1312-1344.

Baldwin, Richard and Paul Krugman, "Industrial Policy and International Competition in Widebodied Jet Aircraft," in Richard Baldwin, ed., Trade Policy Issues and Empirical Analysis, University of Chicago Press, 1988, pp. 45-78.

Barattieri, Alessandro, Matteo Cacciatore, and Fabio Ghironi, "Protectionism and the Business Cycle," 2017. Manuscript.

Bernard, Andrew B., J. Bradford Jensen, Stephen J. Redding, and Peter K. Schott, "Global Firms," Journal of Economic Literature, 2017. forthcoming.

Bloom, Nicholas, Mirko Draca, and John Van Reenen, "Trade Induced Technical Change? The Impact of Chinese Imports on Innovation, IT and Productivity," Review of Economic Studies, 2016, 83 (1), 87-117.

_, Paul M Romer, Stephen J. Terry, and John Van Reenen, "A Trapped-factors Model of Innovation," American Economic Review, Papers and Proceedings, 2013, 103 (3), 208-213.

- , Rachel Griffith, and John Van Reenen, “Do R\&D Tax Credits Work? Evidence from A Panel of Countries 1979-1997," Journal of Public Economics, 2002, 85 (1), 1-31.

Buera, Francisco J. and Ezra Oberfield, "The Global Diffusion of Ideas," 2016. National Bureau of Economic Research 21844. 
Burstein, Ariel and Marc J. Melitz, "Trade Liberalization and Firm Dynamics," in Daron Acemoglu, Eddie Dekel, and Manuel Arellano, eds., Advances in Economics and Econometrics Tenth World Congress. Applied Economics, Vol. 2, 2013, pp. 283-328.

Bustos, Paula, "Trade Liberalization, Exports, and Technology Upgrading: Evidence on the Impact of MERCOSUR on Argentinian Firms," American Economic Review, 2011, 101 (1), 304-340.

Cameron, Gavin, James Proudman, and Stephen Redding, "Technological Convergence, R\&D, Trade and Productivity Growth," European Economic Review, 2005, 49 (3), 775-807.

Capdevielle, Patricia and Donato Alvarez, "International Comparisons of Trends in Productivity and Labor Costs," Monthly Lab. Rev., 1981, 104, 14-20.

Chen, Cheng and Claudia Steinwender, "Import Competition, Heterogeneous Preferences of Managers, and Productivity," 2016. Harvard Business School Working Paper.

Coe, David T., Elhanan Helpman, and Alexander W. Hoffmaister, "International R\&D Spillovers and Institutions," European Economic Review, 2009, 53 (7), 723-741.

Coelli, Federica, Andreas Moxnes, and Karen Helene Ulltveit-Moe, "Better, Faster, Stronger: Global Innovation and Trade Liberalization," 2016. National Bureau of Economic Research 22647.

Coeurdacier, Nicolas and Helene Rey, "Home Bias in Open Economy Financial Macroeconomics," Journal of Economic Literature, 2013, 51 (1), 63-115.

Costinot, Arnaud, Andrés Rodríguez-Clare, and Iván Werning, "Micro to Macro: Optimal Trade Policy with Firm Heterogeneity," 2016. National Bureau of Economic Research 21989.

_ , Dave Donaldson, Jonathan Vogel, and Iván Werning, “Comparative Advantage and Optimal Trade Policy," Quarterly Journal of Economics, 2015, 130 (2), 659-702.

Demidova, Svetlana and Andrés Rodríguez-Clare, "Trade Policy Under Firm-level Heterogeneity in a Small Economy," Journal of International Economics, June 2009, 78 (1), 100-112.

Eaton, Jonathan and Gene M. Grossman, "Optimal Trade and Industrial Policy under Oligopoly," Quarterly Journal of Economics, 1986, 101 (2), 383-406.

Gerschenkron, Alexander, Economic Backwards in Historical Perspective: A Book of Essays, Belknap Press of Harvard University Press, 1962.

Gorodnichenko, Yuriy, Jan Svejnar, and Katherine Terrell, "Globalization and Innovation in Emerging Markets," American Economic Journal: Macroeconomics, April 2010, 2 (2), 194-226.

Grossman, Gene M. and Edwin L.-C. Lai, "International Protection of Intellectual Property," American Economic Review, 2004, 94 (5), 1635-1653.

- and Elhanan Helpman, "Comparative Advantage and Long-run Growth," American Economic Review, 1990, 80 (4), 796-815.

_ and _ , "Growth and Welfare in a Small Open Economy," in E. Helpman and A. Razin, eds., International Trade and Trade Policy, Cambridge, Mass.: MIT Press, 1991, chapter 8, pp. 141-163.

_ and _, "Quality Ladders in the Theory of Growth," Review of Economic Studies, 1991, 58 (1), $43-61$. 
_ and _ , Innovation and Growth In the Global Economy, MIT press, 1993.

Haaland, Jan I. and Hans Jarle Kind, "R\&D Policies, Trade and Process Innovation," Journal of International Economics, 2008, 74 (1), 170-187.

Hall, Bronwyn H., Adam B. Jaffe, and Manuel Trajtenberg, "The NBER Patent Citation Data File: Lessons, Insights and Methodological Tools," 2001. National Bureau of Economic Research 8498.

Hashmi, Aamir Rafique, "Competition and Innovation: The Inverted-U Relationship Revisited," Review of Economics and Statistics, 2013, 95 (5), 1653-1668.

Hombert, Johan and Adrien Matray, "Can Innovation Help US Manufacturing Firms Escape Import Competition from China?," 2015. CEPR Discussion Papers 10666.

Hottman, Colin J., Stephen J. Redding, and David E. Weinstein, "Quantifying the Sources of Firm Heterogeneity," Quarterly Journal of Economics, 2016, 131 (3), 1291-1364.

Hummels, David and Volodymyr Lugovskyy, "Are Matched Partner Trade Statistics a Usable Measure of Transportation Costs?*," Review of International Economics, 2006, 14 (1), 69-86.

Iacovone, Leonardo, "The Better You Are the Stronger It Makes You: Evidence on the Asymmetric Impact of Liberalization," Journal of Development Economics, 2012, 99 (2), 474-485.

_, Wolfgang Keller, and Ferdinand Rauch, "Innovation Responses to Import Competition," 2011. Mimeo, Princeton University.

Impullitti, Giammario, "International Competition and US R\&D Subsidies: A Quantitative Welfare Analysis," International Economic Review, 2010, 51 (4), 1127-1158.

- and Omar Licandro, "Trade, Firm Selection, and Innovation: The Competition Channel," Economic Journal, 2017.

Irwin, Douglas A. and Nina Pavcnik, "Airbus versus Boeing Revisited: International Competition in the Aircraft Market," Journal of International Economics, 2004, 64 (2), 223-245.

Keller, Wolfgang, "International Technology Diffusion," Journal of Economic Literature, 2004, 42 (3), 752-782.

Leahy, Dermot and J. Peter Neary, "Public Policy towards R\&D in Oligopolistic Industries," American Economic Review, 1997, 87 (4), 642-662.

Lileeva, Alla and Daniel Trefler, "Improved Access to Foreign Markets Raises Plant-level Productivity for Some Plants," Quarterly Journal of Economics, 2010, 125 (3), 1051-1099.

López, Ricardo A., "Do Firms Increase Productivity in Order to Become Exporters?," Oxford Bulletin of Economics and Statistics, 2009, 71 (5), 621-642.

Lybbert, Travis and Nikolas Zolas, "Getting Patents and Economic Data to Speak to Each Other: An "Algorithmic Links with Probabilities" Approach for Joint Analyses of Patenting and Economic Activity," Research Policy, 2014, 43 (3), 530-542.

Mayer, Thierry, Marc J. Melitz, and Gianmarco I.P. Ottaviano, "Product Mix and Firm Productivity Responses to Trade Competition," 2016. National Bureau of Economic Research 22433. 
_, Marc Melitz, and Gianmarco I.P. Ottaviano, "Market Size, Competition, and the Product Mix of Exporters," American Economic Review, 2014, 104 (2), 495-536.

Melitz, Marc, "The Impact of Trade on Intra-Industry Reallocations and Aggregate Industry Productivity," Econometrica, 2003, 71, 1695-1725.

Melitz, Marc J. and Stephen J. Redding, "Missing Gains from Trade?," American Economic Review, 2014, 104 (5), 317-321.

Muendler, Marc-Andreas, “Trade, Technology, and Productivity: A Study of Brazilian Manufacturers, 1986-1998," 2004. CESifo Working Paper Series 1148.

Ossa, Ralph, "A Quantitative Analysis of Subsidy Competition in the US," 2015. National Bureau of Economic Research Working Paper 20975.

Perla, Jesse, Christopher Tonetti, and Michael E. Waugh, "Equilibrium Technology Diffusion, Trade, and Growth," 2015. National Bureau of Economic Research Working Paper 20881.

Rivera-Batiz, Luis A. and Paul M. Romer, "Economic Integration and Endogenous Growth," Quarterly Journal of Economics, 1991, 106 (2), 531-555.

Rodrik, Dani, "Industrial Policy for the Twenty-first Century," 2004. CEPR Discussion Paper 4767.

Romer, Paul M., “Endogenous Technological Change,” Journal of Political Economy, 1990, 98, S71S102.

Sampson, Thomas, "Dynamic Selection: An Idea Flows Theory of Entry, Trade, and Growth," Quarterly Journal of Economics, 2016, 131 (1), 315-380.

Segerstrom, Paul S., "Endogenous Growth without Scale Effects," American Economic Review, $1998,88,1290-1310$.

Spencer, Barbara J. and James A. Brander, "International R\&D Rivalry and Industrial Strategy," Review of Economic Studies, 1983, 50 (4), 707-722.

Wilson, Daniel J., "Beggar Thy Neighbor? The In-state, Out-of-state, and Aggregate Effects of R\&D Tax Credits," Review of Economics and Statistics, 2009, 91 (2), 431-436. 


\section{Appendices}

\section{A Additional Empirical Material}

\section{A.1 Empirical Facts}

This section presents empirical regularities in global technological competition and describes the technological convergence between the U.S. and other major economies. An account of federaland state-level R\&D tax credit policies follows. The section concludes with suggestive evidence on the positive effect of R\&D tax credits on firm-level performance.

\section{Fact 1: Technological Convergence}

There is a striking change in the relative position of foreign countries relative to the U.S. in the worldwide technological competition over the course of 1970s until the mid-1980s. At both aggregate and sectoral level, we observe a clear pattern of catching-up, which we measure using patent and citation counts.

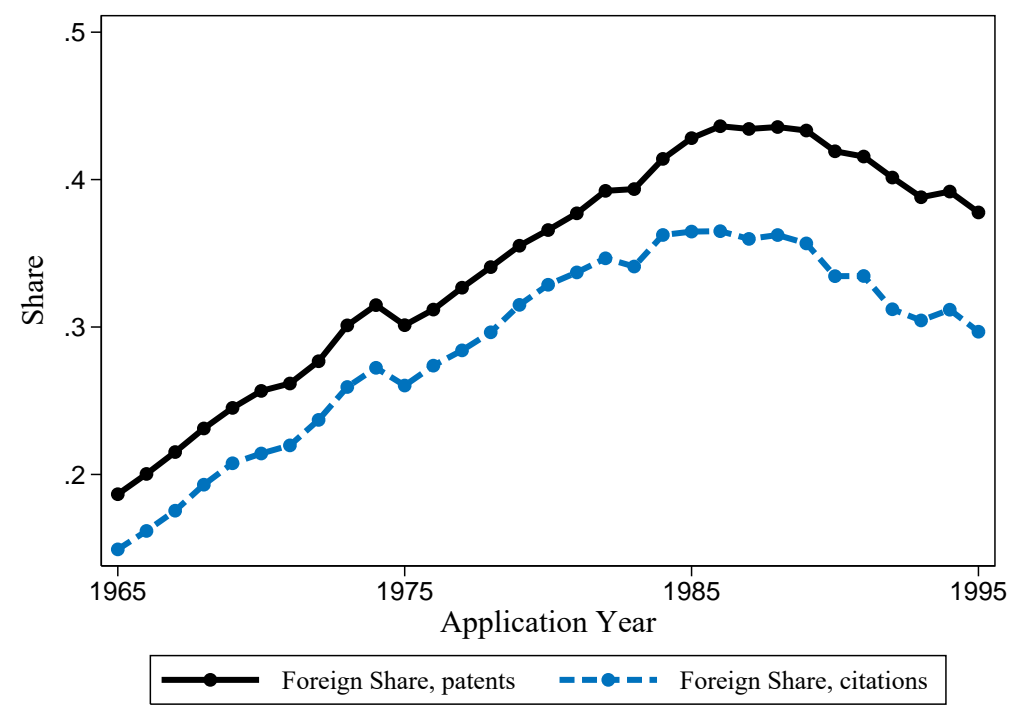

Figure A.1: Share of foreign patents: 1965-1995

Using USPTO data on patent counts, Figure A.1 shows the yearly change in the proportion of patents registered in the U.S. by foreign entities (solid line) ${ }^{56}$ It also depicts the same ratio for the citations received by those patents (dashed line). Both lines display an obvious, increasing trend, which means that the growth in the number of foreign-based patents is higher than the

\footnotetext{
${ }^{56}$ The distinction between domestic and foreign patents is by geographic location of registry. For more detail, see Hall et al. (2001).
} 
growth in U.S.-based ones. Interestingly, the convergence process comes to a halt around the mid-1980s, and we observe an reversal of the trend.

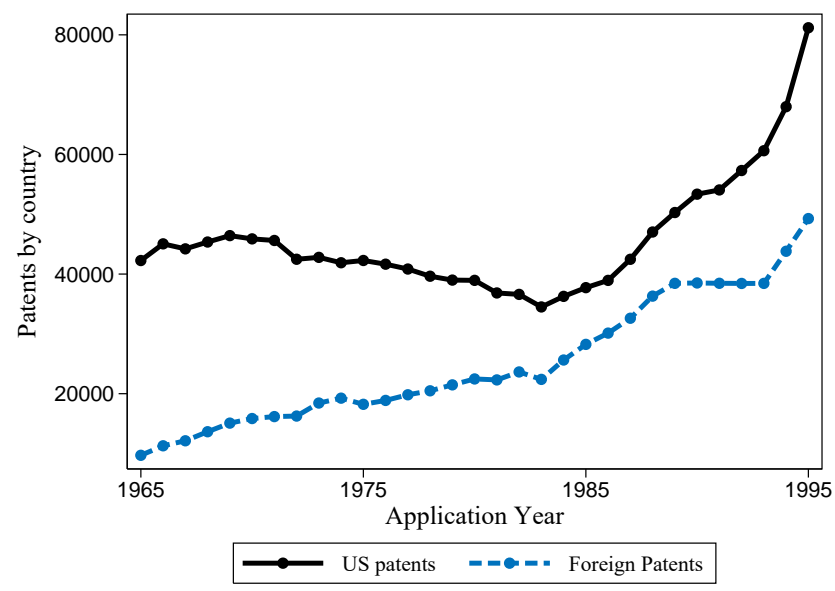

Figure A.2: Patent Counts

\section{Fact 2: R\&D Tax Incentives}

Partly motivated by these and other similar facts, concerns about the strength of the U.S. industries and their ability to compete in a fast-moving global economy increased dramatically in the late 1970s. The key discussions focused on whether the new technologies arising from federally funded R\&D were being fully and effectively exploited for the benefit of the national economy, whether there were barriers slowing down private firms in creating and commercializing innovations and new technologies, and whether public-private collaboration in research and innovation could help the U.S. economy in facing these new challenges. Several new policy measures were introduced in those years, with particular attention to avoiding unduly substitution of government for private firms in activities that the latter can naturally perform better. These actions included several programs to facilitate the transfer of the outcome of the federal R\&D to private businesses (e.g., the National Cooperative Research Act of 1984, and the Technology Transfer Act of 1986), policies to strengthen intellectual property rights such as the Bayh-Dole Act (1980), and in particular tax incentives to innovation that started with the Research and Experimentation Tax Credit (R\&E) in 1981.

The R\&E Tax Credit introduced a 25 percent tax deduction on the increase in R\&D spending over the average of the past three years. In 1985 the statutory rate was reduced to 20 percent, and in 1990 the base for eligibility was defined as the average of the 1984-88 R\&D to sales ratio (with a maximum of 16 percent) times current sales. The U.S. competitors in high-tech industriesJapan and the large European economies-introduced or already had in place tax incentives for innovation. Using corporate tax data, Bloom et al. (2002) estimate the R\&D subsidy produced by tax policies in the U.S., Japan, and key European countries. The data take into account the different tax and tax credit systems used in each country and measure the reduction in the cost of $\$ 1$ of R\&D investment produced by the tax system. Figure 3 of the main text shows the R\&D 
tax subsidy for the set of countries we are interested in.

The variations across countries are mainly due to the presence and effectiveness of a specific tax credit for R\&D. The sudden increase in U.S. subsidies, for instance, takes place with the introduction of the R\&E Tax Credit in 1981 and with the revision of the base defining incremental $R \& D$ in 1990. We can see that in 1980 the reduction in innovation cost attributable to the tax system was about 5 percent; it jumps to about 15 percent in 1981 and further increases to more than 25 percent in 1990. In Japan there is a fixed tax credit of limited effectiveness for the period considered. In the rest of the countries there are no special tax provisions or credits given on $\mathrm{R} \& \mathrm{D}$ expenditures, and the positive and fairly constant subsidy rates are produced by tax credits common to all assets.

In 1982 starting with Minnesota, U.S. states also introduced tax subsidies for R\&D. In Figure A.3 we report the evolution of the average rate of U.S. state tax credits together with the number of states offering a tax credit each year, using tax credit data of Wilson (2009). The simple average of effective tax credits across states offering a credit was about 6 percent in 1995, nearly one-fourth of the federal one, and the number of states following such a policy rose to 32. Figure A.3 also shows the average R\&D credit level weighted by the state-level patent production, whose evolution over time is parallel to the simple average. ${ }^{57}$

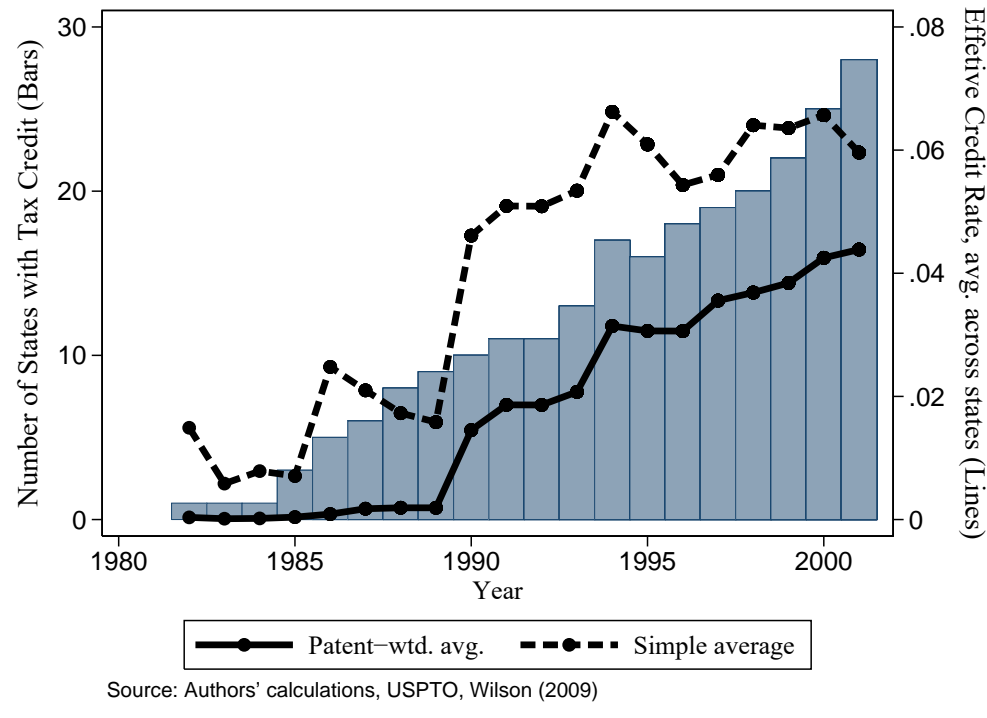

Figure A.3: U.S. state-level R\&D tax credit

\footnotetext{
${ }^{57}$ As opposed to the simple average, the weighted average multiplies the state-level effective credit by the fraction of total U.S.-based patents registered in that state.
} 


\section{B Additional Derivations}

\section{B.1 Proofs}

Lemma 1 We confirm this lemma by guess-and-verify method. Conjecture the following form: $V_{c m t}=q v_{m t}$. Substituting this expression into equation (14), we get:

$$
\begin{aligned}
r_{A t} v_{A m t} q-\dot{v}_{A m t} q & =\max _{x_{A m t}} \Pi(m) q-\left(1-s^{A}\right) \alpha_{A} \frac{\left(x_{A m t}\right)^{\gamma_{A}}}{\gamma_{A}} q \\
& +x_{A m t}\left[\sum_{n_{t}=m+1}^{\bar{m}} \mathbb{F}_{m}\left(n_{t}\right) v_{A n t} \lambda^{\left(n_{t}-m\right)} q-v_{A m t} q\right] \\
& +\tilde{x}_{A m t}\left[0-v_{A m t} q\right] \\
& +\left(x_{B(-m) t}+\tilde{x}_{B(-m) t}\right) \sum_{n_{t}=-m+1}^{\bar{m}} \mathbb{F}_{-m}\left(n_{t}\right)\left[v_{A(-n t)} q-v_{A m t} q\right] .
\end{aligned}
$$

Dividing all sides by $q$, we obtain the desired result.

\section{B.2 Value Functions for Boundary Gaps}

To complete the exposition of incumbents' problem we present the two boundary cases where the incumbent is $\bar{m}$-steps ahead (behind): ${ }^{58}$

$$
\begin{aligned}
r_{A t} V_{A \bar{m} t}(q)-\dot{V}_{A \bar{m} t}(q) & =\max _{x_{A \bar{m} t}}\left\{\left(\pi L_{A}+\pi^{*} L_{B}\right) q-\left(1-s^{A}\right) \alpha_{A} \frac{\left(x_{A \bar{m} t}\right)^{\gamma_{A}}}{\gamma_{A}} q\right. \\
& +x_{A \bar{m} t}\left[V_{A \bar{m} t}(\lambda q)-V_{A \bar{m} t}(q)\right]+\tilde{x}_{A \bar{m} t}\left[0-V_{A \bar{m} t}(q)\right] \\
& \left.+\left(x_{B(-\bar{m}) t}+\tilde{x}_{B(-\bar{m}) t}\right) \sum_{n_{t}=-\bar{m}+1}^{\bar{m}} \mathbb{F}_{-\bar{m}}\left(n_{t}\right)\left[V_{A(-n) t}(q)-V_{A \bar{m} t}(q)\right]\right\},
\end{aligned}
$$

and

$$
\begin{aligned}
r_{A t} V_{A(-\bar{m}) t}(q)-\dot{V}_{A(-\bar{m}) t}(q) & =\max _{X_{A(-\bar{m}) t}}\left\{-\left(1-s^{A}\right) \alpha_{A} \frac{\left(x_{A(-\bar{m}) t}\right)^{\gamma_{A}}}{\gamma_{A}} q\right. \\
& +x_{A(-\bar{m}) t} \sum_{n_{t}=-\bar{m}+1}^{\bar{m}} \mathbb{F}_{-\bar{m}}\left(n_{t}\right)\left[V_{A n t}\left(\lambda^{\left(n_{t}+\bar{m}\right)} q\right)-V_{A(-\bar{m}) t}(q)\right] \\
& +\tilde{x}_{A(-\bar{m}) t}\left[0-V_{A(-\bar{m}) t}(q)\right] \\
& \left.+\left(x_{B \bar{m} t}+\tilde{x}_{B \bar{m} t}\right)\left[V_{A(-\bar{m}) t}(\lambda q)-V_{A(-\bar{m}) t}(q)\right]\right\} .
\end{aligned}
$$

\footnotetext{
${ }^{58}$ These value functions assume that $\bar{m}$-step ahead leader captures both the domestic and the foreign market-i.e., the quality advantage at the largest gap is enough to cover the trade costs.
} 
The last term in the value function of $\bar{m}$-step-behind incumbent captures the knowledge spillovers. When a leader at the maximum gap $\bar{m}$ innovates, the follower in this sector automatically sees its technology jump by a measure $\lambda$. Together with the market-size, escapecompetition, and business-stealing effects described above, the international knowledge spillover is the last key feature driving innovation in our framework. In each period this spillover keeps laggard firms in the innovation race, preventing them from falling too far behind. Because the innovation technology is the same for all firms, laggards always have a chance to catch up.

\section{B.3 Aggregation and the Distribution of Leadership}

The growth rate of this economy is determined by the changes in aggregate quality/productivity across intermediate goods, $Q_{c m t}$. In order to analyze the evolution of aggregate quality and breaking it down into its various sources we need to consider all possible scenarios of innovation outcomes and keep track of the resulting changes in quality levels across product lines at each gap size. Below we report the evolution of aggregate qualities, and in the next subsection we describe the full derivation. Changes in $Q_{A m t}$ are characterized by the following expressions: ${ }^{59}$

$$
\begin{aligned}
\dot{Q}_{A m t} & =\sum_{s=-\bar{m}}^{m-1} \mathbb{F}_{s}(m)\left(x_{A s t}+\tilde{x}_{A s t}\right) \lambda^{m-s} Q_{A s t}+\sum_{s=m+1}^{\bar{m}} \mathbb{F}_{-s}(-m)\left(x_{B(-s) t}+\tilde{x}_{B(-s) t}\right) Q_{A s t} \\
& -\left[x_{A m t}+x_{B(-m) t}+\tilde{x}_{A m t}+\tilde{x}_{B(-m) t}\right] Q_{A m t} \\
\dot{Q}_{A \bar{m} t} & =\left[\left(x_{A \bar{m} t}+\tilde{x}_{A \bar{m} t}\right)(\lambda-1)-x_{B(-\bar{m}) t}-\tilde{x}_{B(-\bar{m}) t}\right] Q_{A \bar{m} t}+\sum_{s=-\bar{m}}^{\bar{m}-1} \mathbb{F}_{s}(\bar{m})\left(x_{A s t}+\tilde{x}_{A s t}\right) \lambda^{\bar{m}-s} Q_{A s t} \\
\dot{Q}_{A(-\bar{m}) t} & =\left[\left(x_{B \bar{m} t}+\tilde{x}_{B \bar{m} t}\right)(\lambda-1)-x_{A(-\bar{m}) t}-\tilde{x}_{A(-\bar{m}) t}\right] Q_{A(-\bar{m}) t}+\sum_{s=-\bar{m}}^{\bar{m}-1} \mathbb{F}_{S}(\bar{m})\left(x_{B s t}+\tilde{x}_{B s t}\right) Q_{A(-s) t} .
\end{aligned}
$$

The first equation is the generic expression that describes the change in the aggregate quality of intermediate goods produced by firms from country $c$ at position $m$. The first sum captures the addition of new incumbents improving to gap $m$. An innovation with step size $\lambda^{m-s}$ by a domestic incumbent or entrant at position $s<m$ happens with probability $\mathbb{F}_{s}(m)$, and it implies that the domestic incumbent in that product line will reach gap $m$. The second sum captures the addition of product lines, where the position of the domestic incumbent worsened to $m$ from a better one. An improvement by foreign incumbents or entrants from position $-s<-m$ to $-m$, which happens with probability $\mathbb{F}_{-s}(-m)$, hits the domestic incumbent in that product line enjoying the position $s>m$ and brings it down to gap $m$. The third component in the equation captures the fact that any innovation in a product line where the domestic incumbent is at position $m$ causes a change in its position and, thus a negative change in the aggregate quality index across product lines of position $m$. The other two equations describe the boundary cases. In case of $\bar{m}$, notice that innovation by the domestic incumbent or entrants does not change the

\footnotetext{
${ }^{59}$ The evolution of the variables for country $B$ is given reciprocally.
} 
gap between the domestic incumbent and the foreign follower due to spillover effects but raises the average quality by the step size. Reciprocally, any innovation by the foreign incumbent or entrant improves the quality of the good that the most laggard domestic incumbents produce because of spillover effects.

The laws of motion that determine the measure of product lines where the incumbent from country $c$ is at position $m$ are described by

$$
\begin{aligned}
& \dot{\mu}_{A \bar{m} t}=\dot{\mu}_{B(-\bar{m}) t}=\sum_{s=-\bar{m}}^{\bar{m}-1} \mathbb{F}_{S}(\bar{m})\left(x_{A s t}+\tilde{x}_{A s t}\right) \mu_{A s t}-\mu_{A \bar{m} t}\left(x_{B(-\bar{m}) t}+\tilde{x}_{B(-\bar{m}) t}\right) \\
& \sum_{s=m+1}^{\bar{m}} \mathbb{F}_{-s}(-m)\left(x_{B(-s) t}+\tilde{x}_{B(-s) t}\right) \mu_{A s t} \\
& \dot{\mu}_{A m t}=\dot{\mu}_{B(-m) t}=+\sum_{s=-\bar{m}}^{m-1} \mathbb{F}_{s}(m)\left(x_{A s t}+\tilde{x}_{A s t}\right) \mu_{A s t} \\
& -\left[x_{A m t}+x_{B(-m) t}+\tilde{x}_{A m t}+\tilde{x}_{B(-m) t}\right] \mu_{A m t} \\
& \dot{\mu}_{A(-\bar{m}) t}=\dot{\mu}_{B \bar{m} t}=\sum_{s=-\bar{m}}^{\bar{m}-1} \mathbb{F}_{s}(\bar{m})\left(x_{B s t}+\tilde{x}_{B s t}\right) \mu_{A(-s) t}-\mu_{A(-\bar{m}) t}\left(x_{A(-\bar{m}) t}+\tilde{x}_{A(-\bar{m}) t}\right) .
\end{aligned}
$$

The drivers of the dynamics are the same as in the case of aggregate quality indices, except that step sizes are not relevant in determining the changes in $\mu$. Notice that the change in the measure of position- $m$ product lines in a country corresponds to the change in the measure of position- $(-m)$ product lines in the other country. Moreover, because there is a unit measure of intermediate product lines we have $\sum_{m} \mu_{c m}=1$. Therefore, information on $2 \bar{m}-1$ measures is enough to describe the distribution of product lines according to the technological gap size between the two active incumbents from each country.

\section{Simplified Model and Analytical Results}

This appendix details the discussion in Section 3 and presents proofs of the propositions.

\section{C.1 Static Effects of Openness}

At the aggregate level, the static effects of openness on the income and welfare of consumers stem from three main channels, with two of them having a positive direction and one having a negative direction. To show this, we consider a closed economy and analyze the effects of it opening up. In autarky, the total output in country $c$ is

$$
Y_{c}^{C}=\left[\frac{1-\beta}{\eta}\right]^{\frac{1-\beta}{\beta}}(1-\beta)^{-1} \int_{0}^{1} q_{c j} d j \equiv \varphi \int_{0}^{1} q_{c j} d j,
$$


which is produced using only domestic intermediates. Likewise, the fixed factor and profit incomes are

$$
w_{c}^{C}=\beta Y_{c}^{C} \quad \text { and } \quad \Pi_{c}^{C}=\pi \int_{0}^{1} q_{c j} d j=\beta(1-\beta) Y_{c} .
$$

The gross national income, sum of profits and fixed factor income, is given by

$$
N I_{c}^{C}=\beta(1-\beta) Y_{c}^{C}+\beta Y_{c}^{C}=(2-\beta) \beta \varphi \int_{0}^{1} q_{c j} d j
$$

When this economy opens to trade (subject only to tariffs) the same expressions become

$$
\begin{aligned}
Y_{c}^{O} & =\left[\frac{1-\beta}{\eta}\right]^{\frac{1-\beta}{\beta}}(1-\beta)^{-1}\left[\int_{0}^{1} \mathbb{I}_{q_{c j}>\hat{q}_{c^{\prime} j}} q_{c j} d j+\int_{0}^{1} \mathbb{I}_{\left.q_{c j}<\hat{q}_{c^{\prime} j} \hat{q}_{c^{\prime} j} d j\right]}\right] \\
& =Y_{c}^{C}+\varphi \int_{0}^{1} \mathbb{I}_{q_{c j}<\hat{q}_{c^{\prime} j}}\left[(1+\tau)^{-\frac{1-\beta}{\beta}} q_{c^{\prime} j}-q_{c j}\right] d j,
\end{aligned}
$$

where we define $\hat{q} \equiv q /(1+\tau)^{\frac{1-\beta}{\beta}}$, abstracting from tariffs for now. Similarly,

$$
w_{c}^{O}=\beta Y_{c}^{O} \quad \text { and } \quad \Pi_{c}^{O}=\pi \int_{0}^{1} \mathbb{I}_{q_{c j}>\hat{q}_{c^{\prime} j}} q_{c j} d j+\pi^{*} \int_{0}^{1} \mathbb{I}_{\hat{q}_{c j}>q_{c^{\prime} j}} q_{c j} d j,
$$

with gross income given by

$$
N I_{c}^{O}=\pi \int_{0}^{1} \mathbb{I}_{q_{c j}>\hat{q}_{c^{\prime} j}} q_{c j} d j+\pi^{*} \int_{0}^{1} \mathbb{I}_{\hat{q}_{c j}>q_{c^{\prime} j}} q_{c j}+\beta Y_{c}^{O}
$$

Thus, the comparison between incomes in autarky and the open economy boils down to the comparison of

$$
\int_{0}^{1} q_{c j} d j \text { and } \int_{0}^{1} \mathbb{I}_{q_{c j}>\hat{q}_{c^{\prime} j}} q_{c j} d j+(1+\tau)^{-\frac{1-\beta}{\beta}} \int_{0}^{1} \mathbb{I}_{\hat{q}_{c j}>q_{c^{\prime} j}} q_{c j} d j,
$$

determining the profit component, and to the comparison of

$$
\int_{0}^{1} q_{c j} d j \text { and } \int_{0}^{1} \mathbb{I}_{q_{c j}>\hat{q}_{c^{\prime} j}} q_{c j} d j+(1+\tau)^{-\frac{1-\beta}{\beta}} \int_{0}^{1} \mathbb{I}_{q_{c j}<\hat{q}_{c^{\prime} j}} q_{c^{\prime} j} d j,
$$

determining fixed factor income. Figure A.4 illustrates these comparisons. As in Figure 6, solid lines determine the domestic technology frontier, whereas dashed lines show the iceberg costadjusted levels of these frontiers that emerge when engaging in trade. The left panel shows the product lines and the associated qualities that determine aggregate profit income for the home country in an open world. The right panel shows the technology frontier that determines the productivity of the domestic fixed factor.

First, compared to the state of autarky, the open economy allows relatively more productive firms to sell to a larger market by providing the opportunity to export. This positive effect of market size on aggregate income is evident from the first component in equation (A.2), as profits of leading firms increase proportionally by $\pi^{*}$. This increase corresponds to the upward expan- 


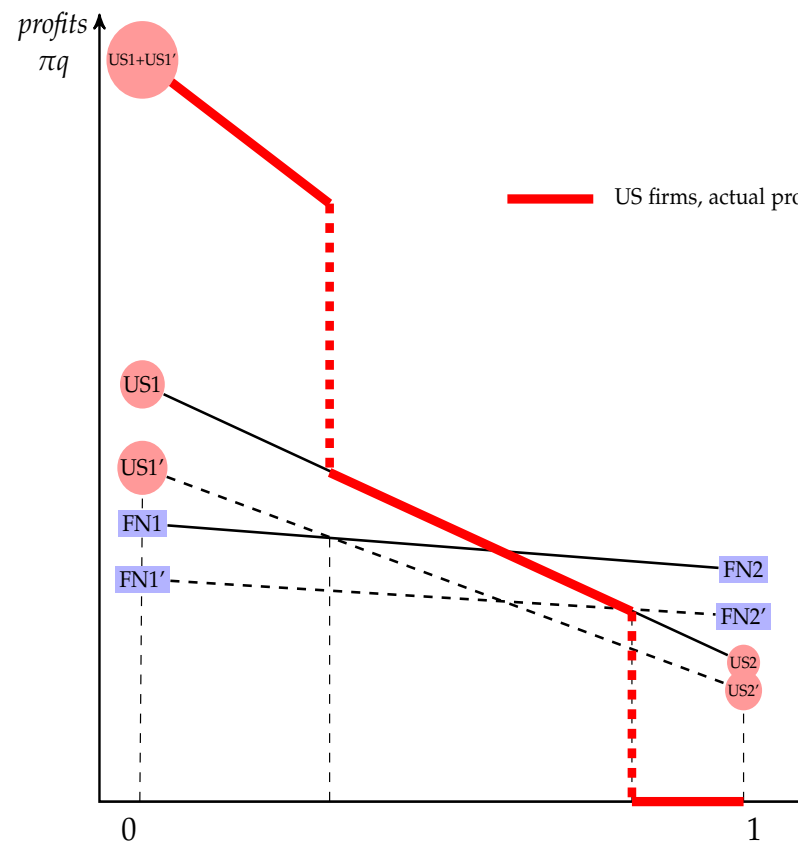

A) Effect on profits

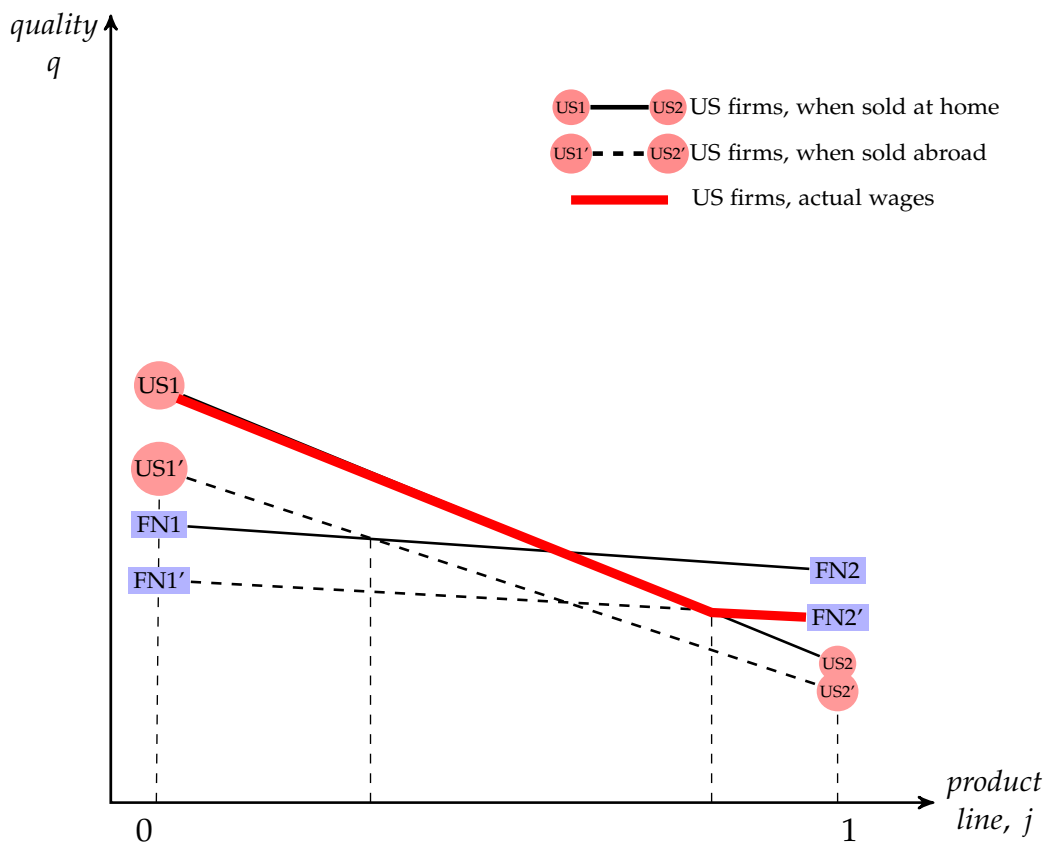

B) Effect on wages

Figure A.4: Static effects of openness

Notes: Panel A illustrates the profits generated by the U.S. incumbents in an example economy. In autarky, profits are given by the solid line US1-US1', whereas in an open economy, profits are given by the thick red line starting at (US1+US1'). When the economy is open, exporters earn the sum of profits from selling both domestically, based on their actual product quality (solid line US1-US2), and abroad, based on their trade-cost-adjusted quality (dashed line US1'-US2'). Firms that cannot export and sell only domestically generate profits based on their actual product quality. Incumbents in sectors where the U.S. imports the specific good have zero profits. Panel B illustrates the relevant quality frontier that determines the labor productivity and, thus, the domestic wage paid in the final good sector. In autarky, the relevant frontier is given by the product qualities of all domestic firms (US1-US1'). In an open economy, the relevant quality frontier (thick red line US1-FN2) is the upper envelope of product qualities available in both countries, taking into account the quality of imported intermediate goods.

sion of the red line in Figure A.4a, determined by the additional income from exporting. Note that the effective quality when exporting is reduced by trade costs. The second static effect of openness works through the selection of more productive intermediate good producers due to increased competition exerted by foreign competitors. This selection channel facilitates the transfer of better-quality intermediate goods across countries, increasing the productivity of the fixed factor utilized in the production of domestic final output. Figure A.4b illustrates this selection mechanism, which indicates that the fixed factor productivity is a function of the upper envelope of product qualities available in the international market. Therefore, this channel, labeled as $d i$ rect transfer of technology in Keller (2004), leads to a higher fixed factor income in both countries. ${ }^{60}$ However, the selection channel implies at the firm level that less productive domestic firms lose the profits to foreign competitors, which they would earn otherwise in autarky, resulting in a decline of aggregate profit income. As illustrated in Figure A.4a, some product lines fail to generate profits, as they are substituted by imports.

\footnotetext{
${ }^{60}$ Notice that iceberg costs prevent the trade of some better-quality foreign goods available in the market.
} 
Next we present the proof of Proposition $1 .^{61}$

Proposition 1 The effect of opening up on wage income is given by $\Delta w=\beta \phi \Delta_{w}$, where $\Delta_{w}$ is defined as the following difference:

$$
\begin{aligned}
\Delta_{w} & \equiv \int_{0}^{1} \mathbb{I}_{q_{c j}>\hat{q}_{c^{\prime} j}} q_{c j} d j+(1+\tau)^{-\frac{1-\beta}{\beta}} \int_{0}^{1}\left[1-\mathbb{I}_{q_{c j}>\hat{q}_{c^{\prime} j}}\right] q_{c^{\prime} j} d j-\int_{0}^{1} q_{c j} d j \\
& =\int_{0}^{1} \mathbb{I}_{q_{c j}<\hat{q}_{c^{\prime} j}}\left(\hat{q}_{c^{\prime} j}-q_{c j}\right) d j \\
& >0 .
\end{aligned}
$$

The transfer of better technology affects this component positively. The total effect on profits given by $\Delta \Pi=\pi \Delta_{\Pi}$, where $\Delta_{w}$ is defined as the following difference:

$$
\begin{aligned}
\Delta_{\Pi} & \equiv \int_{0}^{1} \mathbb{I}_{q_{c j}>\hat{q}_{c^{\prime} j}} q_{c j} d j+(1+\tau)^{-\frac{1-\beta}{\beta}} \int_{0}^{1} \mathbb{I}_{\hat{q}_{c j}>q_{c^{\prime} j}} q_{c j} d j-\int_{0}^{1} q_{c j} d j \\
& =\int_{0}^{1} \mathbb{I}_{\hat{q}_{c j}>q_{c^{\prime} j}} \hat{q}_{c j} d j-\int_{0}^{1} \mathbb{I}_{q_{c j}<\hat{q}_{c^{\prime} j}} q_{c j} d j \\
& \lessgtr 0 .
\end{aligned}
$$

The first component is the gain from exports, and the second component is the loss of profits from firms that are laggard in international competition. The direction of the difference depends on the measure of leading firms in country $c$ as well as on the difference between the average quality of country $c^{\prime}$ s leading and laggard firms.

Therefore, the combined effect on national income, which reads as

$$
\Delta w+\Delta \Pi=\beta \varphi \Delta_{w}+\pi \Delta_{\Pi}
$$

is ambiguous.

In the case of unilateral tariff reduction, domestic exporters are not affected, as the unilateral tariff reduction only affects the cutoff for imports. Therefore, its effect is determined by the loss of domestic profits and the gains from technology transfer driven by the higher import volume.

\section{C.2 Dynamic Effects of Openness and Escape Competition}

As explained in Section 2.3.3, market size and selection channels affect not only the aggregate values, but also firm decisions, introducing a dynamic force. Furthermore, two important dynamic channels whose impact are completely absent in a static comparison are defensive and expansionary R\&D motives, the incentive of firms producing goods of similar (adjusted) qualities to escape

\footnotetext{
${ }^{61}$ Additionally, scale effects arise in a setting where competing countries are of different sizes. For a discussion, see Chapter 15 in Aghion and Howitt (2009).
} 
foreign competition and gain market dominance. To focus on these strategic interactions, consider the simplified environment described in Section 3.2 and abstract from trade frictions. In this environment firm values can be written as

$$
\begin{aligned}
r v_{-\bar{m}} & =-\frac{x_{-\bar{m}}^{2}}{2}+x_{-\bar{m}}\left[v_{0}-v_{-\bar{m}}\right] \\
r v_{-m} & =-\frac{x_{-m}^{2}}{2}+x_{-m}\left[v_{0}-v_{-m}\right]+x_{m}\left[v_{-m-1}-v_{-m}\right] \\
r v_{0} & =-\frac{x_{0}^{2}}{2}+x_{0}\left[v_{1}-v_{0}\right]+x_{0}\left[v_{-1}-v_{0}\right] \\
r v_{m} & =2 \pi-\frac{x_{m}^{2}}{2}+x_{m}\left[v_{m+1}-v_{m}\right]+x_{-m}\left[v_{0}-v_{m}\right] \\
r v_{\bar{m}} & =2 \pi-\frac{x_{\bar{m}}^{2}}{2}+x_{\bar{m}}\left[v_{\bar{m}}-v_{\bar{m}}\right]+x_{-\bar{m}}\left[v_{0}-v_{\bar{m}}\right]
\end{aligned}
$$

with $m \in\{1, \ldots, \bar{m}-1\} .{ }^{62}$ The following proposition argues that, in this environment, firms in neck-and-neck position have the highest innovation intensity.

Proposition 2 First, note that $v_{-m}=v_{-\bar{m}}$ and $v_{m}=v_{\bar{m}}$ satisfy the set of equation for $m>0$. This implies that we have three distinct firm values and innovation rates, and that $x_{\bar{m}}=x_{m}=0$.

Now we show $x_{0}>0, x_{-\bar{m}}>0$ and $x_{0}>x_{-m}=x_{-\bar{m}}$.

1. $v_{\bar{m}}>v_{0}:$ Assume not such that $v_{0} \geq v_{\bar{m}}=v_{1}$. Then $\left[v_{1}-v_{0}\right] \leq 0$, and $x_{0}=0$. This implies $v_{0}=0 \geq v_{\bar{m}}=v_{1}$. But $v_{0}=0$ would mean $r v_{\bar{m}}=2 \pi-x_{-\bar{m}} v_{\bar{m}}$ and thus $v_{\bar{m}}>0$, a contradiction. Therefore $x_{0}>0$.

2. $v_{0}>v_{-\bar{m}}$ : Assume not such that $v_{-\bar{m}} \geq v_{0}$. Then $x_{-\bar{m}}=0$ implying that $v_{-\bar{m}}=0 \geq v_{0}$. This is possible only if $x_{0}=0$. But since $v_{\bar{m}}>v_{0}$ as shown above, $x_{0}>0$, a contradiction. Therefore $x_{-\bar{m}}>0$.

3. $\left[v_{\bar{m}}-v_{0}\right]>\left[v_{0}-v_{-\bar{m}}\right]$ : Assume not such that $\left[v_{0}-v_{-\bar{m}}\right] \geq\left[v_{\bar{m}}-v_{0}\right]$.This means $v_{0}<0$ unless $x_{0}=0$. If $v_{0}<0$, it is a contradiction by step 2. If $x_{0}=0$ meaning that $v_{0}=0$ it is a contradiction by step 1 . Therefore $\left[v_{\bar{m}}-v_{0}\right]>\left[v_{0}-v_{-\bar{m}}\right]$ and $x_{0}>x_{-m}=x_{-\bar{m}}>x_{\bar{m}}=$ $x_{m}=0$.

\section{Quantitative Appendix}

\section{D.1 Solution Algorithm}

1. Let $\mathbb{M}$ be the set of data moments and $\mathbb{M}^{m}$ be the model counterpart. Define $\mathbf{R}\left(\mathbb{M}-\mathbb{M}^{m}\right)$ as the function that calculates a weighted sum of the difference between data and model moments.

\footnotetext{
${ }^{62}$ Lemma 1 applies also in this environment. For the sake of the argument, we assume that neck-and-neck firms have zero profits. We also drop country identifiers thanks to symmetry.
} 
2. Guess a set of values for the internally calibrated parameters $\theta_{\text {guess }}$.

3. Calculate the balanced growth path (BGP), where time derivatives are zero by definition. Start iteration $h=0$ with the guess $\left\{r_{T}^{A}, r_{T}^{B}\right\}^{h=0}$.

(a) At iteration $h$, take $\left\{r_{T}^{A}, r_{T}^{B}\right\}^{h}$ given and solve incumbent firm values jointly for both countries by backward iteration.

i. Guess $\left\{v_{A m T+\Delta t}, v_{B m T+\Delta t}\right\}_{m \in\{-\bar{m}, . ., \bar{m}\}}$. Assuming these to be the true BGP values compute innovation rates $\left\{x_{A m T}, \tilde{x}_{A m T}, x_{B m T}, \tilde{x}_{B m T}\right\}_{m \in\{-\bar{m}, . ., \bar{m}\}}$. Notice that these are innovation rates at one period before, as innovation is a forward looking decision and thus depends on the next period value in discrete time.

ii. Compute $\left\{v_{A m T}, v_{B m T}\right\}_{m}$ using the value function equations. By the definition of BGP, values at $T+\Delta t$ and $T$ should be the same.

iii. Check if

$$
\max _{m, c}\left\|v_{m T+\Delta t}^{c}-v_{m T}^{c}\right\|<\varepsilon .
$$

If not met, set $\left\{v_{c m T+\Delta t}\right\}_{m}=\left\{v_{c m T}\right\}_{m}$ and repeat.

(b) Take the BGP innovation rates and set $Q_{A m 0}=1 \forall m$. Iterate forward on aggregate quality indices $Q_{c m t}$ using the transition equations until growth rates of the implied income processes for both countries stabilize. Call these $\left\{g_{T}^{A}, g_{T}^{B}\right\}^{h}$.

(c) Check if $\left\{r_{T}^{A}, r_{T}^{B}\right\}^{h}$ and $\left\{g_{T}^{A}, g_{T}^{B}\right\}^{h}$ meet the Euler equation. If not, set $\left\{r_{T}^{A}, r_{T}^{B}\right\}^{h+1}$ to interest rates implied by the Euler equation with $\left\{g_{T}^{A}, g_{T}^{B}\right\}^{h}$ and repeat until convergence.

4. Next calculate the equilibrium over the transition. Start iteration $h=0$ by guessing a time path for interest rates $\left\{r_{t}^{A}, r_{t}^{B}\right\}_{t=\{1975, \ldots, 1975+T\}}^{h=0}$. The terminal values are set to the BGP at every iteration.

(a) At iteration $h$, given the terminal (BGP) values $\left\{v_{A m T}, v_{B m T}\right\}_{m}^{h}$ compute the implied innovation rates $\left\{x_{A m T-\Delta t}, \tilde{x}_{A m T-\Delta t}, x_{B m T-\Delta t}, \tilde{x}_{B m T-\Delta t}\right\}_{m}^{h}$. Then, given terminal interest rates $\left\{r_{T}^{A}, r_{T}^{B}\right\}^{h}$, compute $\left\{v_{A m T-\Delta t}, v_{B m T-\Delta t}\right\}_{m}^{h}$. Iterate backwards using the $\left\{r_{t}^{A}, r_{t}^{B}\right\}_{t=\{1975, \ldots, 1975+T\}}^{h}$ until $t_{0}=1975$ to obtain the implied series $\left\{x_{A m t}, \tilde{x}_{A m t}, x_{B m t}, \tilde{x}_{B m t}\right\}_{m t=\{1975, \ldots, 1975+T\}}^{h}$.

(b) Set $Q_{A m 0}=1 \forall m$. Using the implied innovation rates, compute $Q_{c m t}$ for $t=$ $\{1975, \ldots, 1975+T\}$ by forward iteration and back up the implied income processes.

(c) Compute income growth rates $\left\{g_{t}^{A}, g_{t}^{B}\right\}_{t}^{h}$. Using period-by-period Euler equations, check if

$$
\max _{m, c, t}\left\|\left\{g_{t}^{c}\right\}^{h}-\frac{\left\{r_{t}^{c}\right\}^{h}-\rho}{\psi}\right\|<\varepsilon .
$$

for $\{1975, \ldots, 1975+T-1\}$. If not, set $\left\{r_{t}^{A}, r_{t}^{B}\right\}_{t=\{1975, \ldots, 1975+T-1\}}^{h+1}$ to interest rates im- 
plied by the Euler equation with $\left\{g_{t}^{A}, g_{t}^{B}\right\}_{t=\{1975, \ldots, 1975+T-1\}}^{h}$ and repeat until convergence.

5. Once step 4 converges, use the final interest rates $\left\{r_{t}^{A}, r_{t}^{B}\right\}_{t=\{1975, \ldots, 1975+T\}}$ to compute the aggregate variables and the model counterparts of the data moments.

6. Minimize $\mathbf{R}\left(\mathbb{M}-\mathbb{M}^{m}\left(\theta_{\text {guess }}\right)\right)$ using an optimization routine.

\section{D.2 Additional Figures}

Figure A.5 demonstrates the effect of tariff and R\&D policies on the model-implied time path of average technological lead of U.S. firms over their competitors. Increasing unilateral protection leads to a relatively lower path, while higher subsidies result in a uniformly higher path relative to the one in the case of no policy intervention.

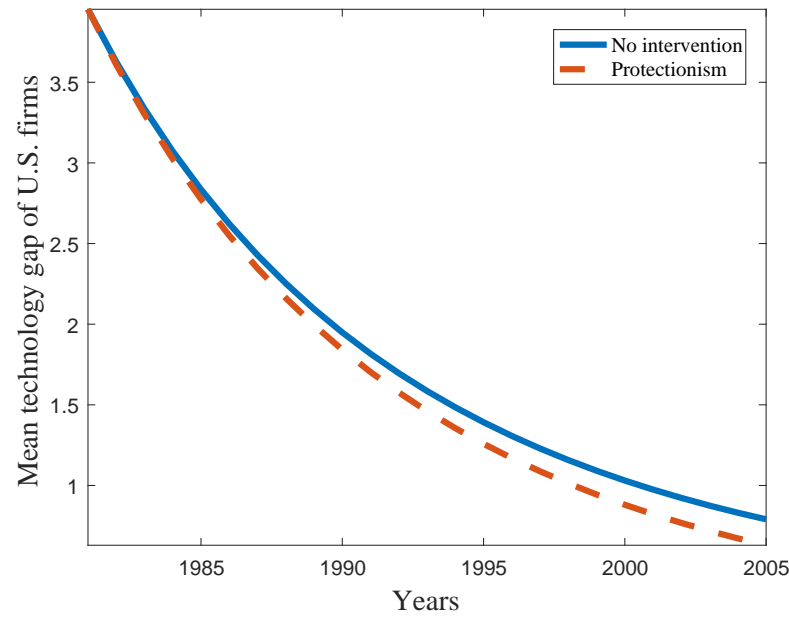

A) 4 percentage point tariff hike

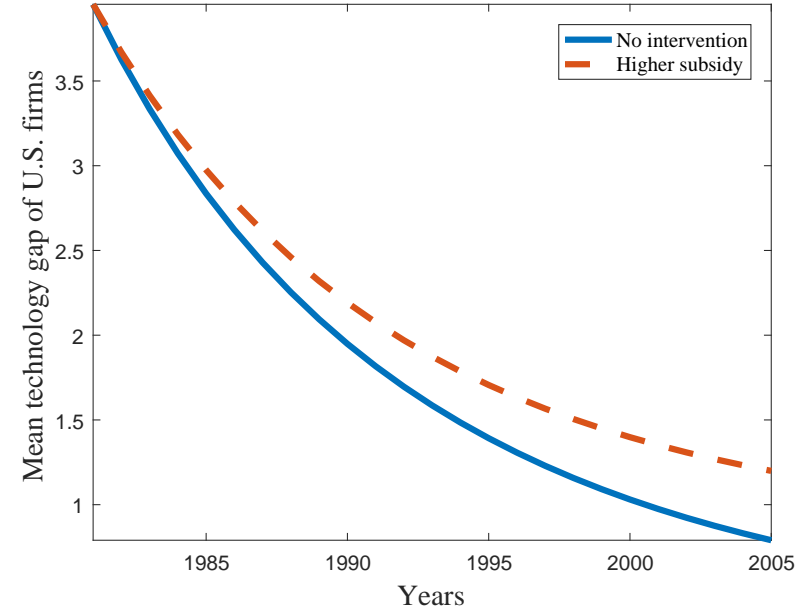

в) Actual R\&D policy

Figure A.5: Average technology lead of the U.S. firms, after policy intervention

Figure A.6 replicates 9b incorporating patents with assignee id " 0 " in the analysis. The inclusion of these patents lead to sharper peaks.

Figure A.7 shows optimal R\&D policies over policy horizons fixing unilateral import tariffs at various levels. It illustrates the interaction between optimal R\&D subsidies and the level of tariffs in the model. In a more liberal regime, more firms face stiffer competition, damping the need for aggressive R\&D subsidies. 


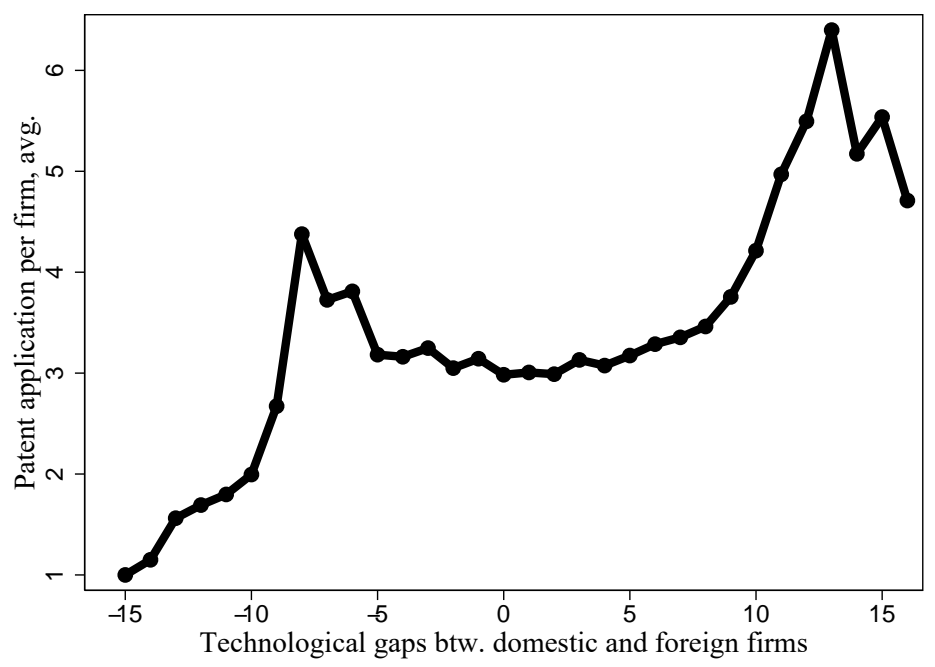

Figure A.6: Patenting intensity in USPTO data, including assignee id " 0 ”

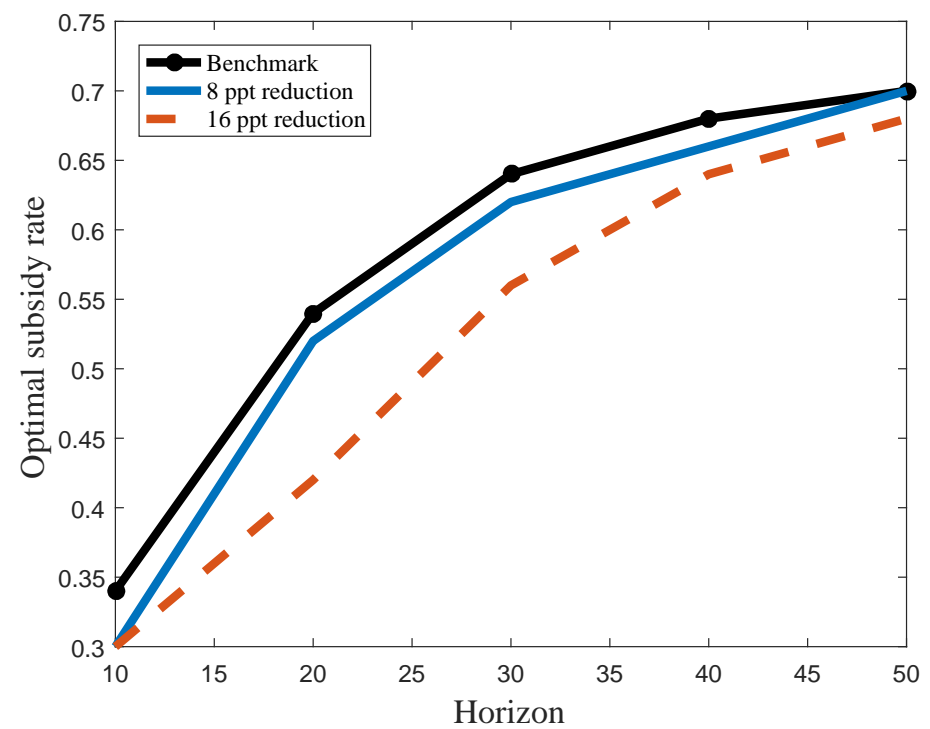

Figure A.7: Optimal R\&D subsidy over policy horizons for different levels of unilateral tariff policy

Figure A.8 displays the alternative empirical initial technological gap distributions employed in sensitivity analysis in Sections 7.2 and 7.3. Solid blue lines represent the distribution used in the baseline analysis.

Figure A.9a compares empirical initial technological gap distributions used in the baseline analysis (dashed red line) and in the alternative calibration specified in Section 7.4 (solid blue line). Figure A.9b displays the model-generated distribution in 1981 (circled blue line), in juxtaposition with its empirical counterpart (solid black line) and the baseline calibration result (dashed red line). The 1981 distribution generated by the alternative calibration is noticeably to 


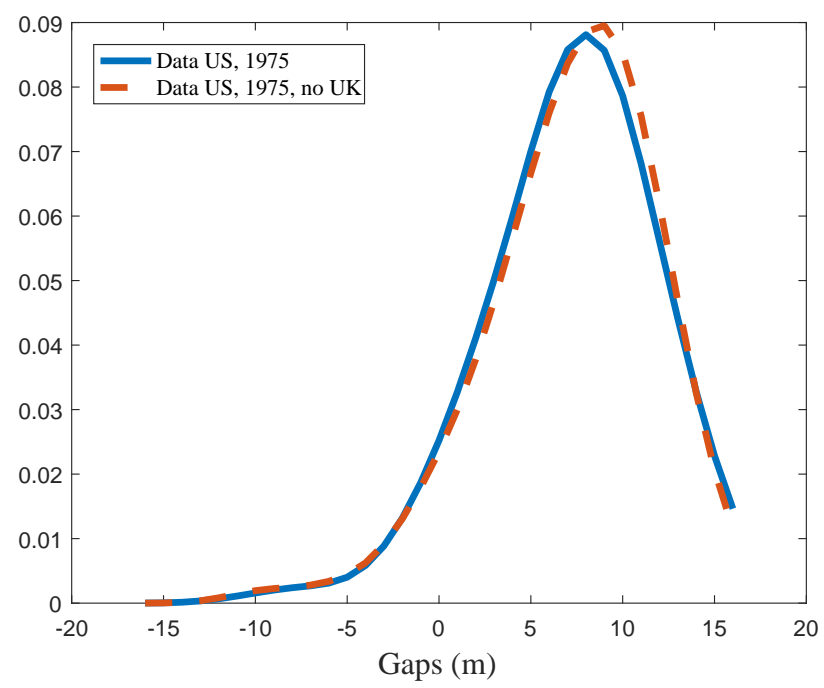

A) Dropping the U.K.

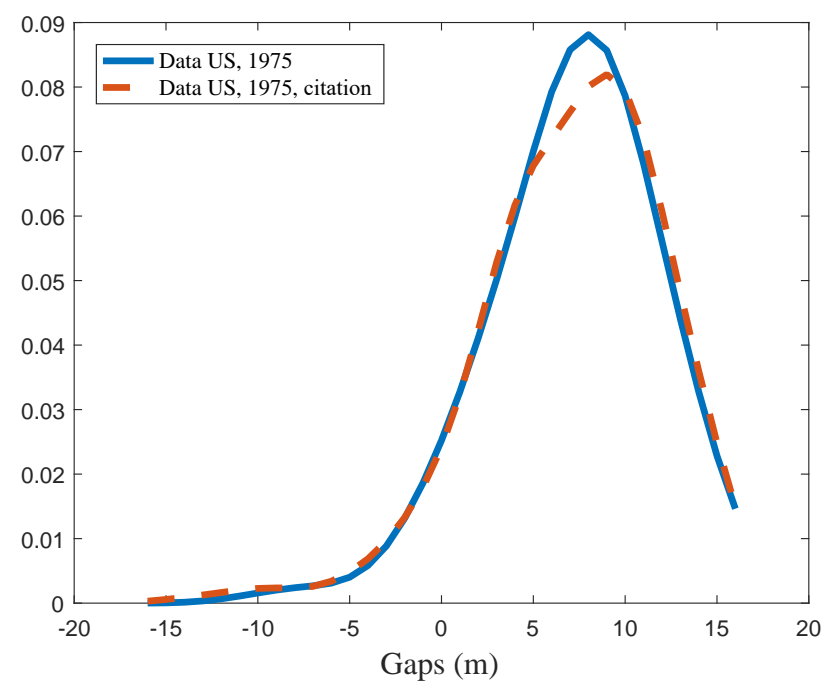

в) Citation-weighted patents

Figure A.8: Alternative initial technological gap distribution

Notes: The figure contrasts alternative initial technological gap distributions (red dashed lines) with the baseline (solid blue lines). Panel A depicts the version omitting the U.K., while panel B shows the version based on citation-weighted patents.

the right of the baseline one, in line with a smaller shift in the empirical counterparts, albeit a tad larger than that.

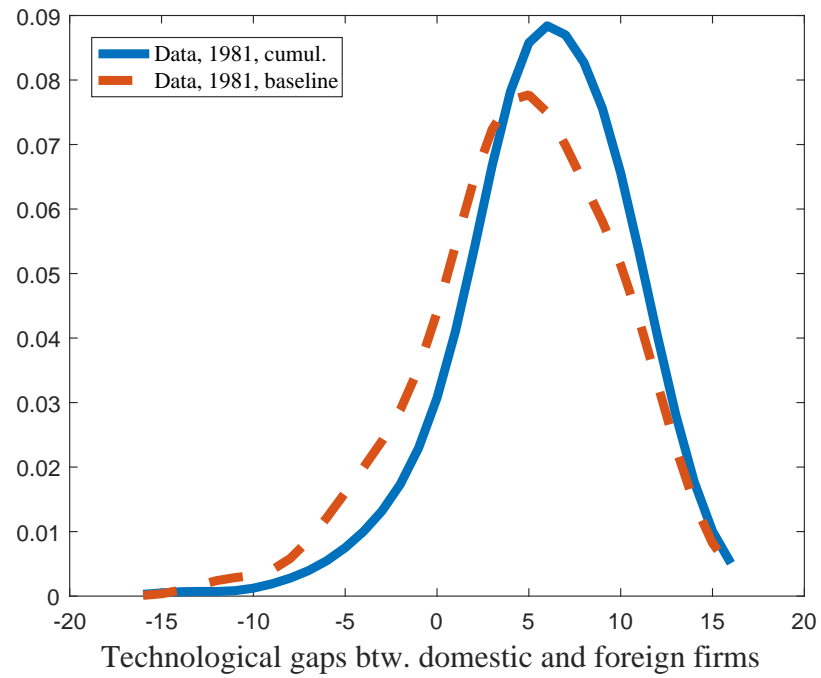

A) Baseline and alternative 1981 distributions (data)

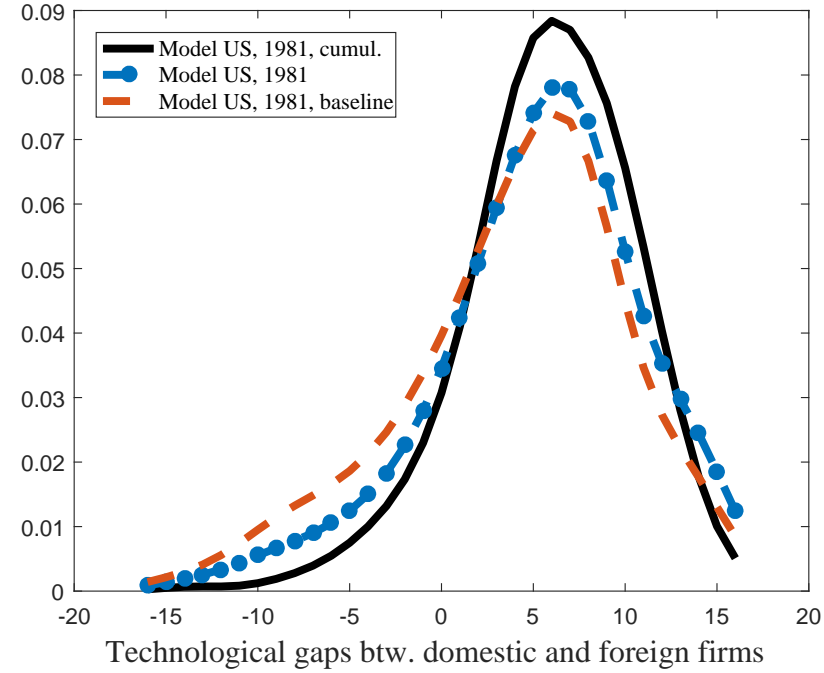

в) Calibrated 1981 distributions

Figure A.9: Calibration and comparison to baseline with the alternative empirical gap distribution

Notes: Panel A contrasts model-generated 1981 technological gap distribution in the alternative calibration (solid blue line) with the baseline (red dashed line). Panel B displays optimal tariff policy in the robustness experiment. Horizontal dashed line denotes the calibrated tariff level. 


\section{E Robustness with Labor in the Intermediate Goods Sector}

Following Akcigit and Kerr (2017), assume that final goods are produced by combining a fixed factor (again normalized to 1 for both countries), while intermediate goods are produced using labor:

$$
k_{j t}=\frac{\bar{q}_{c t}}{\eta} h_{j t}
$$

Here, $\bar{q}_{c t}$ denotes the economy-wide labor productivity in intermediate good production, which is common across all sectors. Equilibrium profits from domestic sales and exports become

$$
\pi\left(q_{j t}\right)=\left[\frac{1-\beta}{\eta} \frac{\bar{q}_{c t}}{w_{c t}^{h}}\right]^{\frac{1-\beta}{\beta}} \beta q_{j t} \text { and } \pi^{*}\left(q_{j t}\right)=\left[\frac{1-\beta}{(1+\kappa) \eta} \frac{\bar{q}_{c t}}{w_{c t}^{h}}\right]^{\frac{1-\beta}{\beta}} \beta q_{c j t},
$$

where $w_{c t}^{h}$ denotes wages of workers in intermediate good production.

We assume that there is a unit measure of workers $h$ supplied inelastically. The market clearing condition for labor reads as $H_{c}=\int_{0}^{1} h_{c j t} d j$. Solving for the wage from the labor market condition, we obtain

$$
\frac{w_{c t}^{h}}{\bar{q}_{c t}}=\chi \bar{q}_{c t}^{-\beta}[\underbrace{Q_{c t}^{D}+Q_{c t}^{X}+(1+\kappa)^{\frac{\beta-1}{\beta}} Q_{c t}^{X}}_{\text {denote } \bar{Q}_{c t}}]^{\beta} .
$$

where $\chi \equiv(1-$ beta $) / \eta^{1-b e t a}$. The superscripts $D$ and $X$ refer to sales in domestic and export markets, respectively. Thus, $\bar{Q}_{c t}$ can be interpreted as the average quality of sales of all active domestic firms, adjusted for trade costs that exported goods are subject to. In the special case we are considering-i.e., $\bar{q}_{c t}=\bar{Q}_{c t}$-we have $w_{c t}=\chi \bar{Q}_{c t}$.

\section{Calibration}

We recalibrate this model following similar steps as in the baseline version. External parameters share the baseline values. We also kept the tariff rate at the calibrated baseline value, which generates about a $7 \%$ tariff revenue in equilibrium. Internally calibrated parameters are presented in Table A.1. As summarized in Table A.2, this model also performs well in matching the data targets, except some overestimation of R\&D-to-GDP ratio and the growth rate of the U.S. ${ }^{63}$

\footnotetext{
${ }^{63}$ Earnings that accrue to the fixed factor and labor combined makes up about 75 percent of the aggregate income during the calibration period.
} 
Table A.1: Internally Calibrated Parameters

\begin{tabular}{ccccccc}
\hline \hline \multicolumn{2}{c}{ R\&D scale } & \multicolumn{2}{c}{ R\&D scale } & Step size & Iceberg & $\mathbb{F}(n)$ \\
$\alpha_{A}$ & $\alpha_{B}$ & $\tilde{\alpha}_{A}$ & $\tilde{\alpha}_{B}$ & $\lambda$ & $\kappa$ & $\phi$ \\
\hline 0.20 & 0.85 & 61.1 & 10.5 & $0.78 \%$ & $1.78 \%$ & 1.15 \\
\hline \hline
\end{tabular}

Table A.2: Model fit

\begin{tabular}{cccc}
\hline \hline Moment & Estimate & Target & Source \\
\hline TFP Growth U.S. & $1.08 \%$ & $0.55 \%$ & Coe et al. (2009) 1975-81 \\
TFP Growth FN & $1.50 \%$ & $1.73 \%$ & Coe et al. (2009) 1975-81 \\
R\&D/GDP U.S. & $2.15 \%$ & $1.75 \%$ & OECD 1981 \\
R\&D/GDP FN & $2.05 \%$ & $1.96 \%$ & OECD 1981 \\
Entry Rate U.S. & $10 \%$ & $10 \%$ & BDS 1977-81 \\
Export Share U.S. & $5.84 \%$ & $7 \%$ & WB 1975-81 \\
\hline \hline
\end{tabular}

\section{Policy Implications}

In terms of R\&D subsidies, Table A.3 reveals that subsidies lead to larger welfare gains compared to the baseline model. This is an intuitive result because in this setting, the acceleration in domestic innovation increases the productivity of labor in intermediate good production, in addition to the effects present in the baseline model. This mechanism also leads to a higher level of optimal R\&D subsidy. Figure A.10a confirms that this result holds true across all horizons. Also, it implies that the policy function for optimal R\&D subsidy over different horizons is qualitatively similar to what has been found in the baseline setting.

Table A.3: Observed and optimal U.S. R\&D subsidy: 1981-2016

\begin{tabular}{lcc}
\hline \hline & Subsidy rate & $\begin{array}{c}\text { Welfare gains } \\
1981-2016\end{array}$ \\
\hline Observed R\&D subsidy & $19.2 \%$ & $2.73 \%$ \\
Optimal R\&D subsidy & $76 \%$ & $21.9 \%$ \\
\hline \hline
\end{tabular}

Next, we analyze the effects of protectionist policies. Figure A.11 presents the consumptionequivalent welfare change and the change in optimal innovation effort of incumbent firms following a unilateral 3 percentage-point increase in U.S. tariffs. First, Figure A.11a demonstrates the decline in innovation efforts of laggard U.S. firms, again due to less foreign competition thanks to higher protection. Similar to the baseline experiment, protection leads to the loss of better-quality imports, and domestic innovation is not enough to compensate for this loss. However, in sharp 


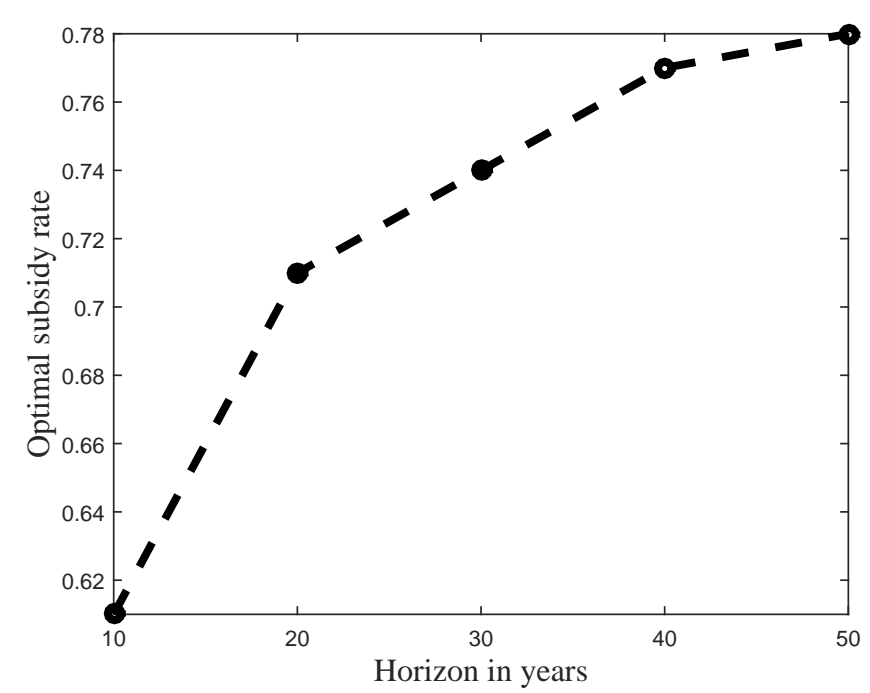

A) Over different horizons

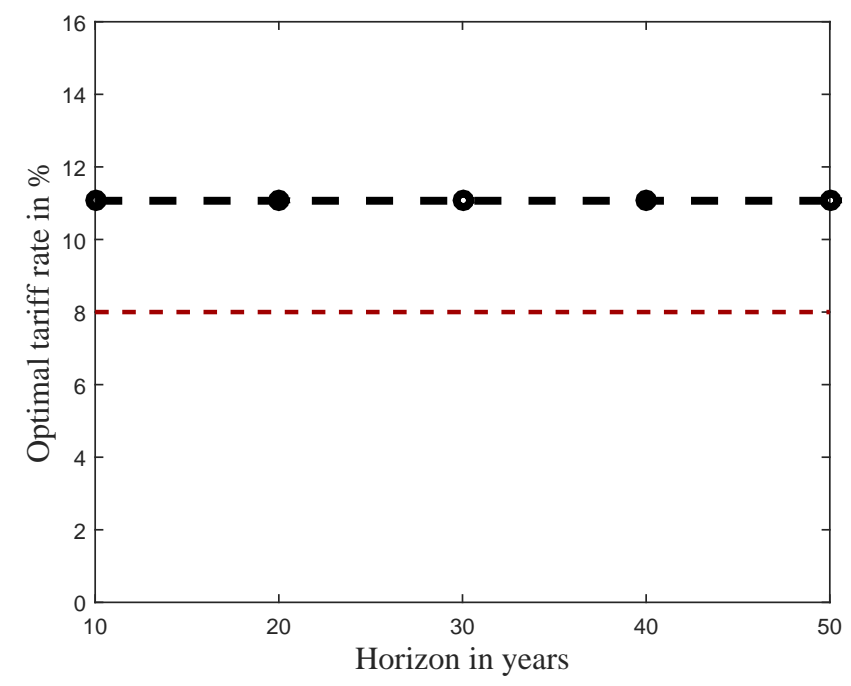

в) Optimal tariff policy

Figure A.10: Optimal U.S. R\&D subsidy, over different horizons and levels of openness

contrast to the baseline, the protectionist policy leads to welfare gains over all time horizons in this modified setting, as shown in Figure A.11b. The reason is that now protectionist policies prohibit not only business stealing, but also "wage stealing"-i.e., the decline in wages due to the loss of domestic activity to foreign importers. This mechanism strengthens the positive effect of protectionist policies. Therefore, as depicted in Figure A.10b, the optimal tariff policy is a constant 11 percent, which essentially implies full protection from imports at all horizons. This boundary result is very different than its baseline counterpart, which calls for a declining tariff profile over longer time horizons. This difference is again driven by the protective effect of tariffs on domestic wage income.

Finally, Figure A.12 shows the optimal joint policy response, in case of bilateral tariff changes. As in the baseline model, the reversal of the trade policy emerges when the foreign country retaliates. This result implies that the gains from wider export markets for the home firms dominate the additional negative effect of import penetration on domestic wages. 


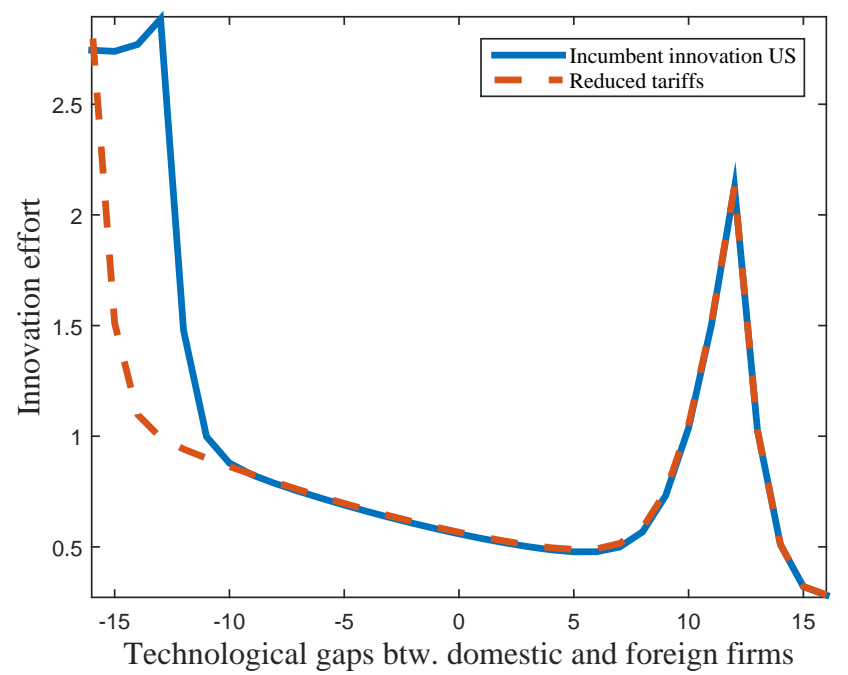

A) Consumption equivalent welfare

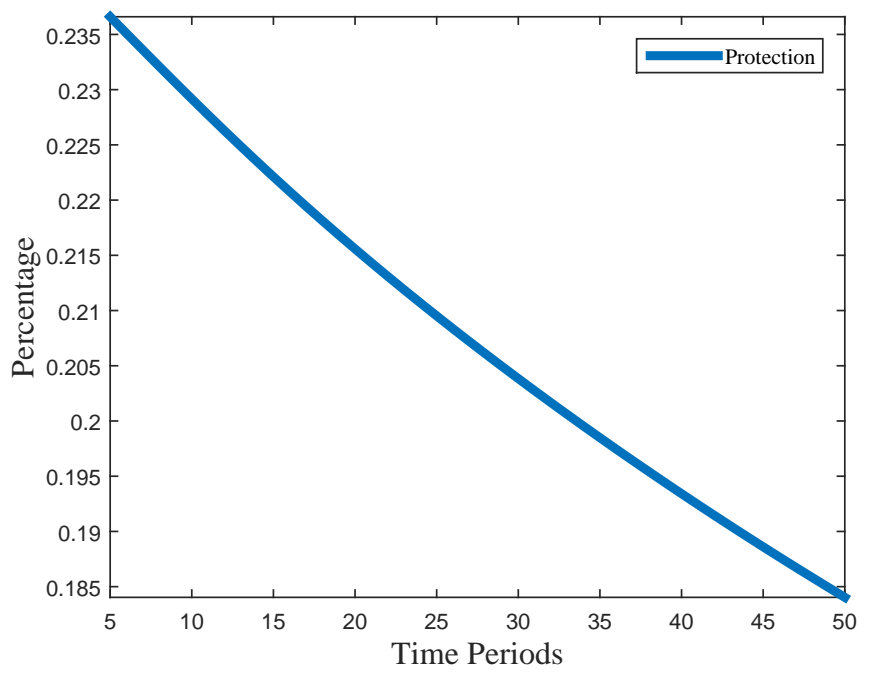

в) Innovation response of incumbents

Figure A.11: Welfare effects of protectionism: unilateral 3 percent point increase in tariffs

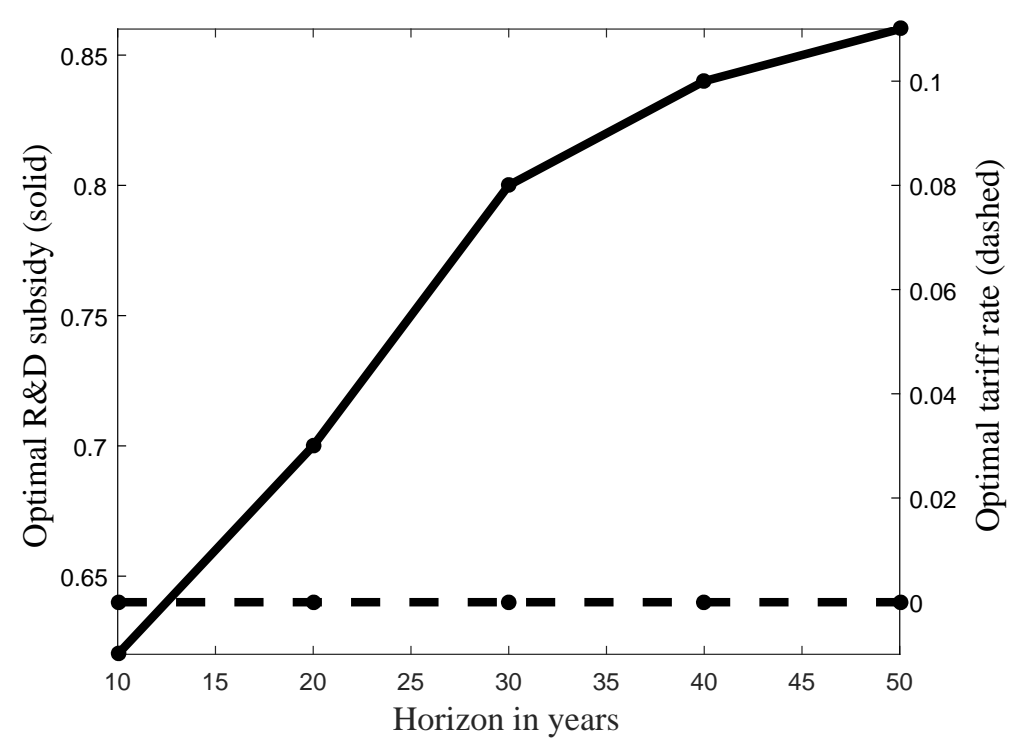

Figure A.12: Optimal joint policy in bilateral tariff change

Notes: The figure compares horizon-dependent optimal joint policy in case of (trade-policy) retaliation to that in the baseline. 